\title{
Socio-demographic and behavioral factors associated with HIV testing and HIV seropositivity among women and children in sub- Saharan Africa: A population-based multilevel analysis
}

\author{
Zelalem T. Haile
}

Follow this and additional works at: https://researchrepository.wvu.edu/etd

\footnotetext{
Recommended Citation

Haile, Zelalem T., "Socio-demographic and behavioral factors associated with HIV testing and HIV seropositivity among women and children in sub-Saharan Africa: A population-based multilevel analysis" (2014). Graduate Theses, Dissertations, and Problem Reports. 5734.

https://researchrepository.wvu.edu/etd/5734

This Dissertation is protected by copyright and/or related rights. It has been brought to you by the The Research Repository @ WVU with permission from the rights-holder(s). You are free to use this Dissertation in any way that is permitted by the copyright and related rights legislation that applies to your use. For other uses you must obtain permission from the rights-holder(s) directly, unless additional rights are indicated by a Creative Commons license in the record and/ or on the work itself. This Dissertation has been accepted for inclusion in WVU Graduate Theses, Dissertations, and Problem Reports collection by an authorized administrator of The Research Repository @ WVU. For more information, please contact researchrepository@mail.wvu.edu.
} 
Socio-demographic and behavioral factors associated with HIV testing and HIV seropositivity among women and children in sub-Saharan Africa:

A population-based multilevel analysis

Zelalem T. Haile, MPH, MA

Dissertation submitted

to the School of Public Health

at West Virginia University

in partial fulfillment of the requirements for the degree of

Doctor of Philosophy in

Epidemiology

Ilana R. A. Chertok, PhD, MSN, RN, IBCLC, Chair

Usha Sambamoorthi, PhD

Michael Andrew, PhD

Arif Sarwari, MD

R. Constance Wiener, PhD, DMD, MA

Department of Epidemiology

Morgantown, West Virginia

2014

Keywords: HIV testing, HIV seropositivity, women, children, sub-Saharan Africa

Copyright 2014 Zelalem T. Haile, MPH, MA 


\title{
ABSTRACT \\ Socio-demographic and behavioral factors associated with HIV testing and HIV seropositivity among women and children in sub-Saharan Africa: A population-based multilevel analysis
}

\begin{abstract}
Zelalem T. Haile
Introduction: In sub-Saharan Africa, HIV/AIDS is one of the leading causes of mortality that disproportionately affects women and children. In this sub-region, 57\% of those living with HIV are women and is home for $90 \%$ of children under the age of 15 that are living with HIV. This study examined socio-demographic and behavioral factors associated with HIV testing and HIV seropositivity among women and children using nationally representative data.

Methods: The study employed a cross-sectional study design using data from Demographic and Health Survey and AIDS Indicator Survey, conducted between the years 2006 and 2012 from 25 countries in sub-Saharan Africa. The main outcomes of interest for the three studies included testing and receiving test results of HIV among women $15-45$ years $(n=255,048)$, HIV seropositivity among women $15-45$ years $(\mathrm{n}=155,356)$, and HIV seropositivity in children $0-14$ years $(n=15,034)$. Multi-level modeling techniques were employed to explore the association of these outcomes and individual, community and country-level factors.

Results: With respect to HIV testing and reporting test results, women who were married or who had been married were more likely to report HIV testing and receiving test results,. Higher parity was associated with higher likelihood of HIV testing. The odds of HIV testing and receiving test results reduced with decreasing education and decreasing household wealth status. Employed women and women with moderate and high media exposure were more likely to report HIV testing and receipt of test results. Rural residents had reduced odds HIV testing and receiving test results (Adjusted odds ratio, aOR $=0.79 ; 95 \%$ CI 0.69, 0.90). The odds of HIV testing and receipt of test results was lower for women with high enacted HIV/AIDS stigma (aOR=0.77; 95\% CI $0.72,0.81$ ). A one-unit increase in a country's expenditure on public health (\% of GDP), the odds of testing and receipt of test results increased by $48 \%(\mathrm{aOR}=1.48 ; 95 \% \mathrm{CI} 1.19$ to 1.83$)$. In terms of HIV seropositivity, factors that include age, marital status, parity, and pregnancy status, type of residence, stigma, and age at first sex, involvement in premarital sex and having multiple partners were significantly associated with higher odds of testing HIV positive. Factors associated with HIV seropositivity in children 0-14 years include maternal HIV seropositivity (Adjusted odds ratio, aOR $=16.61 ; 95 \%$ CI 16.40, 16.82), maternal age at birth, maternal marital status, maternal employment status and maternal level of HIV/AIDS awareness.

Conclusions: Testing for HIV and receiving test results and HIV seropositivity among women and children in sub-Saharan Africa are influenced by a complex set of socio-demographic and behavioral characteristics at different levels. The development of effective intervention to prevent HIV infection in these groups requires a much deeper exploration of the influence of these factors.
\end{abstract}




\section{DEDICATION}

I dedicate my doctoral dissertation to my late parents, Teka Haile and Tarekesh Haile. Thank you for your unconditional love, support and encouragement throughout my life. I am forever honored to have you as my parents. I miss you both. I will always love you.

\section{ACKNOWLEDGEMENTS}

I would like to extend my heartfelt gratitude to my family. To my late father Teka Haile and my late mother, Tarekesh Haile who always believed in me, loved and encouraged me. To my siblings, Nardos, Sasinos, Selamawit, Mizan and Million, who have provided devotion and moral support. To my wife, Asli, who has been a continuous source of love, balance, inspiration and ideas during my studies. Your encouragement, humor and wit, no matter the situation, have been most appreciated. I appreciate your patience and initiative to manage our household matters throughout my PhD studies and for being my second pair of eyes in my work. I will forever be grateful for your love and support. To my beloved daughter Leah, who has and continues to add so much joy and happiness in my life. To all my friends and family near and far, I am grateful for your love and support.

My deepest gratitude goes to Dr. Ilana Chertok who has been an excellent dissertation committee chairperson and who always has provided me sufficient and timely feedback and pushed me to think critically in my research. I truly appreciate the attitude and knowledge you continually and persuasively conveyed throughout my $\mathrm{PhD}$ studies. Without your support, supervision and constant help, my $\mathrm{PhD}$ journey and this dissertation would not have been possible. I would like to convey my gratitude to Dr. Usha Sambamoorthi from whom I have gained knowledge and skills that I perceive to be a valuable component in my future career. I cannot express enough appreciation to my PhD dissertation committee members: Dr. Michael Andrew, Dr. Arif Sarwari, and Dr. Constance Wiener for their guidance and encouragement.

I would like to express my thanks to the faculty and staff at the WVU Health Sciences Center, and especially those in the School of Public Health, with whom I studied and/or interacted. I would also like to recognize and thank Public Health Sciences PhD program director, Dr. Keith Zullig and PhD program director, Dr. Motao Zhu for their support and thoughtful advice.

An honorable mention goes to my friend and mentor Dr. Steve Howard, Director of African Studies program at Ohio University; I offer my deepest gratitude for believing in me and for always being available and abundantly helpful. My appreciation also goes to Dr. Ghirmai Negash and his family for their kindness and hospitality and for encouraging me to take the extra step. My heartfelt gratefulness also goes to my friends, Abraham Gebrekidan, Dr. Dawit Woldu, Andualem Alemayehu and all of my friends in Morgantown, Dr. Gerard Akindes, Kwabena Owusu-Kwarteng, Bose Maposa, Jason Brayda, Dr. Winsome Chunnu-Brayda, Dr. Andrea Frohne, Dr. Caroline Kingori, and Dr. Benson Mwaura and his family, who have been a great source of support to my family and me.

Special thanks go to all of the graduate students in the PhD program in Public Health Sciences. 
Furthermore, I would like to acknowledge the crucial role the staff members at the Demographic and Health Survey program have played in providing me with full access and technical support when requested.

Last, but not least, many thanks go to researchers and field workers and participants of the Demographic and Health Survey program without whom this study would not have been possible. 


\section{TABLE OF CONTENTS}

Chapter 1: Overview of the Research

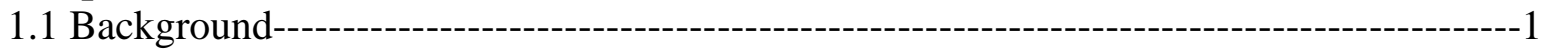

1.2 HIV testing and receiving test results-----------------------------------------------------------2

1.3 HIV seropositivity among women and children---------------------------------------------3

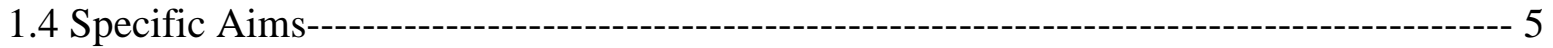

Chapter 2: Manuscript 1

Socio-demographic and behavioral characteristics associated with HIV testing among women in sub-Saharan Africa: A population based analysis

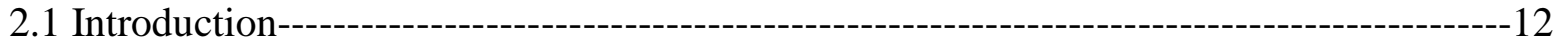

2.2 Methods----------------------------------------------------------------------------------------------16

2.3 Results----------------------------------------------------------------------------------------------------22

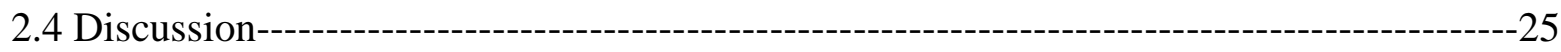

Chapter 3: Manuscript 2

A multi-level analysis of socio-demographic and behavioral characteristics associated with HIV seropositivity among women in sub-Saharan Africa

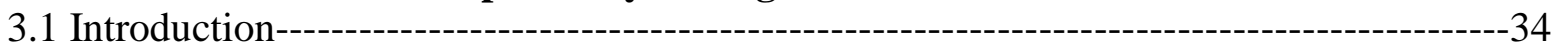

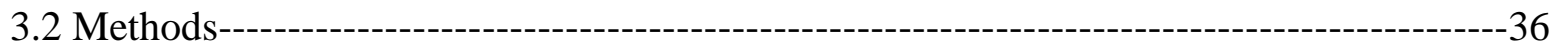

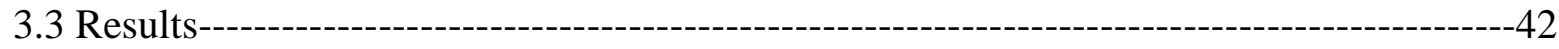

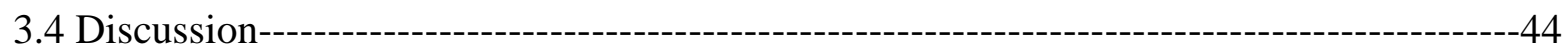

\section{Chapter 4: Manuscript 3}

A population based analysis of the socio-demographic and behavioral characteristics associated with HIV seropositivity among children 0-14 years in sub-Saharan Africa

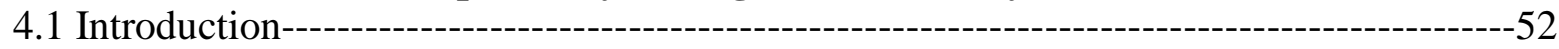

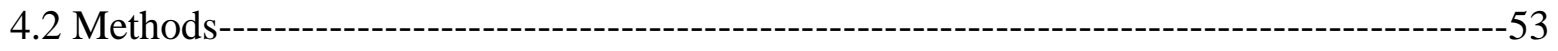

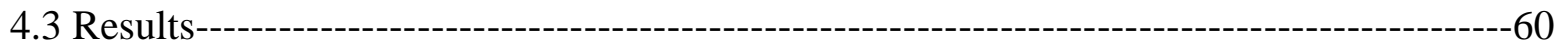

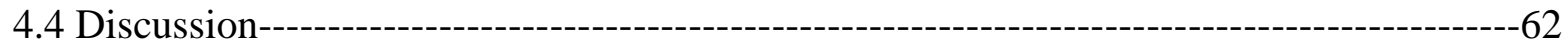

Chapter 5: Discussion

5.1 Summary of key findings--------------------------------------------------------------------67

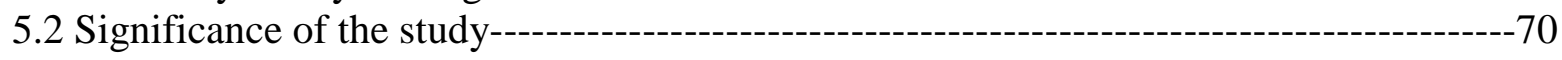

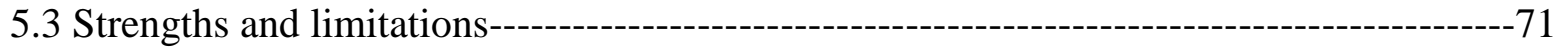

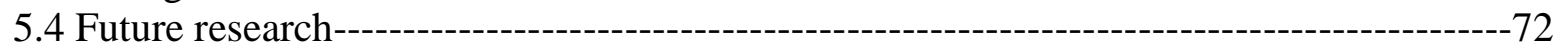

References--------------------------------------------------------------------------------------------------74

Figures-------------------------------------------------------------------------------------------------------95

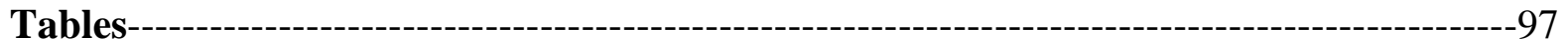




\subsection{Background}

\section{Chapter 1 \\ Overview of the Research}

The HIV virus that causes AIDS is one of the world's most serious health plight and a challenge to development and economic growth of many low to middle - income countries in the world (UNAIDS, 2012). Since the discovery of the disease in 1981, AIDS has resulted in the deaths of more than 25 million people (UNAIDS, 2011, 2013). Although the disease affects all parts of the world, studies show that about $97 \%$ of those affected by the disease live in low to middle income countries (Musheke et. al., 2013; 2012 UNAIDS, 2011; MacPhail et al., 2009). Recent reports have demonstrated that sub-Saharan Africa is disproportionately affected by the epidemic (UNAIDS, 2013). In 2012, the sub-region was home to 25 million people who were living with HIV, an estimated 1.6 million new HIV infections and 1.2 million AIDS-related deaths (UNAIDS, 2013). Most countries in this region have HIV/AIDS prevalence of at least $1 \%$ (UNAIDS, 2011, 2012, 2013). In this sub-region, 57\% of those living with HIV are women and it is home to $90 \%$ of children under the age of 15 that are living with HIV (UNAIDS, 2013). The epidemic has disrupted the development, culture and other socio-economic fabric of communities in sub-Saharan Africa (May, 2003; Rosen et al. 2004; Greener et al., 2004). The development and implementation of effective HIV prevention in this region necessitates a broader understanding of the multiplicity of factors influencing HIV seropositivity at various levels. In sub-Saharan Africa, population level examination of the relative contribution of sociodemographic and behavioral determinants of screening for HIV and HIV seropositivity is lacking. This problem is exacerbated further by the lack of data on population-based data, which in turn creates additional problem in measuring the burden of HIV infection. 


\subsection{HIV testing and receiving test results}

The World Health Organization (WHO) defines HIV testing - commonly referred to as HIV Testing and Counseling (HTC) - as the means by which people learn their HIV status and if tested positive, will have the opportunity to learn about long-term care and treatment options (WHO, n.d.). According to WHO (n.d.), in 2012 alone, there was an estimated 95 million people globally that received HIV testing and counseling services. Research has established that secondary prevention, as with early identification through screening and provision of treatment to HIV infected individuals, can prevent new infections (Cohen et al. 2011; Granich et al. 2009). Early detection is a proven, effective strategy to improve treatment and significantly reduce morbidity and mortality due to infection (Helleringer et al, 2009; Kigozi et al., 2009). Studies have shown that once HIV positive individuals know their status they are more likely to avoid risky behavior (King et al., 2009; Denison et al., 2008). Furthermore, along with good quality counseling, HIV testing during pregnancy prevents potential mother to child transmission (MTCT). A number of sub-Saharan African countries have recently implemented national campaigns to encourage uptake of HIV testing. With this broad approach, both primary prevention among uninfected individuals and secondary prevention among those infected individuals can be achieved. However, despite their widespread availability, utilization of HIV testing and receipt of test results remain as low as 82 tests per 1000 people (WHO/UNAIDS/UNICEF, 2011).

Findings from small scale, community and health facility-based studies identified several individual level determinants of HIV testing, which includes socio-demographic characteristics (Gage \& Ali, 2005; Matovu et. al., 2005; Hutchinson \& Mahlalela, 2006; Matovu \& Makumbi, 2007; Wringe et. al., 2008; Cremin et. al., 2012; Leta et al., 2012), stigma (Bayer \& Edington 
2009; Matovu \& Makumbi 2007; Leta et al., 2012), access (Hutchinson \& Mahlalela, 2006;

Csete \& Elliot, 2006; Matovu \& Makumbi, 2007), and HIV/AIDS awareness (Hutchinson \& Mahlalela, 2006; Jereni \& Muula, 2008).

Recent systematic review of qualitative findings on factors enabling and deterring uptake of HIV testing in sub-Saharan Africa identified additional determinants such as deterioration of physical health and/or death of sexual partner or child, availability of treatment, social support, perceived low risk of HIV infection, perceived lack of confidentiality among health workers, fear of HIV-related stigma, direct and indirect financial costs of accessing HIV testing, and gender inequality (Musheke et. al., 2013). Other studies have focused primarily on uptake and acceptability of HIV screening in different clinical settings (Daniel \& Oladapo, 2006; Morin et al., 2006; Worku \& Enquselassie, 2007; Collier et al., 2007; Wringe et al., 2008). While the findings of these studies have important contribution, they have limited generalizability. A large scale, multi-level and population based investigation of factors associated with HIV testing and receipt of test results will have a significant contribution to comprehending the disease and in the development of effective HIV prevention programs.

\subsection{HIV seropositivity among women and children}

Globally, women constitute about 50\% of all people living with HIV (UNAIDS, 2013). However, in sub-Saharan Africa, women are disproportionately affected by the epidemic and constitute $61 \%$ of all people living with HIV (UNAIDS, 2010). The prevalence of HIV infection is about 3 to 7 times higher among adolescent women compared to men (Karim et. al., 2010). Studies have shown that a complex set of biological, behavioral, and structural factors place women in sub-Saharan Africa at higher risk for HIV (Karim et. al., 2010; Peters et al., 2013). Population level examination of socio-demographic and behavioral factors associated with HIV 
seropositivity among women in sub-Saharan Africa is currently lacking. A multi-level analysis of these factors using large population-based HIV surveillance has a potential contribution to evaluating the impact of existing HIV prevention programs and developing new and effective strategies for prevention.

In 2012, an estimated 260,000 children were newly infected with HIV (UNAIDS, 2013). HIV/AIDS is one of the leading causes of child deaths in sub-Saharan Africa, accounting for about $3 \%$ of deaths among children under five years of age (Ngwende et. al., 2013). Approximately, $89 \%$ of AIDS orphans or children who lost one or both of their parents to HIV/AIDS, reside in this sub-region (Ubesie, 2012; U.S. Global health policy, 2010). The transmission of the HIV virus in pediatric population, which is about $90 \%$, occurs through mother to child during pregnancy, during labor or delivery, and through breastfeeding (Newell, 1998; De Cock et al., 2000; Ubesie 2012; WHO, 2012). Factors associated with MTCT of HIV includes, low CD4 cell counts, age of infant, duration and consistency of breastfeeding, health condition of mother's breast, level of viral load, immune status of mother, maternal susceptibility to HIV infection as well as oral health of infants (Fowler et al. 2007; Embree et al., 2000; Leroy et al., 2001; Ciaranello et al., 2011). Other factors, such as early breakage of mother's bag of membranes as well as premature birth increases the risk of MTCT of HIV (Leroy et al., 2001; Newell, 2006; Taha, 2011). In order to combat MTCT of HIV, UNAIDS developed a fourpronged strategy. This includes Keeping women and their partners HIV-negative, avoiding unwanted pregnancies among HIV-infected women and women at risk of HIV, Ensuring HIV testing of pregnant women and timely access to effective antiretroviral therapy, and better integration of HIV care, treatment and support for HIV-infected women and their families (UNAIDS, 2011). A deeper understanding of factors associated with HIV seropositivity among 
women and children using large nationally representative data is key to guiding the development of strategic and targeted interventions suitable for preventing HIV infection in women and hinder its transmission to children.

\subsection{Specific Aims}

In separate but related studies this study aims at characterizing individual, community and country-level socio-demographic and behavioral factors associated with:

- Testing for HIV and receipt of test results among women of child bearing age;

- HIV seropositivity among women of child bearing age; and

- HIV seropositivity among children 0-14 years in sub-Saharan Africa.

The study utilized the World Health Organization's Commission for Social Determinants of Health (CSDH) conceptual framework to guide selection of independent variables for analysis. To date, the relative contribution of social determinants of health to testing for HIV in a large population-based study has not been evaluated. Drawing substantially on the contributions of Solar and Irwin (2007), the commission developed a conceptual framework to describe relationships among individual and structural variables influencing health status. The framework is now widely used in the development of targeted interventions on social determinants of health (CSDH, 2008). This framework is depicted in Figure 1. According to the framework socioeconomic and political factors have the capability to generate societal stratifications by income, education, occupation, gender, and other factors (CSDH, 2008). Along with other biological, behavioral and health system related factors, these stratifications influence the health status of individuals.

Identification of the various level determinants that influence HIV testing and receipt of test results and HIV seropositivity among women and children should be a critical component of 
HIV/AIDS prevention including prevention of MTCT (PMTCT) programs. It is imperative that interventions and communication strategies aimed at reducing HIV infection among women and MTCT of HIV begin with an assessment of the relative contribution of individual and structural determinants of health that affect women's HIV screening, women's HIV serostatus and children's HIV serostatus. Translating this kind of evidence into political action will have a significant contribution in the reduction of morbidity and mortality due to HIV.

This project utilizes secondary data from de-identified Demographic and Health Surveys (DHS) and AIDS Indicator Surveys (AIS). Since 1984, the United States Agency for International Development (USAID) assisted several developing countries in collecting nationally representative demographic and health data (MEASURE DHS, 2013). Over the past three decades, DHS data has provided a useful, population-based data to national and international decision-makers to develop informed and effective policies, health programs and accessible services. So far, the DHS project has collected analyzed and disseminated data on population, health, HIV, and other characteristics through more than 260 surveys in over 90 countries (MEASURE DHS, 2013). The data were collected using a standard survey questionnaire, developed by Monitoring and Evaluation to Assess and Use Results Demographic and Health Surveys (MEASURE DHS) (MEASURE DHS, 2013). The AIDS Indicator Survey (AIS) was also developed by MEASURE DHS to provide countries with a standardized tool to obtain indicators for effective monitoring of national HIV/AIDS programs. Specifically, the design for the AIS was guided by the need for a survey protocol that provides, in a timely fashion and at a reasonable cost, information required for meeting HIV/AIDS program reporting requirements including collection of President's Emergency Plan For AIDS Relief (PEPFAR), UN General Assembly Special Session on HIV/AIDS (UNGASS), and other indicators, while 
ensuring comparability of findings across countries and over time (MEASURE DHS, 2013). Country-level data in the study was derived from the World Bank Development Indicators. The primary World Bank collection of development indicators were compiled from officially recognized international sources. The data presents the most current and accurate global development data available, and includes national, regional and global estimates (World Bank, 2012a).

The use of the standardized survey instruments makes it easier to compare results in different sub-Saharan African countries. At least one DHS dataset is now available for 43 countries in sub-Saharan Africa. In 2001, as part of this national biomarker data collection process, DHS introduced testing for HIV. The testing protocol is anonymous, informed, and voluntary (MEASURE DHS, 2013). All respondents receive educational materials and referrals to free testing and counseling (MEASURE DHS, 2013). HIV test results for women in the 15-49 age group are available for 25 sub-Saharan African countries. Only three countries in subSaharan Africa have implemented HIV testing for children. For testing children, laboratory technicians administered informed consent to the child's parent or guardian. Additional details of the DHS HIV testing protocol can be found elsewhere (MEASURE DHS, 2013).

The 25 sub-Saharan African countries for which HIV testing data is available along with the standard DHS and AIS health interview were the focus of this project. These countries include Burkina Faso, Burundi, Cameroon, Congo Brazzaville, Democratic Republic of Congo, Cote d'Ivoire, Ethiopia, Gabon, Guinea, Kenya, Lesotho, Liberia, Malawi, Mali, Mozambique, Niger, Rwanda, Sao Tome and Principe, Senegal, Sierra Leone, Swaziland, Tanzania, Uganda, Zambia, and Zimbabwe. Figure 2 illustrates the sample size for the study population by country. 
Of these countries, only Mozambique, Swaziland and Uganda have implemented HIV testing for children younger than 14 years.

Data from each country were merged using one-to-one merging. A new variable that identified each country was created. Descriptive summaries and prevalence estimates was assessed using frequencies, proportions, median and interquartile range. Simple bivariate tests for differences with categorical variables were examined using Rao-Scott chi-square test of independence. Regression diagnostics were utilized to identify potential collinearity. Multilevel logistic regression models were utilized to assess the influence of measured individual, community and country-level factors on each outcome variables. For the first two outcomes, three level multi-level logistic regression models were fitted to compute the fixed effect odds ratios (OR) and 95\% confidence interval (CI) of the three outcome variables. Four nested models at level 1, level 2, level 3 and level 4 were constructed. Model 1 constitutes an empty model without any covariate variables. This model was specified to decompose the variance between community and country-levels. Model 2 represents individual level covariates and the relationships among the individual level variables; Model 3 contains individual and communitylevel variables and model 4 includes explanatory variables at the individual, community and country-levels. Intra-cluster correlation (ICC) was used to measure community and country-level random effects. The linear threshold model formula was used to compute the ICC (Snijders \& Bosker, 1999).

Chapter 2 examines the socio-demographic and behavioral characteristics associated with HIV testing and receiving test results among women in sub-Saharan Africa.

In order to link HIV positive individuals to effective treatment and care it is necessary to identify the determinants that influence testing and receiving test results. This study 
hypothesized that various individual, community and country-level factors influence women's utilization of HIV testing and receipt of test results.

Up until the last decade, most if not all information about HIV screening comes from antenatal care centers, hospital-based or from studies among high-risk groups. Unlike antenatal care-based surveillance techniques, population-based HIV screening allows direct estimation of the prevalence and factors associated with screening for HIV in the population. The main purpose of the study in Chapter 2 was to explore patterns of HIV screening among women in relation to the socio-demographic and behavioral characteristics measured at different levels with data from 25 countries in sub-Saharan Africa. The World Health Organization's (WHO) Commission for Social Determinants of Health (CSDH) conceptual framework was used to guide selection of independent variables for analysis.

Chapter 3 presents a multi-level analysis of socio-demographic and behavioral characteristics associated with HIV seropositivity among women in sub-Saharan Africa.

The development and implementation of an effective HIV prevention program requires a sound understanding of factors associated with HIV infection. This study hypothesized that various individual, community and country-level factors influence HIV seropositivity among women of childbearing age in sub-Saharan Africa

Until recent times, data related to HIV prevalence and risk factors were derived using data from targeted high-risk group or other health facility-based studies. This was primarily due to the lack of large population based HIV testing. One major advantage of population-based HIV testing is that it allows direct estimation of the prevalence and distribution of HIV infection in a given population. The main purpose of the study in Chapter 3 was to discern the role sociodemographic and behavioral characteristics play measured at different levels on HIV 
seropositivity among women using nationally representative data. In this study, selection of independent variables was based on the WHO CSDH conceptual framework.

The study in Chapter 4 included a population-based analysis of the socio-demographic and behavioral characteristics associated with HIV seropositivity among children 0-14 years in subSaharan Africa.

The development of intervention strategies for the prevention of HIV infection in children requires a holistic understanding of the complex relationship between biological, sociodemographic and behavioral at various levels. Previous studies examining factors associated with HIV seropositivity in children relied on hospital-based data and placed significant emphasis on the major biological determinants of MTCT. This study hypothesized that certain sociodemographic and behavioral are associated with HIV infection among women thereby increasing the likelihood of MTCT of HIV. This study utilized data from three countries in sub-Saharan Africa namely Mozambique, Swaziland and Uganda, that implemented HIV testing in children. Chapter 5 presents a summary of key findings, significance and limitations of the study as well as potential direction for future investigation.

The diversity and complexity of the biological, socio-demographic and behavioral factors that influence HIV testing and receipt of test results among women, and HIV seropositivity among women and children calls for a broader and deeper understanding of these factors at various levels. In addition to a discussion on major findings, this chapter will provide potential areas of future HIV/AIDS research in sub-Saharan Africa. 


\title{
Chapter 2
}

Socio-demographic and behavioral characteristics associated with HIV testing among women in sub-Saharan Africa: A population based analysis

\begin{abstract}
Objectives: Screening for HIV is one of the most common prevention strategies that local, international and multilateral organizations in sub-Saharan Africa utilize to tackle the HIV/AIDS epidemic. However, despite the ubiquity of the provisions of HIV testing services participation in screening for HIV and receipt of test results remain low. The purpose of this study is to examine individual, community and country-level factors associated with testing and receipt of test results among women of childbearing age in sub-Saharan Africa.
\end{abstract}

Method: The study utilizes a cross-sectional examination of 255,048 women who participated in the Demographic and Health Survey and AIDS Indicator Survey between 2006 and 2012 in 25 sub-Saharan African countries. Multilevel modeling techniques were used to identify the association between individual and community and country-level factors and HIV testing and receipt of test results.

Results: Overall about $40 \%$ of women reported having been tested and receiving test results. In the multivariable-adjusted model, women who were married or who had been married were more likely to report HIV testing and receiving test results as compared to never married women.

Compared to nulliparity, higher parity was associated with higher likelihood of HIV testing. The odds of HIV testing and receiving test results reduced with decreasing education and decreasing household wealth status. Employed participants were more likely to report HIV testing and receipt of test results than their unemployed counterparts (Adjusted Odds Ratio, aOR=1.10; 95\% CI 1.03, 1.18). Compared to urban residents, residents of rural area had reduced odds HIV testing $(\mathrm{aOR}=0.79 ; 95 \% \mathrm{CI} 0.69,0.90)$. The likelihood of HIV testing is higher for women with moderate and high media exposure, compared to women with low media exposure. The odds of HIV testing and receipt of test results was lower for women with high enacted HIV/AIDS stigma $(\mathrm{aOR}=0.77 ; 95 \% \mathrm{CI} 0.72,0.81)$. On a country-level, for each one-unit increase in a country's expenditure on public health as a percentage of GDP, the odds of testing and receipt of test results increased by $48 \%$ (aOR=1.48; 95\% CI 1.19 to 1.83 ).

Conclusion: Interventions aimed at improving HIV testing in sub-Saharan Africa should take into account the importance of individual, community and country-level enablers and barriers to participation in HIV testing and receipt of test results. 


\subsection{Introduction}

The HIV and AIDS pandemic disproportionately affects populations in sub-Saharan Africa. This sub-region has $10 \%$ of the world's population and, in 2012 was home to $70 \%$ of all new HIV infections (UNAIDS, 2013). Unlike in Europe and the United States, the HIV infection in sub-Saharan Africa is known to have a generalized epidemic pattern that places every individual at risk for infection and is one of the leading causes for premature death (Wilson, 2006; Merson, 2006). However, a number of biological, social, cultural and economic factors contribute to an increasing vulnerability of women for HIV infection. Women account for a greater proportion of the infected population. In the absence of a cure, preventive measures are essential to mitigate the spread of the disease.

Primary prevention is the optimal approach to preventing HIV infection, especially with regard to mother-to-child transmission (MTCT) of HIV. Various levels and methods of accessible and targeted education and training can be utilized using primary prevention as the approach to comprehensive and integrated reproductive health. Primary prevention involves women to be educated in and counseled on prevention of sexually transmitted infections (STI) and unintended pregnancy, safe sexual practices, partner involvement and disclosure, prompt and effective STI treatment, STI and HIV screening, family planning, prevention of MTCT of HIV, and newborn care prior to pregnancy. Additionally, female empowerment is a component of primary prevention that promotes their ability to engage in prevention. If consistently implemented, this early intervention is an effective approach for preventing HIV infection in infants and young children.

Although educating women about HIV infection contributed significantly in the reduction of new infections, the asymptomatic nature of the disease, especially in the early stages 
contributes to the underestimation of the personal risk for infection and to spreading the disease (Smith \& Morrison, 2006; Klimas et al., 2008). It is therefore critical to screen and educate all women through HIV prevention programs.

Previous studies have demonstrated that secondary prevention as with early identification through screening and treatment of HIV infected individuals has the potential to mitigate the transmission of the disease (Cohen et al. 2011; Granich et al. 2009). Similar studies have shown that early detection has the potential to improve treatment and significantly reduce morbidity and mortality due to infection (Helleringer et al, 2009; Kigozi et al., 2009). Other studies have demonstrated that HIV positive individuals who know their HIV status are less likely to be involved in risky sexual behavior (King et al., 2009; O`Dell et al., 2008; Denison et al., 2008; Marks 2005). Similarly, the provision of quality testing and counseling for HIV during pregnancy has an additional benefit in reducing the MTCT risk. A number of sub-Saharan African countries have recently implemented national campaigns to encourage uptake of HIV testing. With this broad approach, both primary prevention among uninfected individuals and secondary prevention among already infected individuals can be achieved.

Despite the importance of screening, barriers to screening make compliance difficult. Historically, fear, stigma and discrimination of being HIV positive has hampered the potential gain of early intervention, and screening only occurred through voluntary initiation for testing by clients (Bayer \& Edington 2009; Matovu \& Makumbi 2007; Csete \& Elliot, 2006). Yet, knowledge of HIV status can decrease one's level of stigma and has the potential to increase sensitivity and openness about the disease (Denison et al. 2008; Tedrow et al. 2011). In an effort to promote screening, several countries and international organizations adopted a new approach commonly referred to as provider-initiated testing and counseling (PITC) by which all clinical 
patients are routinely offered an HIV test, particularly in hyper-endemic areas (Csete \& Elliot, 2006; MMWR, 2007). Some researchers emphasize the importance of this approach in alleviating fear and stigma while also facilitating a timely diagnosis and early initiation of treatment (Klimas et al, 2008; Lifson \& Rybicki, 2007). Others, however argue that this approach may eventually lead to a situation where testing may become mandatory (Csete \& Elliot, 2006). Others claim the potential challenges of PTIC in resource-poor settings such as sub-Saharan Africa where there is lack of a well-organized infrastructure to provide service and care (Asante, 2007). Current HIV testing strategies in this sub-region constitute both facilitybased and community-based approaches. Facility-based testing are usually part of the general and specific health care services such as clinics, hospitals and maternal and child health services. Community-based approaches focus on testing in different settings that include workplaces and educational facilities and other targeted events and utilizing testing campaigns, through mobile voluntary counseling and testing (VCT) services, and in people's homes (WHO/UNAIDS/UNICEF 2011; WHO 2012).

A 2010 assessment report indicated that there were 82 tests per 1000 people performed in sub-Saharan Africa (WHO/UNAIDS/UNICEF, 2011). The authors of the report also stated that 45 million people aged 15-49 years old received HIV testing and counseling in the past year and were informed of the results. In addition, between 2009 and 2010, while there was nearly a 10\% increase (52\% to $61 \%$ ) in estimated number of pregnant women who received HIV testing in eastern and southern Africa, and nearly two-thirds of pregnant women did not know their status (WHO/UNAIDS/UNICEF, 2011). However, these estimates do not address individual, community and country-level factors that are associated with screening for HIV and receipt of HIV test results. The development and implementation of effective policy and intervention for 
prevention requires a comprehensive understanding of these individual and contextual level factors that influence women's utilization of screening services.

Previous studies that examined utilization of HIV screening and receipt of test results among women in sub-Saharan Africa have focused on small community or health facility-based programs and on specific high-risk groups. Population level studies examining factors associated with utilization of HIV screening among women of childbearing age in general and among pregnant women in particular are lacking. Previous studies focused primarily on uptake and acceptability of HIV screening in different clinical settings (Daniel \& Oladapo, 2006; Worku \& Enquselassie, 2007; Collier et al., 2007; Morin et al., 2006; Wringe et al., 2008). As such, these studies have limited generalizability to the population. Unlike health facility-based surveillance techniques, population-based HIV surveillance allows direct estimation of the prevalence and distribution of HIV testing in the population. To date, few studies have examined population level patterns of utilization of HIV screening using nationally representative data in sub-Saharan Africa, with a primary focus on cross-country comparisons of the prevalence of HIV testing (Hall 2010; Cremin, 2012; Staveteig et al; 2013).

The present study aimed to explore how individual, community and country related factors influence screening for HIV among women in sub-Saharan Africa using pooled data from 25 countries collected in the period from 2006 to 2012. Considering the benefit of HIV screening in abating the HIV epidemic and in reducing MTCT of HIV, results of this study can inform policy-makers in developing effective HIV screening programs and equitable access to screening services. 


\subsection{Methods}

\section{Data}

The study utilizes data from the Demographic and Health Surveys (DHS) and the AIDS Indicator Surveys (AIS) conducted from 2006 through 2012 in 25 sub-Saharan African countries. The study design and methodology of the DHS and AIS are available in detail elsewhere (DHS, 2013). In brief, these surveys are conducted by the Monitoring and Evaluation to Assess and Use Results Demographic and Health Surveys (MEASURE DHS). These are nationally representative surveys designed to monitor the health and dietary status of noninstitutionalized civilian populations in developing countries. MEASURE DHS is implemented by ICF International and is mainly funded by the United States Agency for International Development. Other donors of this program include United Nations Children's Fund (UNICEF), United Nations Population Fund (UNFPA), World Health Organization (WHO), and the Joint United Nations Program on HIV and AIDS (UNAIDS). Methods employed in the data collection included: face-to face interviews using a pre-tested and validated questionnaire; clinical, physical and laboratory examinations. For the purposes of accurately representing these populations, DHS and AIS surveys were collected using a multi-stage stratified probability sampling technique. Selection was based on strata, cluster, households and individuals within households. In some countries, HIV testing and testing for other nutritional deficiencies were conducted among the participants who consented to be tested. The use of standardized questionnaire in each country makes DHS and AIS data suitable to generate estimates based on pooled data.

DHS and AIS data have a pre-calculated weighting factor that is used to adjust for nonresponse and to ensure representativeness. However, the standard weighting factor is not valid for pooled data from different surveys. Following the recommendation from MEASURE DHS, in this paper 
the standard weights were de-normalized to account for variation in the number of women sampled in each country. This process involves multiplication of the standard weight by an additional adjustment factor $\left(\mathrm{t} / \mathrm{t}_{\mathrm{s}}\right)$ to obtain $\mathrm{wt}^{*}\left(\mathrm{t} / \mathrm{t}_{\mathrm{s}}\right)$, where $\mathrm{wt}$ is the standard weight, $\mathrm{t}$ is the total number of females aged 15-49 years in the country at the time of the survey, and $t_{s}$ is the number of women aged 15-49 interviewed in the survey. Both standard weight and the number of women aged 15-49 interviewed in the survey are provided in DHS and AIS. The estimated number of total males and females aged 15-49 in the country at the time of the survey were derived from the United Nations World Population Prospects (http://esa.un.org/wpp/).

The present study sample consisted of 260,987 DHS and AIS women of childbearing age (15-49 years) who were interviewed between 2006 and 2012 in sub-Saharan Africa. Participants who reported having been tested but who had not received test results were excluded $(n=5,938)$. The final sample consisted of 255,048 participants from 25 countries.

\section{Ethics statement}

This study is based on an analysis of de-identified secondary data using a standard protocol developed by the DHS program. The survey was approved by the Institutional Review Board of ICF Macro in Calverton, Maryland, USA, and other country-specific ethics-related committees. Before participating in the survey, participants gave informed consent and all information was collected confidentially. Approval for the current study was also obtained from the Institutional Review Board of the academic institution of the researchers.

\section{Outcome variable: Tested for HIV and received test results}

Study participants were asked about their experiences with HIV testing in DHS and AIS. They were asked, "I don't want to know the results, but have you ever been tested to see if you have the AIDS virus?" and those who respond "yes" to this question were asked, "How many 
months ago was your most recent test," and "I don't want to know the results, but did you get the results of the test?" Using these questions MEASURE DHS provides two basic outcome indicators on HIV testing, ever tested and received results, and received results of the last HIV test. It is to be noted that this variable does not include participants' willingness to participate in the HIV testing during DHS and AIS surveys. In this context, HIV refers to self-reported participation in HIV testing and receiving the results before being selected for an interview in the DHS or AIS.

\section{Independent Variables}

The World Health Organization's Commission for Social Determinants of Health (CSDH) conceptual framework was used to guide selection of independent variables for analysis (Figure 1).To date, the relative contribution of social determinants of health to testing for HIV in a large population-based study has not been evaluated. Drawing substantially on the contributions of Solar and Irwin (2007), the commission developed a conceptual framework to describe relationships among individual and structural variables that collectively influence health outcomes. The framework is now widely used in the development of targeted interventions on social determinants of health (CSDH, 2008). In this study individual, community and countrylevel variables were examined. The decision to select variables was based on availability across the various datasets to ensure the largest possible sample size.

The individual level factors were categorized and included: age at the time of interview (15-19, 20-24, 25-29, 30-34, 35-39, 40-44, 45-49); marital status (never married, marriedmonogamous, married-polygamous, widowed, divorced or separated); parity (none, one, two or more); education (no education, primary, secondary or higher); household wealth index (poorest, poorer, middle, richer, richest); employment status at the time of interview (no, yes); place of 
residence (rural, urban); media exposure (low, moderate, high); HIV/AIDS awareness (low, moderate, high); HIV/AIDS stigma (low, high); age at first marriage (never married, $<16,16-17$, $18-19, \geq 20$ ); age at first sex (never had sex, $<16,16-17,18-19, \geq 20$ ); premarital sex (no, yes); risky sexual behavior (no, yes). Having multiple sex partners refers to having more than one sex partner in the past 12 months. Risky sexual behavior is defined as having last sex with nonspousal partner without using condom.

In the standard DHS and AIS, household wealth index was calculated based on the data from the household's ownership of consumer goods, dwelling characteristics, source of drinking water, toilet facilities, and other characteristics that relate to a household's socioeconomic status. The method applied in the calculation of wealth index in DHS and AIS can be found elsewhere (Rutstein \& Johnson, 2004). In short, this index was constructed by assigning each of these assets a factor score generated through principal component analysis. These scores were then standardized in relation to a standard normal distribution with a mean of zero and a standard deviation of one and total score of the household were used to rank individuals based on the household they resided. Finally, the scores were converted into quintiles from one (poorest) to five (richest). In the current study, a similar procedure for creating wealth index was used to create exposure to media, HIV awareness and HIV/AIDS stigma variables. In the standard DHS and AIS, participants were asked about the frequency that they read newspaper or magazine, listen to the radio, and watch television. Three questions were used to assess the level of HIV/AIDS stigma. Participants were asked if they are willing to care for a relative with AIDS, if a teacher infected with HIV, but is not sick, should be allowed to continue teaching, and if they would buy vegetables from a vendor with HIV. Awareness of HIV/AIDS was based on an established and widely used measure where each woman was asked whether or not she agreed or 
disagreed with the following statements: 1) HIV can be prevented by using condoms every time you have sexual intercourse; 2) HIV can be prevented by limiting intercourse to one uninfected partner; 3) it is possible for a healthy-looking person to have the AIDS virus; 4) the AIDS virus can be transmitted from mosquito bites; 5) a person can get HIV by sharing food with a person who has AIDS; 6) a person can get the AIDS virus because of witchcraft or other supernatural means; 7) the virus that causes AIDS can be transmitted from a mother to her baby during pregnancy; 8) the virus that causes AIDS can be transmitted from a mother to her baby during delivery; 9) the virus that causes AIDS can be transmitted from a mother to her baby by breastfeeding.

Community level factors were directly calculated from DHS and AIS data and include community level poverty measured as the proportion of individuals living in poor households in the community; community level education measured as the proportion of individuals with less than high school education in the community and low community media exposure measured as the proportion of individuals with low media exposure in the community. Country-level variables were derived from World Bank's World Development Indicators and include: national income measured as per capita gross domestic product (GDP) adjusted for purchasing power parity, based on the United Nations Development Program estimates. This refers to the sum of gross value added by all resident producers in the economy plus any product taxes and minus any subsidies not included in the value of the products, expressed in international dollars using purchasing power parity rates and divided by total population during the same period; expenditure on public health (\% of GDP) (\%): calculated based on current and capital spending from central and local government budgets, external borrowings and grants (including donations 
from international agencies and nongovernmental organizations), and social (or compulsory) health insurance funds, expressed as a percentage of GDP (World Bank, 2012a).

\section{Statistical Analyses}

Median and interquartile ranges were used to describe continuous variables. Frequencies and proportions were used to describe categorical covariates in relation to the outcome variables of having been tested and receiving test results. Rao-Scott chi-square was used to test for relationships between the status of testing and each of the covariates. As recommended, pooled sample weights that account for the unequal probabilities of selection, oversampling, nonresponse, country-level variability in population and complex survey design were incorporated in all analyses. Regression diagnostics were utilized to identify potential collinearity. Three level multi-level logistic regression models were fitted to compute the fixed effect odds ratios (OR) and 95\% confidence interval (CI) of HIV testing and receipt of test results. Four nested models at level 1, level 2, level 3 and level 4 were constructed. Model 1 constitutes an empty model without any covariate variables. This model was specified to decompose the variance between community and country-levels. Model 2 represents individual level covariates and the relationships among the individual level variables; Model 3 models contain community-level variables and model 4 includes explanatory variables at the individual, community and country-levels. Intra-cluster correlation (ICC) was used to measure community and country-level random effects. The linear threshold model formula was used to compute the ICC (Snijders \& Bosker, 1999). Descriptive analyses were conducted using SAS 9.3 (SAS Institute Inc., Cary, North Carolina) and multilevel regression estimates were computed using MLwiN 2.30 (Rasbash et al., 2008). 


\subsection{Results}

Table 2.1 presents the countries selected for this study, the year data collection was implemented, the total sample size for the study and number of regions sampled per country. The study utilized DHS and AIS surveys that were conducted between 2006 and 2012 for which HIV testing data are available. A total of 200,968 women were interviewed in 25 sub-Saharan African countries. The median number of women interviewed per country was 9,513; the minimum was 2,615 in Sao Tome and Principe and the maximum was 23,020 in Malawi. The median number of communities per country from which participants were selected for an interview was 376; the minimum was 104 and the maximum was 916 . The minimum number of respondents per community was 10 and the maximum was 36 .

Descriptive statistics for the final pooled sample are shown in table 2.2. A greater proportion of the participants aged 15-19 years (21\%). Most respondents were married monogamously (53\%), and had two or more children (47\%). Some participants were pregnant at the time of the survey (9\%). A greater proportion of the participants had a primary level education (42\%), and were employed at the time of the interview (58\%). Most of the participants lived in rural areas (68\%). However, greater proportion of participants had low stigma towards people living with HIV/AIDS (65\%). Among those who were married, age at first marriage was evenly distributed. A slightly higher proportion of participants had their sexual debut when they were less than 16 years old (32\% overall and $36 \%$ among those who ever had sex). Fewer proportions of participants reported premarital sex (23\%), multiple sex partners (2.3\%) and risky sexual behavior (7.3\%).

At the community level, the median proportion of women living in communities with less than high school education was $85 \%$. The median proportion of women residing in communities 
with poor households was $32 \%$. The median proportion of participants in the community with low media exposure was about $30 \%$.

At the country-level, the median GDP per capita (2005 PPP) was 978 USD and median expenditure on public health (\% of GDP) was $2.40 \%$.

Table 2.3 displays association between each covariate and the outcome variable. With the exception of women's participation in risky sexual behavior, each individual-level covariate was significantly associated with HIV testing and receipt of test results. Compared to women who have not been tested, women who were tested and who received test results resided in communities that have lower proportions of women with less than high school education, lower proportion of women with poor household wealth, and lower proportion of women with poor media exposure. The median GDP per capita of countries among women who have been tested and received test results is higher than those who have not been tested.

Results of fixed-effect and random-effect measures from multilevel analysis are shown in table 2.4. Model 1 showed that there is variation in the likelihood of testing and receiving test results across communities and countries were significant. Examination of the ICC reveals that that about $43 \%$ and $34 \%$ of the total variation in HIV testing and receiving test results are attributable to community and country-level differences, respectively. Model 2 takes into account individual level characteristics and in this model, $37 \%$ and $29 \%$ of the total unexplained variation in the odds of HIV testing and receiving test results is attributable to unobserved community and country-level factors, respectively. This proportion slightly reduces to $36 \%$ and $28 \%$ once community level factors are adjusted in Model 3. Including country-level factors in model 4 further reduced the total unexplained variation to $30 \%$ and $22 \%$ at community and country-levels. Even after adjustment for individual, community and country-level factors the 
community and country-level variance in the odds of testing for HIV and receiving test results remains large indicating that that the odds of testing for HIV and receiving test results varied noticeably across communities and countries. This evidence suggests the use of multilevel modeling that accounts for community and country variations is appropriate.

Table 2.4 also shows results of fitting the multilevel model including individual-level, community level, and country-level factors. In the final model, younger women were more likely to report HIV testing and receiving test results compared to women aged 45-49 years. Compared to never married women, women who were married or who had been married were more likely to report HIV testing and receiving test results. Higher parity was associated with higher likelihood of HIV testing compared to nulliparity. The odds of HIV testing and receiving test results reduced with decreasing education and decreasing household wealth status. Compared with respondents who were unemployed, respondents who were employed were more likely to have reported HIV testing (Adjusted Odds Ratio, aOR =1.10; 95\% CI 1.03, 1.18). Respondents residing in rural area were less likely to have reported HIV testing than those from urban counterparts $(\mathrm{aOR}=0.79 ; 95 \% \mathrm{CI} 0.69,0.90)$.Compared to women with low media exposure, the likelihood of HIV testing is higher for women with moderate and high media exposure. Compared to women with low enacted HIV/AIDS stigma, the odds of HIV testing and receipt of test results was lower for women with high enacted HIV/AIDS stigma (aOR=0.77; 95\% CI 0.72, 0.81). A each one-unit increase in a country's expenditure on public health (\% of GDP) increased the odds of testing and receipt of test results by $48 \%$ (aOR=1.48; 95\% CI 1.19 to 1.83 ). A positive association was found between HIV testing and receipt of test results and a country's GDP per capita adjusted for purchasing power parity. 


\subsection{Discussion}

The principal finding of the current study was that several individual, community and country-level factors were associated with HIV testing and receipt of test results among women in sub-Saharan Africa, thereby demonstrating the importance of examining population-based multilevel factors. Specifically, individual level characteristics including age, marital status, parity, place of residence, education, and household wealth index, employment, media exposure, and HIV/AIDS stigma, age at first sex, premarital sex, and risky sexual behavior were significantly associated with HIV testing and receipt of test results. Similarly, community and country-level variables were significantly associated with testing for HIV and receipt of test results.

Current literature on the association between marital status and HIV testing is inconclusive. The finding observed in the current study is consistent with previous studies that married women are more likely to be tested than unmarried women (Demssie et al., 2009), as opposed to the other researchers who have found otherwise (Fabiani et.al, 2007; Westheimer, 2004). Future research should focus on the mechanisms of how women of different marital status decide to be tested to determine the relationship between women's autonomy in household decision-making and their participation in HIV testing. Unfortunately, these variables were not collected in the five countries included in the current study and therefore were not captured in the analysis.

Our finding of the association between younger age, particularly women in their twenties and thirties, and HIV testing and receipt of test results is not surprising. These findings could partly be explained by variation in the laws and policies for the age of consent for seeking medical care including testing for HIV across different countries. For example, age of consent 
for HIV testing and counseling varies from 12 years in Lesotho and Uganda to 18 in Burkina Faso, Cameroon, Cote d'Ivoire, Sierra Leone and Tanzania (Fox et al., 2013). In other countries such as Rwanda reproductive health services are accessible without any age restriction including consent from parents or guardians (UNFPA, IPPF, and The Global Coalition on Women and AIDS 2008b). The low prevalence of testing among older adults in sub-Saharan Africa has been found previously (Negin et.al. 2012). Possible explanations include lack of awareness of HIV/AIDS, and higher level of HIV/AIDS stigma among older population (Negin et.al. 2012).

The association between higher levels of stigma and reduced odds of HIV testing and receipt of test results can partly be explained by the fear and potential discrimination that women anticipate from co-workers, family members, partners, due to their HIV status. Previous studies have found that such anticipation of negative consequences often force women to refuse HIV testing during antenatal care visit (Kilewo et al. 2001) and avoid antenatal care visits (Painter et al., 2011; Turan et al., 2008). Studies in Kenya and other sub-Saharan African countries have shown that stigma plays an important role in pregnant women's refusal of HIV testing (Larsson et al., 2009; Stringer et. al, 2008). Overall, this evidence suggests the need to understand women's lack of participation in HIV testing and develop interventions that will encourage women to be screened for HIV while ensuring confidentiality.

The association between HIV testing and receipt of test results and parity can be explained by the availability of HIV testing during antenatal care visit. Many countries in subSaharan Africa have implemented provider-initiated, opt-out HIV counseling and testing during antenatal care visit (WHO and UNAIDS 2007). This approach has increased the proportion of women tested, especially during pregnancy (Dehal et.al, 2008; Mugore et. al.; 2008). Some studies have found that women with a greater number of children had a higher likelihood of HIV 
testing (Matovu et al. 2005; Venkatesh et al., 2011). However, other studies have shown that women who had at least two live births are more likely to refuse testing compared to first time pregnant women (Fanta \& Worku, 2012). A possible explanation for refusal suggested by previous research is fear and insecurity of partner abandonment because of HIV status (Charles et al. 2006; Haddis \& Jerene, 2006; Fanta \&Worku, 2012).

Some education was also associated with uptake of HIV testing and receipt of test results. Primarily, education improves information exposure and awareness of HIV/AIDS, the importance of testing, and knowledge regarding testing locations. Studies have shown that having education is associated with improved access to antenatal care and other health care services (Nwogu, 2009; Ibor, 2011). Studies have shown that the higher the level of school education, the more there is access to information and adoption of protective lifestyle and behavior (Geregson 2004; Buve 2002; Ramjee \& Daniels, 2013).

The association between increasing household wealth index wealth index and HIV testing and receipt of test results support previous findings (Gage \& Ali, 2005; Cremin et al. 2009; Mitchell; 2010). This evidence is extremely important considering recent findings that identified involvement in risky sexual behavior among wealthy segments of the population in developing countries (Awusabo-Asare and Annim, 2008; Mishra et al, 2007), which can be used to inform strategies and approaches to prevention, education, and care. One possible explanation is that because of their access to information and other resources, wealthy individuals are placed in a better position to utilize HIV testing as a way to mitigate personal risk of HIV infection. The current finding of the association between employment and testing for HIV and receipt of test results is an indicator that economically productive women are more likely to seek care (Demissie et al., 2009). Employment can empower women to have better access to healthcare 
services. In this context, employment can create opportunities to interact with other individuals and to participate in workplace-based HIV testing and other peer education programs (Houdmont, Munir, \& Grey, 2013; Elisabeth et.al 2007; Richter et al., 2012).

The current finding of decreased odds of HIV testing and receipt of test results among rural residents compared to their urban counterparts is attributable to a number of factors. Previous studies have noted the lack of information, access to care, and other resources associated with residing in rural areas. For example, a study on risk and protection among youth in sub-Saharan Africa found that individuals residing in rural areas do not know where to obtain condoms (Bankole et al., 2007). Recent study of pregnant women in rural Kenya found that anticipation of stigma from friends and family members is a barrier to acceptance of HIV testing (Turan et al., 2011). This evidence suggests the need for the development of targeted intervention to address the needs of specific groups of populations. The association between higher level of stigma and reduced odds of HIV testing and receipt of HIV test results can partly be explained by fear and potential discrimination that women anticipate from co-workers, family members, partners, due to their HIV status. Previous studies have found that such anticipation of negative consequences often force women to refuse HIV testing during antenatal care visit (Kilewo et al. 2001) and avoid antenatal care visits (Painter et al., 2011; Turan et al., 2008). Studies in Kenya and other sub-Saharan African countries have shown that stigma plays an important role in pregnant women's refusal of HIV testing (Larsson et al., 2009; Stringer et. al, 2008) Overall, this evidence suggest the need to understand women's lack of participation in HIV testing and develop interventions that will encourage women to be screened for HIV. The association between greater media exposure and HIV testing and receipt of test results is not unique to this study. Over the past three decades, mass media has been utilized as a 
method to increase awareness, provide information, promote healthy behaviors such as condom use, improve attitudes and minimize stigma and discrimination of HIV/AIDS (Singhal \& Rogers, 2003). Utilizing media, many countries have reduced the rate of new HIV infections (UNAIDS, 2004b). In order to gauge the effectiveness of media exposure in improving uptake of HIV testing, critical examination of the nature and content of media campaigns in each country is needed. Unfortunately, these variables are not collected in standard DHS and AIS surveys. Nonetheless, the current evidence is an indication that providing information is an important platform for potential intervention. In the current study, the finding that may relate to media exposure is the association between increasing HIV/AIDS awareness and HIV testing and receipt of test results. Previous studies have found a significant association between sufficient knowledge on HIV/AIDS, and HIV testing (Demissie et al., 2009; Westheimer, 2004). It has been noted previously that women who had frequent conversations about HIV and women who heard of antiretroviral treatment (ART) had greater acceptance of HIV testing (Hendriksen et. al 2009; Warwick, 2006).

Women who were involved in risky sexual behavior, defined as having last sex with nonspousal partner without using condom, were more likely to report testing for HIV and receiving test results. This finding is consistent with other studies in sub-Saharan Africa (Ryder et al., 2005; Matambo et al., 2006; Matovu et al., 2007). This finding is important considering the findings from recent surveys in several countries in sub-Saharan Africa that found decreases in condom use and/or an increase in the number of sexual partners (UNAIDS 2013). This evidence is an indication of the need to develop targeted counseling programs in conjunction with HIV testing. The finding that non-sexually active women were less likely to get tested and received test results compared to women whose sexual experience starts as early as less than 16 years of 
age is not surprising. Women who are not sexually active may not value the importance of HIV testing as sexually active women. More effort is needed to encourage women who may soon become at risk especially in countries with generalized epidemics. The finding of increasing odds of HIV testing and receipt of test results for DHS and AIS surveys conducted in the 2009-2011 period compared to the 2006-2009 period was not surprising. Over the past few years, there has been a continuous increase in the number of women screened for HIV in sub-Saharan Africa. Such an increase is also an indication of expansions in HIV/AIDS programs and health facilities providing HIV testing and counseling (WHO, 2013).

In the current study, the multilevel random intercept models allowed us to shed some light into individual, community, and country-level variations in HIV testing and receipt of test results. Although the community level variables adjusted in the multivariable-adjusted models did not reach conventional levels of statistical significance, the relatively higher proportion of community level random variance provides evidence that community level factors influence patterns of HIV testing in sub-Saharan Africa. This may partly be explained by the shared sociocultural preference and experience that people living in the same area face as a group in communities they reside (Andrulis \& Brach, 2007; Singleton \& Krause, 2009). The increasing likelihood of HIV testing with increasing GDP per capita and increasing proportion expenditure on public health (\% of GDP) is an indication that country-level socioeconomic status influences patterns of HIV testing (Larose et al., 2011). Overall, the country and community level variances suggest that these factors play an important role in shaping patterns of HIV testing behaviors. This evidence also suggests the need to incorporate broad community and population level interventions aiming at improving the uptake of HIV testing and receipt of test results. 
A major strength of the current study was the large representative population-based sample with high response rates. This allows generalizability and representativeness of these findings. Previous studies examining patterns of HIV testing in sub-Saharan Africa have often relied on health facility-based populations, which may not represent the general female population and may have a selection bias. This study also has a number of limitations. Primarily, data were collected based on self-report, which may increase the risk of under-reporting and/or over-reporting of participation in HIV testing and receipt of test results. In addition, information on important variables such as perceived risk of HIV infection were not captured in the standard DHS and AIS data. The cross-sectional design of the current study precludes causal or temporal inferences from the associations observed. Some sensitive questions such as involvement in premarital sex, risky sexual behavior and having multiple sex partners have the potential for misreporting due to social desirability and recall bias, especially when asked in a face-to-face interviews, although DHS and AIS surveys are confidential and no identifiable personal information was collected.

\section{Conclusions}

In conclusion, the current study attempted to shed light on individual, community and country-level factors that are associated with utilization of HIV testing and receipt of test results among women in sub-Saharan Africa. Characteristics of individuals who are less likely to utilize these services are those who were older, unmarried, who were nulliparous, who had no education, who lived in the poorest households, who were unemployed, lived in rural areas, had low exposure to media, had low awareness about HIV/AIDS, and who stigmatized people living with HIV/AIDS. Other individual characteristics such as no sexual experience, no involvement in premarital sex, and risky sexual behavior were found to contribute to lack of utilization of 
HIV testing and receipt of test results. From a public health point of view, this evidence suggests that individuals who are at risk are more likely to use HIV testing. However, more effort is needed to improve uptake of HIV testing among rural and marginalized population. Current efforts to improve HIV testing among women especially in antenatal care settings in most of these sub-Saharan African countries are encouraging. Allocating resources to develop and implement strategies that effectively reach women of childbearing age in both clinical and nonclinical settings, especially those who exhibit the characteristics identified as at risk in the current study, can play a significant role in reducing new HIV infection among women. Future studies need to explore whether factors that were identified in the current study also influence utilization of HIV testing and receipt of test results among men along with utilization patterns among couples. Studies should also examine the mechanisms by which other factors such as perceived risk and perceived susceptibility, unmeasured in DHS and AIS, affect participation in HIV testing and receipt of test results. 


\title{
Chapter 3 \\ A multi-level analysis of socio-demographic and behavioral characteristics associated with HIV seropositivity among women in sub-Saharan Africa
}

\begin{abstract}
Objectives: In sub-Saharan Africa, women are disproportionately affected by the HIV/AIDS epidemic. The main purpose of this study is to examine individual, community and country-level factors associated with testing HIV positive among women of childbearing age in sub-Saharan Africa.

Method: This study constitutes a cross-sectional examination of 155,356 women who participated in the HIV testing during the Demographic and Health Survey and AIDS Indicator Survey between 2006 and 2012 in 25 sub-Saharan African countries. Multilevel logistic regression was utilized to assess the association between measured individual and community and country-level factors and HIV seropositivity.
\end{abstract}

Results: The overall prevalence of HIV seropositivity among women of childbearing age in subSaharan Africa was 5.5\%. In the multivariable-adjusted model, factors that include age, marital status, parity, and pregnancy status, type of residence, stigma, and age at first sex, involvement in premarital sex and having multiple partners were significantly associated with higher odds of testing HIV positive.

Conclusion: Individual level factors were predictors of HIV seropositivity in sub-Saharan Africa. Reducing HIV infection among women in this sub-region requires a concerted effort that includes identification of individual characteristics and high-risk groups as well as behavior change programs that address the cultural and individual needs of the target population. 


\subsection{Introduction}

HIV/AIDS is one of the world's most serious health plights and challenges the development and economic growth of many low to middle-income countries in the world (UNAIDS 2012). Since the initial identification of the disease in 1981, AIDS has resulted in the death of more than 25 million people (UNAIDS, 2011, 2013). Authors of recent reports on HIV and AIDS indicate that about 33.4 million people are living with HIV/AIDS (UNAIDS, 2011, 2013; WHO, UNAIDS, UNICEF report, 2011). In 2010 the estimated new infection rate was approximately 1.9 million people per year (WHO, UNAIDS, UNICEF report, 2011), an increase to approximately 2.3 million people in 2012 , or more than 6000 new infections per day (UNAIDS, 2012). While the disease affects people in all parts of the world, studies show that about $97 \%$ of those affected by the disease live in low to middle income countries, and subSaharan African countries are placed at the core of the pandemic (Musheke et al., 2013; UNAIDS, 2011; MacPhail et al., 2009). Recent UNAIDS estimates on global HIV/AIDS statistics reveals that sub-Saharan Africa contains about $71 \%$ of people living with HIV (1 in every 20 adults) (UNAIDS, 2013). Most countries in this sub-region have HIV/AIDS prevalence of at least 1\% (UNAIDS, 2011, 2012, 2013). Women living with HIV constitute $49 \%$ of all adults living with HIV (UNAIDS, 2012) and approximately 61\% of HIV infected women live in sub-Saharan Africa (Karim et al, 2010). In 2012, an estimated 4.7\% women 15-49 years in subSaharan Africa were infected with HIV (UNAIDS, 2013).

There are various complex factors associated with the higher rate of HIV infection among women. Whereas women in Europe, Latin America and North America experience higher risk of HIV infection through drug use and subsequent partner infection, women in sub-Saharan experience higher risk through heterosexual contact (Rombo, 2009). Studies show that 
transmission of the HIV infection via vaginal intercourse is largely influenced by the physiology that exposes women to increased bodily fluid exchange during sexual intercourse when compared to men (Karim, 2010; Rombo, 2009). Various studies have demonstrated that heterosexual transmission and the transmission efficiency from men to women increases by approximately 8-fold as compared to transmission from women to men (Padian et al., 1997; Pettifor et al., 2004; Hladik \& McElrath, 2008; Karim et al., 2010). In addition to the biological factors, in sub-Saharan Africa other factors such as poverty, power balance between men and women, gender based violence, poor access to sexual and reproductive health services, and other sociocultural factors place women at greater risk for HIV infection (Gray et al., 2001; Karim et al., 2010; Quinn et al., 2000; Wawer et al., 2005).

Currently, numerous efforts are underway across the region aimed at providing effective prevention and treatment strategies such as: HIV testing; male circumcision; blood supply safety; harm reduction for injecting drug users; provision of Pre-Exposure antiretroviral Prophylaxis (PrEP) and Anti-Retroviral Therapy (ART). Each of these efforts has the potential to reduce the risks of HIV transmissions and HIV/AIDS related deaths. In many countries of this sub-region, HIV prevention is one of the top priorities. In order to develop a comprehensive intervention for prevention it is necessary to understand the socio-demographic, behavioral, biomedical factors that are associated with the risk of infection. Numerous studies that examined HIV infection among women in sub-Saharan Africa used small, community or health facility based approaches that may have limited generalizability to the population (Ramjee and Daniels, 2013; Karim, 2010; Stockl et al., 2012; Pettifor et al., 2008; Ncube, 2009; Nwoye, 2007; Humphreys et al., 2007). These studies have focused primarily on identification of individual level demographic, biological, socioeconomic and behavioral risk factors for HIV infection. 
There is currently a dearth of literature examining factors associated with HIV infection among women of childbearing age using population level data. Compared to community or health facility-based surveillance techniques, population-based HIV surveillance allows direct estimation of the factors associated with HIV infection in the population. To date, few studies have attempted to examine factors associated with HIV infection using nationally representative data in sub-Saharan Africa (Bärnighausen et al. 2007; Magadi, 2011; Magadi \& Desta 2011). The study by Bärnighausen et al. (2007) focused primarily on only socioeconomic determinants of HIV incidence in rural South Africa. On the other hand, Magadi and Desta (2011) examined cross-national variations and gender disparities in the risk of HIV seropositivity using data collected during 2003-2008. The primary objective in the present study is to examine the association between individual, community and country related factors and HIV infection among women in sub-Saharan Africa using the most recent Demographic and Health Survey and AIDS Indicator Survey data from 25 countries collected between 2006 and 2012.

\subsection{Methods}

\section{Data}

Data for the study were obtained from the Demographic and Health Surveys (DHS) and AIDS Indicator Surveys (AIS) for 25 sub-Saharan African countries. The study design and methodology of the DHS and AIS are available in detail elsewhere (DHS, 2013). These studies are conducted by the Monitoring and Evaluation to Assess and Use Results Demographic and Health Surveys (MEASURE DHS). The DHS and AIS are nationally representative surveys designed to monitor the health and dietary status of non-institutionalized civilian populations in developing countries. MEASURE DHS is implemented by ICF International and is mainly funded by the United States Agency for International Development. Other donors of this 
program include United Nations Children's Fund (UNICEF), United Nations Population Fund (UNFPA), World Health Organization (WHO), and the Joint United Nations Program on HIV and AIDS (UNAIDS). Data collection methods utilized by DHS and AIS include face-to face interview using a pre-tested and validated questionnaire, clinical, physical and laboratory examinations. At the end of each interview, blood samples were collected by interviewers for laboratory testing of HIV from all women age 15-49 years who consented to the test. MEASURE DHS has developed a standardized protocol for the blood specimen collection. Details of the analytical procedures involved in the DHS and AIS HIV testing are published elsewhere (MEASURE DHS, 2014). To ensure accurate representation of populations, DHS and AIS surveys are collected using a multi-stage stratified probability sampling technique. Selection is based on strata, cluster, households and individuals within households. The use of standardized questionnaire in each country makes DHS and AIS data suitable to generate estimates based on pooled data.

DHS and AIS data have pre-calculated weighting factor that is used to adjust for nonresponse ensure representativeness. However, the standard weighting factor is not valid for pooled data from multiple countries. Following the recommendation from MEASURE DHS, in this paper the standard weight were de-normalized to account for variation in the number of women tested for HIV in each country. This process involves multiplication of the standard HIV weight by additional adjustment factor given by $(\mathrm{t} / \mathrm{HIVt})$ to obtain $\mathrm{HIV} w \mathrm{t}^{*}(\mathrm{t} / \mathrm{HIVt})$, where HIVwt is the standard HIV weight, $t$ is the total males and females aged 15-49 in the country at the time of the survey and HIVt is the total number of males and females aged 15-49 tested for HIV in the survey. Both standard HIV weight and the number of women aged 15-49 tested for HIV in the survey are provided in DHS and AIS. In this paper, estimated number of total males 
and females aged 15-49 in the country at the time of the survey were derived from the United Nations World Population Prospects (http://esa.un.org/wpp/).

The present study sample consisted of 155,386 DHS and AIS women age 15-49 years who were interviewed and consented for HIV testing between 2006 and 2012 in sub-Saharan Africa. We excluded 28 cases whose HIV test result could not be determined. The final study sample constitutes 155,356 participants from 25 countries.

\section{Outcome variable: HIV test result}

The primary outcome of interest in the study was the women's test results derived from

confirmatory HIV testing. This variable was categorized into two groups, women who were HIV seropositive and those who were HIV seronegative.

\section{Independent Variables}

The World Health Organization's (WHO) Commission for Social Determinants of Health $(\mathrm{CSDH})$ conceptual framework was used to guide selection of independent variables for analysis. To date, the relative contribution of social determinants of health to testing for HIV in a large population-based study has not been evaluated. Drawing substantially on the contributions of Solar and Irwin (2007), the commission developed a conceptual framework to describe relationships among individual and structural variables that determine health outcomes. The framework is now widely used in the development of targeted interventions on social determinants of health (CSDH, 2008). In this study individual, community and country-level variables were examined.

The individual level factors include age at the time of interview (15-19, 20-24, 25-29, 3034, 35-39, 40-44, 45-49); marital status (never married, married-monogamous, marriedpolygamous, widowed, divorced or separated); parity (none, one, two or more); pregnancy status 
(no, yes); education (no education, primary, secondary or higher); household wealth index (poorest, poorer, middle, richer, richest); employment status at the time of interview (no, yes); place of residence (rural, urban); media exposure (low, moderate, high); HIV/AIDS awareness (low, moderate, high); HIV/AIDS stigma (low, high); age at first marriage (never married, < 16,

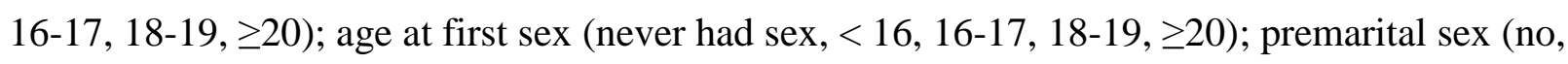
yes); risky sexual behavior (no, yes).

In the standard DHS and AIS household wealth index is calculated is based on the data from the household's ownership of consumer goods; dwelling characteristics; type of drinking water source; toilet facilities; and other characteristics that relate to a household's socioeconomic status. Method applied in the calculation of wealth index in DHS and AIS can be found elsewhere (Rutstein \& Johnson, 2004). In short, this index is constructed by assigning each of these assets a factor score generated through principal component analysis. These scores are then standardized in relation to a standard normal distribution with a mean of zero and a standard deviation of one and total score of the household were used to rank individuals based on the household they resided. Finally, the scores were converted into quintiles from one (poorest) to five (richest). In the current study, a similar procedure for creating wealth index was used to create exposure to media, HIV awareness and HIV/AIDS stigma variables. In the standard DHS and AIS participants were asked about the frequency that they: read newspaper or magazine, listen to the radio, and watch television. Three questions were used to assess the level of HIV/AIDS stigma. Participants were asked if they are willing to care for relative with AIDS; if a teacher infected with HIV, but is not sick, should be allowed to continue teaching; if they would buy vegetables from vendor with HIV. HIV/AIDS awareness was measured using is based on an established and widely used measure where each woman was asked whether or not she agreed or 
disagreed with the following statements: 1) HIV can be prevented by using condoms every time you have sexual intercourse; 2) HIV can be prevented by limiting intercourse to one uninfected partner; 3) it is possible for a healthy-looking person to have the AIDS virus; 4) the AIDS virus can be transmitted from mosquito bites; 5) a person can get HIV by sharing food with a person who has AIDS; 6) a person can get the AIDS virus because of witchcraft or other supernatural means; 7) the virus that causes AIDS can be transmitted from a mother to her baby during pregnancy; 8) the virus that causes AIDS can be transmitted from a mother to her baby during delivery; 9) the virus that causes AIDS can be transmitted from a mother to her baby by breastfeeding.

Community level factors were directly calculated from DHS and AIS data. In this context, communities are geographically defined by the primary sampling units (PSU) within each country. These variables include community level poverty measured as the proportion of individuals living in poor households in the community; community level education measured as the proportion of individuals with less than high school education in the community and low community media exposure measured as the proportion of individuals with low media exposure in the community. Country-level variables were derived from World Bank's World Development Indicators and include: national income measured as per capita gross domestic product (GDP) adjusted for purchasing power parity, based on the United Nations Development Program estimates. This refers to the sum of gross value added by all resident producers in the economy plus any product taxes and minus any subsidies not included in the value of the products, expressed in international dollars using purchasing power parity rates and divided by total population during the same period and expenditure on public health (\% of GDP) (\%): calculated based on current and capital spending from central and local government budgets, external 
borrowings and grants (including donations from international agencies and nongovernmental organizations), and social (or compulsory) health insurance funds, expressed as a percentage of GDP (World Bank, 2012a).

\section{Statistical Analyses}

Median and interquartile ranges were used to describe continuous variables. Frequencies and proportions were used to describe categorical covariates in relation to HIV status. Rao-Scott chi-square was used to test for relationships between the HIV status and each of the covariates. As recommended, pooled sample weights that account for the unequal probabilities of selection, oversampling, nonresponse, country-level variability in population and complex survey design were incorporated in all analyses. Regression diagnostics were utilized to identify potential collinearity. A three level multi-level logistic regression models were fitted to compute the fixed effect odds ratios (OR) and 95\% confidence interval (CI) of HIV testing and receipt of test results. Four nested models at level 1, level 2, level 3 and level 4 were constructed. Model 1 constitutes an empty model without any covariate variables. This model was specified to decompose the variance between community and country-levels. Model 2 represents individual level covariates the relationships among the individual level variables; Model 3 models contain community-level variables and model 4 includes explanatory variables at the individual, community and country-levels. Intra-cluster correlation (ICC) was used to measure community and country-level random effects. The linear threshold model formula was used to compute the ICC (Snijders and Bosker, 1999). Descriptive analyses were conducted using SAS 9.3 (SAS Institute Inc., Cary, North Carolina) and multilevel regression estimates were computed using MLwiN 2.30 (Rasbash et al., 2008). 


\subsection{Results}

The overall HIV prevalence was 5.5\%. Descriptive statistics for the final pooled sample are shown in table 3.1. A greater proportion of the participants were of age 15-19 years (21.6\%). Most respondents were married in a monogamous relationship (53.5\%), and had two or more children (47.5\%). Some participants were pregnant at the time of the survey $(9.5 \%)$. A greater proportion of the participants had a primary level education (42.3\%), and was employed at the time of the testing (57.8\%). Most of the participants lived in rural areas (68.6\%). However, greater proportion of participants had low stigma towards people living with HIV/AIDS (64.8\%). Among those who were married, age at first marriage was evenly distributed. A slightly higher proportion of participants had their sexual debut when they were less than 16 years old (31.6\%). Fewer proportions of participants had premarital sex (23\%), had multiple sex partners (2.3\%) and were involved in risky sexual behavior (7.4\%).

The median proportion of women living in communities with less than high school education was $87 \%$. The median proportion of women residing in communities with poor households was $33 \%$. The median proportion of participants in the community with low media exposure was about 30\%. At the country-level, the median GDP per capita (2005 PPP) was 972 USD median expenditure on public health (\% of GDP) (\%) was $2.44 \%$.

Table 3.2 displays association between HIV status and each covariate. Each individuallevel covariate was significantly associated with HIV status. Compared to HIV seronegative women, HIV positive women resided in communities with lower proportions of women having less than high school education, lower proportion of women with poor household wealth, and lower proportion of women with poor media exposure. The median GDP per capita of countries 
where HIV seropositive women resided is slightly higher than median GDP per capita of countries for HIV seropositive women.

Results of fixed-effect and random-effect measures from multilevel analysis are shown in table 3.3. The lack progressive declines in the community and country-level variance estimates and in the ICC in model 2, 3, and 4 indicate that the community and country-level variables that were added in the model did not contribute much towards explaining the unexplained variation in the odds of testing HIV positive. Based on the ICC about $22 \%$ of the total variation in the odds of testing HIV positive are attributable to country-level differences. After adjustment for individual, community and country-level factors about $18 \%$ of the total unexplained variation in the odds of testing HIV positive was attributable to country-level factors. This evidence supports the use of multilevel modeling that accounts for community and country variations as an appropriate approach.

Table 3.3 also shows results of fitting the multilevel model including individual-level, community level, and country-level factors. In the final model, the odds of testing HIV positive among women in the $25-29,30-34,35-39$, and 40-44 age categories was higher compared to women 45-49 years. However, the odds of testing HIV positive were lower for women in the youngest 15-19 and 20-24 age categories. Compared to never married women, women who were married monogamously had lower odds of testing HIV positive. On the other hand, women who were widowed and those who were divorced had higher odds of testing HIV positive (Adjusted Odds Ratio, aOR=3.81; $95 \%$ CI 2.95, 4.92; and $1.61 ; 95 \%$ CI 1.37, 1.90), respectively. Compared to nulliparous women, primiparous women had higher odds of testing HIV positive. However, multiparous women had reduced odds of testing HIV positive. Compared to nonpregnant women, women who were pregnant at the time of their interview had lower odds of 
testing HIV positive $(\mathrm{aOR}=0.82 ; 95 \%$ CI 0.79, 0.94). Compared to women with no education, the odds of testing HIV positive is higher for women with primary level education. However, no significant difference in the odds of testing HIV positive was detected between women with no education and women with at least secondary school education. Women residing in rural area had lower odds of testing HIV positive compared to women residing in urban areas $(\mathrm{aOR}=0.72$; 95\% CI 0.64, 0.81). Women with higher level of enacted stigma had higher odds of testing HIV positive compared to women with low enacted stigma (aOR=1.20; 95\% CI 1.11, 1.30).

Compared to women who reported never having sex, women who initiated sexual activity at any point had higher odds of testing HIV positive, the strongest association being among women with whose sexual debut was at an earlier age (aOR=3.45; 95\% CI 2.77, 4.30). Women who reported involvement in premarital sex and women who had multiple sex partners had higher odds of testing HIV positive $(\mathrm{aOR}=1.17 ; 95 \%$ CI 1.06, 1.27; and 1.39; 95\% CI 1.02, 1.88). Controlling for all individual level variables, no significant association have been detected between community and country-level variables and the odds of testing HIV positive.

\subsection{Discussion}

The findings of the current study have demonstrated that the overall prevalence of HIV seropositivity among women of childbearing age in sub-Saharan Africa is 5.5\%, compared to the overall estimated prevalence among adults of $4.7 \%$ (UNAIDS, 2013). This difference in prevalence can partly be explained by the fact that UNAIDS estimates includes both males and females. Factors such as age, marital status, parity, pregnancy status, type of residence, stigma, age at first sex, premarital sex and having multiple partners are associated with HIV infection. While some of these findings are consistent with existing body of literature, others contradict 
previous findings. Identification of factors associated with HIV infection is essential in the development of targeted interventions for prevention, treatment and care.

The current finding of the association between age and HIV status is consistent with the literature. Studies have found lower prevalence in younger age and higher prevalence in HIV among women who are in their thirties (Humphrey et. al., 2007; Magadi \& Desta 2011; Wand \& Ramjee, 2012). The association between being widowed or divorced and higher odds of testing HIV positive has been noted previously (Magadi \& Desta 2011; Hajizadeh et al., 2014). However, contrary to the findings in the current study, reports have shown that women who are married or are in a stable relationship have higher odds of HIV infection than their single counterparts mainly because of their inability to negotiate contraceptive use such as condoms (UNICEF, n.d.). For example in Zimbabwe, the HIV prevalence ranges from $6.2 \%$ among unmarried women, increases to $14.2 \%$ among married women and further increases to $26 \%$ among those that reported divorced or widowed (UNICEF, n.d.). The higher odds of infection among divorced or widowed can partly be explained by former spouses HIV infection which might have resulted in divorce or death, respectively, although this needs to be confirmed with a prospective study design as the information regarding former partner status was not available in the dataset. It has to be noted that there are socio-cultural factors that are critical in understanding the association of HIV infection to marital status. Bakilana (2005) suggests the importance of taking into account additional factors that may contribute to higher risk of HIV infection among married women. These factors include couples living arrangements, years in marriage, engaging in extramarital sex, age at first marriage, education and age differences between the spouses (Rombo, 2009), domestic violence and rape (Jewkes \& Abrahams, 2002; Kim et. al., 2003; Ncube,2009) as well as other religious, and traditional marital practices such 
wife inheritance and polygamy in response to childlessness and infertility of partner (Nwoye, 2007), and sexual coercion within marriage (Pettifor et al., 2004; Ncube, 2009).

Studies that examined the association of parity and HIV status have yielded mixed results. A study in Uganda found a significant interaction between age and parity and the odds of testing HIV positive (Humphrey et. al., 2007). The finding of the significant association between being pregnant and reduced odds of testing HIV positive may be explained partly by the fact that pregnant women are less likely to engage in risky sexual behavior as well as higher likelihood of getting HIV tested during pregnancy. Studies in Uganda and in South Africa have found that HIV positive women are less likely than their uninfected peers to want to have a child (Doskoch, 2013; Snow et al.; 2013; Kaida 2011). The association between being primiparous and having higher odds of HIV seropositivity as observed in the current study may partly be explained by the lack of desire to have more children among HIV infected women, although the crosssectional design precludes this temporal sequence of association.

The finding that women with primary level of education had higher odds of HIV seropositivity is not surprising. Previous studies examining the association between education and HIV infection have yielded mixed results. Some studies showed that women with some education were less likely to be infected with HIV than women who had not completed high school (Bärnighausen et al., 2007; Pettifor et al., 2008; Wand, H., \& Ramjee, 2012). These studies show that better educated women are more likely to negotiate contraceptive use such as condoms, and are also more likely to delay age at sexual debut (UNAIDS, 2000; Pettifor et. al., 2008). On the contrary, earlier studies found having more education was either not associated with higher likelihood of HIV infection or was associated with higher likelihood of HIV infection (Hargreaves \& Glynn; 2002). A systematic review that explored time trends in the 
association between educational attainment and risk of HIV infection have found a change through time in the pattern of the association between education and HIV infection in subSaharan Africa (Hargreaves et al., 2008). Regardless of the nature of this relationship there appears to be a need for incorporating and strengthening HIV/AIDS education into school curriculum.

The association between rural residence and lower odds of HIV infection found in this study has been documented in other studies (Magadi \& Desta 2011; Magadi, 2013). These studies also suggest that this relationship is moderated by poverty placing urban poor at greatest risk for HIV infection. Possible explanations to the lower risks of verified HIV infection among rural population include decreased HIV testing, geographic isolation, limited sexual networking and influence of traditional behavioral norms and values (Johnson \& Budlender, 2002).

The finding of the association between high level of stigma and increased odds of HIV infection is consistent with findings from other studies (Brown et al., 2006; Clum et al., 2009). Stigma and its associated negative consequences such as decreased or lack of social support, social exclusion, symptoms of distress, depression, guilt feelings and shame, feelings of failure, negative self-image and lack of hope for the future due to incurable nature of HIV, manifests in the engagement of risky sexual behaviors such as nondisclosure of HIV status to sexual partner, engaging in unprotected sex and substance abuse thereby increase the risk of HIV infection (Clum et. al., 2009; Mustanski, 2007; Magadi, 2012). This evidence suggests the need for the development of an effective HIV/AIDS sensitization program that will eradicate stigma and improve access to prevention and treatment services.

As observed in the current study, early sexual debut has consistently been found to be significantly associated with HIV infection among women in sub-Saharan Africa (Stockl et al., 
2012; Slaymaker et al. 2009; Ghebremichael et al., 2009; Pettifor et al., 2004; Pettifor et al., 2008). Some studies suggest that this association could be due to the longer or extended period of time of sexual activity which increases the chances of HIV exposure and infection (Hallet et al, 2004; Pettifor et al., 2004). The biological immaturity of the reproductive tract of women at early age has also been proposed as a possible explanation (Pettifor, 2004; Pettifor et al., 2008). Others noted that women who engage in sex at an early age will be more prone to engage in risky sexual behaviors at a later age, including having multiple and concurrent partners, engage in transactional sex, engage in unprotected sex and be exposed to other have previous sexually transmitted infections all of which are known to increase the risk of HIV infection (Pettifor et al., 2008; Boileau et al., 2009; Ghebremichael et al., 2009; Wand \& Ramjee, 2012). A good understanding of the mechanism by which early sexual debut increase the odds of HIV infection is essential in the development effective programs that will allow women to navigate their sex life.

The finding that having engaged in premarital sex is associated with having higher odds of HIV infection is consistent with previous studies in sub-Saharan Africa (Zaba et al., 2009; Ghebremichael \& Finkelman, 2013). Women with longer duration of premarital sex are more likely to report multiple sexual partners (Ghebremichael \& Finkelman, 2013). This may partly be the mechanism by which early sexual debut contribute to higher odds of HIV infection. The association between having multiple sex partners and higher odds of HIV infection observed in this study has been noted elsewhere (Chen et al., 2007; Epstein, 2007; Magadi \& Desta, 2011). The high viral load immediately after infection is a major risk factor for transmission especially in concurrent rather than in sequential multiple partnerships (Shelton et al., 2004). 
The current study has several strengths that include its population based nature, inclusion of nationally representative samples, adequate sample size, and the availability of information on potential individual, community and country-level confounders for multivariable adjustment. The main limitation of our study is that, owing to the cross-sectional nature of our study, it is impossible to make causal inferences and determine the temporal nature of the associations. We also cannot rule out the effects of other unmeasured characteristics including sexual behavior of partners/husband, substance abuse, prior experience with sexually transmitted disease, intimate partner violence, population movement, and other cultural differences. In addition, participants' self-reports especially on sensitive questions such as premarital sex, age at first sex, multiple sex partners could have introduced misclassification and bias.

\section{Conclusions}

In conclusion, identification of the factors associated with HIV/AIDS infection among women of childbearing age is an important strategy in the fight against the HIV/AIDS. This paper attempted to shed light on the role of different levels of socio-demographic and behavioral characteristics that are associated with HIV infection in sub-Saharan Africa combining nationally representative surveys among women of childbearing age. The findings have important public health implications, especially the need for considering factors identified in this study while designing prevention programs. As demonstrated by the current study, the magnitude of the odds of testing positive for HIV varies across different socio-demographic and behavioral characteristics. Along with the biological and other environmental risk factors that were not captured by the current study, factors identified in this study may place women at greater risk for HIV infection. Nevertheless, the modifiable nature of many of these factors identified in the study suggests that these can be substantially mitigated through the development and 
implementation of an effective, target oriented public health policy and practice. Furthermore, addressing HIV/AIDS in women of childbearing age can substantially reduce MTCT of the virus. Strategies that include provision of effective education and counseling about HIV and educating community members about prevention, transmission, and treatment of HIV have the potential to empower women to make decisions for themselves. Furthermore, factors identified in this study should be taken into account when allocating resources for HIV prevention, treatment and care. 


\title{
Chapter 4 \\ A population based analysis of the socio-demographic and behavioral characteristics associated with HIV seropositivity among children in sub-Saharan Africa
}

\begin{abstract}
Objectives: Despite the significant reduction in mother to child transmission of HIV over the past few years, HIV infection has increasingly become one of the leading causes of overall child mortality in sub-Saharan Africa. The purpose of this study was to examine individual and community-level factors associated with HIV seropositivity among children 0-14 years in subSaharan Africa.

Method: This study utilizes a cross-sectional design to examine 15,034 children 0-14 years who participated in a population based HIV testing of the Demographic and Health Survey and AIDS Indicator Survey between 2006 and 2011 in 3 sub-Saharan African countries. Multilevel modeling was used to identify the association between individual maternal and community-level characteristics and HIV seropositivity of children.

Results: The overall prevalence of HIV seropositivity among children $0-14$ years was $1.22 \%$. In the multivariable-adjusted model, maternal characteristics that were significantly associated with the odds of HIV seropositivity in children, included maternal HIV seropositivity (Adjusted odds ratio, aOR $=16.61 ; 95 \%$ CI $16.40,16.82$ ). Children whose maternal age at birth was greater than 16 years had higher odds of HIV seropositivity, although the odds of testing seropositive diminish with increasing maternal age. Compared to children whose mothers have never been married, children whose mothers were divorced/separated and widowed had higher odds of testing positive $(\mathrm{aOR}=2.92 ; 95 \%$ CI $2.98,3.05$ and $\mathrm{aOR}=1.41 ; 95 \%$ CI 1.35, 1.48, respectively). Similarly, children whose mothers were married monogamously had higher odds of testing HIV positive (aOR=1.69; 95\% CI 1.62, 1.77). Children whose mothers were employed were more likely to test HIV positive than were children with unemployed mothers $(\mathrm{aOR}=1.44 ; 95 \% \mathrm{CI}$ 1.42, 1.46). The likelihood of HIV seropositivity was higher for children whose mothers had high HIV/AIDS awareness compared to those whose mothers had low level of HIV/AIDS awareness $(\mathrm{aOR}=1.46 ; 95 \% \mathrm{CI} 1.44,1.48)$.
\end{abstract}

Conclusion: Programs aimed at reducing HIV infection among children 0-14 years in subSaharan Africa should consider biological as well as maternal socio-demographic profiles. Elimination of vertical transmission can only be achieved when programs acknowledge the intricate relationships between these and other factors. 


\subsection{Introduction}

In 2012, an estimated 260,000 children were newly infected with HIV (UNAIDS, 2013; WHO, 2014). In the same year there were 3.3 million children under the age of 15 living with the HIV virus (UNAIDS, 2013; WHO, 2014). Over 90\% of the newly infected children under the age of 15 years were from developing countries, the largest burden was from sub-Saharan African countries (WHO, UNAIDS, UNICEF, 2012; Ubesie, 2012; UNAIDS, 2014). The epidemic has become one of the leading causes of child mortality in sub-Saharan Africa and it accounts for about 3\% of deaths among children under age 5 years (Ngwende et. al., 2013). It is estimated that about $89 \%$ of orphans or children who have lost one or both parents due to AIDS resided in sub-Saharan Africa. (Ubesie, 2012; U.S. Global health policy, 2010).

One risk factor for the high number of pediatric HIV infections in sub-Saharan Africa is the increased number of infections among women. Women constitute 56-63\% of all HIV infected persons in sub-Saharan Africa (Ubesie, 2012; Nassali et. al., 2009). MTCT of HIV is a primary mode by which the epidemic affects children under the age of 15 years. In 2012, an estimated 260,000 children contracted HIV during the perinatal and breastfeeding period (UNAIDS, 2014). During the same period, an estimated 210,000 children died from AIDSrelated illnesses predominantly in sub-Saharan African countries (UNAIDS, 2014).

There are three ways by which MTCT of HIV occurs: during pregnancy, during labor or delivery, and through breastfeeding (Newell, 1998; De Cock et al., 2000). It is estimated that $90 \%$ of pediatric HIV infections is through transmission from the mother to her child during either pregnancy, birth or breastfeeding (Ubesie 2012; WHO, 2012). The estimated risk of infection varies across MTCT modes. The risk of MTCT is higher during pregnancy either during labor or through breastfeeding (De Cock et al., 2000). In the absence of any intervention, 
there is a $15 \%$ to $45 \%$ MTCT risk of HIV (WHO, 2013). The risk of transmission is higher for women have secondary bacterial, viral, or parasitic placental infection or other AIDS related infections (Fowler et al. 2007; Boily-Larouche et al. 2009). During labor, HIV can also be transmitted during accidental mixing of maternal and placental blood. During delivery, HIV can be transmitted due to the rupturing of membranes (Anderson, 1997; Fowler et al. 2007). Acute and chronic chorioamnionitis (mainly derived from untreated diseases and infections as well as other abnormalities during delivery) also increases the risk of MTCT (Anderson, 1997; Chi et al., 2006). Other factors such as early chorionic membrane rupture and premature birth increases the risk of MTCT of HIV (Leroy et al., 2001; Newell, 2006; Taha, 2011). The risk of transmission through breastfeeding is influenced by other factors such as the age of the infant, nature, duration and consistency of breastfeeding, health condition of the mother's breasts, level of viral load and immune status of the mother, mother's susceptibility of HIV infection and oral health of infants (Fowler et al. 2007; Embree et al., 2000; Leroy et al., 2001; Ciaranello et al., 2011). Studies suggest that in the absence of appropriate interventions and treatments, less than $10 \%$ of infants with HIV will live to adolescence (Marston et. al., 2005). With effective intervention, the risk of MTCT can be reduced to as low as $2 \%$ (WHO, 2012).

In addition to the biological mechanisms for MTCT of HIV, other factors that include: lack of access to timely care, lack of transportation, poor adherence to recommended treatment, stigma and discrimination related to HIV/AIDS, lack of availability of infant feeding options and other psychosocial factors (Ubesie, 2012). There is little known knowledge or evidence about the magnitude of the relative contribution of socio-demographic, behavioral, and community-level factors of MTCT in sub-Saharan Africa. One study cannot consider all of the possible factors, although the factors may be duly recognized. The primary objective in the current study is to 
examine the association between maternal individual and community-level characteristics and HIV seropositivity among children ages 0-14 years in three sub-Saharan African countries: Mozambique, Swaziland and Uganda.

\subsection{Methods}

\section{Data}

The study utilizes data from the Demographic and Health Surveys (DHS) and the AIDS Indicator Surveys (AIS) conducted from 2006 through 2011 in three sub-Saharan African countries. The study design and methodology of the DHS and AIS are available in detail elsewhere (DHS, 2013). In brief, conducted by the Monitoring and Evaluation to Assess and Use Results Demographic and Health Surveys (MEASURE DHS), DHS and AIS are nationally representative surveys designed to monitor the health and dietary status of noninstitutionalized civilian populations in developing countries. With funding from United States Agency for International Development and other international organizations such as United Nations Children's Fund (UNICEF), United Nations Population Fund (UNFPA), World Health Organization (WHO), and the Joint United Nations Program on HIV and AIDS (UNAIDS MEASURE DHS is implemented by ICF International. Data collection methods included face-to face interviews using a pre-tested and validated questionnaire; clinical, physical and laboratory examinations. Details of the analytical procedures involved in the DHS and AIS HIV testing are published elsewhere (MEASURE DHS, 2014). DHS and AIS surveys are collected using a multi-stage stratified probability sampling technique to accurately represent populations of each country. Selection of participants was based on strata, cluster, households and individuals within households. In some countries, HIV testing and testing for other nutritional deficiencies were 
conducted among participants who consented. The use of standardized questionnaire in each country makes DHS and AIS data suitable to generate estimates based on pooled data.

Both DHS and AIS datasets have a pre-calculated weighting factor that is used to adjust for nonresponse and to ensure representativeness. However, the standard weighting factor is not valid for pooled data from different surveys. Following the recommendation from MEASURE DHS, in this paper the standard weight were de-normalized to account for variation in the number of children sampled in each country. This process involves multiplication of the standard HIV weight, HIVwt, by an additional adjustment factor given by (t/HIVt), to obtain HIVwt*(t/HIVt), where, $\mathrm{t}$ is the total number children in the given age group in the country at the time of the survey, and HIVt is the number children in the given age group who tested for HIV. Both standard HIV weight factor and the number of children tested in the survey are provided in DHS and AIS. The estimated total number of children in a given age group at the time of the survey was derived from the United Nations World Population Prospects (http://esa.un.org/wpp/).

The study sample consisted of 21,948 children 0-14 years who were tested for HIV between 2006 and 2011 in three sub-Saharan African countries. Children who participated in the HIV testing but whose mothers were not tested $(n=5,272)$, or whose mother had missing data on covariates examined in the current study were excluded $(n=1,577)$. The final sample consisted of 15,034 children $0-14$ years.

\section{Ethics statement}

This study is based on an analysis of de-identified secondary data using a standard protocol developed by the DHS program. The survey was approved by the Institutional Review 
Board of ICF Macro in Calverton, Maryland, USA, and other country-specific ethics-related committees. Before participating in the survey, parents and guardians of participants gave informed consent and all information was collected confidentially. Approval for the current study was also obtained from the Institutional Review Board of the academic institution of the researchers.

\section{Outcome variable: HIV test result}

The primary outcome of interest in the study was the HIV test results derived from confirmatory HIV testing. This variable was categorized into two groups, children who were HIV seropositive and children who were HIV seronegative.

\section{Independent Variables}

The selection of the independent variable for the current study was guided by the World Health Organization's Commission for Social Determinants of Health (CSDH) conceptual framework. Drawing substantially on the contributions of Solar and Irwin (2007), the CSDH developed a conceptual framework to describe relationships among individual and structural variables influencing health outcomes. The framework is now widely used in the development of targeted interventions on social determinants of health (CSDH, 2008). The magnitude of the relative contribution of social determinants of health to HIV seropositivity in children in a large population-based study has limited study.

In this study, maternal individual and community-level factors were examined. In order to ensure largest possible sample size, the decision to include variables was based on availability across the datasets from the three countries. Maternal individual level factors were categorized and included: maternal HIV status (negative, positive); maternal age at delivery $(<16,16-19,20-$ 24, >24); marital status (never married, married-monogamous, married-polygamous, widowed, 
divorced or separated); parity (none, one, two or more); education (no education, primary, secondary or higher); household wealth index (poorest/poorer, middle, richer/richest); employment status at the time of interview (no, yes); place of residence (rural, urban); HIV/AIDS stigma (low, high); age at first marriage (never married, < 16, 16-17, 18-19, $\geq 20$ ); age at first sex $(<16,16-17,18-19, \geq 20)$; premarital sex (no, yes); risky sexual behavior (no, yes). Having multiple sex partners refers to having more than one sex partner in the past 12 months. Risky sexual behavior is defined as having last sex with non-spousal partner without using condom. Other variables examined included whether or not mother tested for HIV and received results during antenatal care visit (no, yes) and the level of maternal exposure to HIV related information during antenatal care visit (poor, optimal). Children's individual characteristics examined in this study include age (0-1, 2-4, 5-9, and 10-14) and sex (male, female).

In the standard DHS and AIS, household wealth index is calculated based upon the data from the household's ownership of consumer goods, dwelling characteristics, source of drinking water, toilet facilities, and other characteristics that relate to a household's socioeconomic status. The method applied in the calculation of wealth index in DHS and AIS can be found elsewhere (Rutstein \& Johnson, 2004). In short, this index were constructed by assigning each of these assets a factor score generated through principal component analysis. These scores were then standardized in relation to a standard normal distribution with a mean of zero and a standard deviation of one and total score of the household were used to rank individuals based on the household they resided. Finally, the scores were converted into quintiles from one (poorest) to five (richest). This study utilized a similar procedure to create variables for HIV/AIDS awareness, HIV/AIDS stigma, and maternal level of exposure to HIV related information during antenatal care visit. Three questions were used to assess attitudes toward individuals with 
HIV/AIDS held by the mothers. Participants were asked if they would be willing to care for a relative with AIDS, if a teacher infected with HIV, but is not sick, should be allowed to continue teaching, and if they would buy vegetables from a vendor with HIV. Awareness of HIV/AIDS was based on an established and widely used measure where each woman was asked whether or not she agreed or disagreed with the following statements: 1) HIV can be prevented by using condoms every time you have sexual intercourse; 2) HIV can be prevented by limiting intercourse to one uninfected partner; 3) it is possible for a healthy-looking person to have the AIDS virus; 4) the AIDS virus can be transmitted from mosquito bites; 5) a person can get HIV by sharing food with a person who has AIDS; 6) a person can get the AIDS virus because of witchcraft or other supernatural means; 7) the virus that causes AIDS can be transmitted from a mother to her baby during pregnancy; 8) the virus that causes AIDS can be transmitted from a mother to her baby during delivery; 9) the virus that causes AIDS can be transmitted from a mother to her baby by breastfeeding. Three questions were used to evaluate maternal level of exposure to HIV related information during antenatal care (ANC) visit. These questions relate to whether or not mother's talked about: HIV transmitted mother to child; things to do to prevent getting HIV; and getting tested for HIV.

In this context, communities are geographically defined by the regions within each country. Community-level factors were directly calculated from DHS and AIS data and include community-level poverty measured as the proportion of mothers living in poor households in the community; community-level education measured as the proportion of mothers with less than high school education in the community. 


\section{Statistical Analyses}

Median and interquartile ranges were used to describe continuous variables, education and wealth index. Frequencies and proportions were used to describe categorical covariates in relation to the outcome variables of having been tested and receiving test results. Rao-Scott chisquare was used to analyze the data for relationships between the status of testing and each of the covariates. As recommended, pooled sample weights that account for the unequal probabilities of selection, oversampling, nonresponse, country-level variability in population and complex survey design were incorporated in all analyses. Regression diagnostics were utilized to identify potential collinearity. Two level multi-level logistic regression models were fitted using PROC GLIMMIX procedures to compute the fixed effect odds ratios (OR) and $95 \%$ confidence interval (CI) of HIV status. Three nested models at level 1, level 2, and level 3 were constructed. Model 1 constitutes an empty model without any covariate variables. This model was specified to decompose the total variance into two components, namely individual and community components. The main purpose of the empty model is to determine whether the overall difference between communities and individuals in terms of child HIV seropositivity was significant. Model 2 represents individual level covariates and the relationships among the individual level variables and the outcome. The purpose of this model is to examine whether or not variations in child seropositivity across communities could be explained by the individual characteristics of mothers residing within that community. Model 3 contains individual and community-level explanatory variables and is used to test for the independent effect of community-level variables in the presence of the individual-level variables. Intra-cluster correlation (ICC) was used to measure community-level random effects. The linear threshold 
model formula was used to compute the ICC (Snijders \& Bosker, 1999). All analyses were conducted using SAS 9.3 (SAS Institute Inc., Cary, North Carolina).

\subsection{Results}

Descriptive statistics for the final pooled sample are displayed in table 4.1. A greater proportion of the participants were aged 2 to 4 years (36\%). Fifty-one percent of the children were male. Approximately $9 \%$ of children had HIV positive mothers. A greater proportion of children were born to mothers who were 24 years or older (55\%), monogamously married (85.8\%), and had two or more children $(82.4 \%)$. A greater proportion of children had mothers who had primary level education (61\%), were employed at the time of the interview (69\%), lived in poor households (44\%) and were from rural areas (80\%). HIV/AIDS awareness of the mothers was evenly distributed. However, a greater proportion of children had mothers who exhibited low stigma levels towards people living with HIV/AIDS (80\%). A slightly higher proportion of children had mothers whose age at first marriage and age at first sex were less than 16 years (33\% and $41 \%$, respectively). Fewer proportions of children had mothers who had: experience with premarital sex (33\%); multiple sex partners (2.2\%) and were involved in risky sexual behavior (6.2\%). A slightly lower proportion of children in the sample had mothers who were tested for HIV and received results during antenatal care visit (45\%). On the other hand, a slightly greater proportion of children had mothers who received optimal HIV related information during ANC visit (54\%).

At the community-level, the median proportion of children who lived in communities where mothers had less than high school education was $85 \%$. The median proportion of children who lived in communities with poor households was $32 \%$. Table 4.2 displays association 
between each covariate and the outcome variable, HIV/AIDS status. Children's age, maternal HIV status, maternal age at birth, maternal marital status, maternal employment status, and maternal HIV/AIDS awareness and year the survey was conducted were significantly associated with HIV status of children. Results of fixed-effect and random-effect measures from multilevel analysis are shown in table 4.3. Model 1 showed that there was a significant variation in the likelihood of HIV seropositivity in children across communities. Examination of the Intra-cluster correlation coefficient (ICC) reveals that about $54 \%$ of the total variation in HIV seropositivity in children was attributable to community-level differences. Model 2 accounted for maternal individual level characteristics demonstrating that $47 \%$ of the total unexplained variation in the odds of HIV seropositivity was attributable to unobserved community-level factors. Including community-level factors in model 3 did not change the total unexplained variation observed in model 2. This is an indication that community-level clustering of HIV seropositivity observed was not due to contextual differences rather was related to composition of communities by individual characteristics. However, even after adjustment for individual and community-level factors the community-level variance in the odds of HIV seropositivity remains large, suggesting noticeable differences in the odds of testing for HIV seropositivity across communities. This evidence supports the use of multilevel modeling is appropriate.

Table 4.3 also shows results of fitting the multilevel model including individual-level, and community-level factors. Maternal HIV seropositivity was strongly associated with the odds of HIV seropositivity in children (Adjusted odds ratio, aOR $=16.61$; 95\% CI 16.40, 16.82). Children whose maternal age at birth was greater than 16 years had higher odds of HIV seropositivity compared to those whose maternal age at birth was less than 16 years. Children whose mothers were divorced/separated and widowed had higher odds of testing positive as 
compared to children whose mothers' have never been married, $(\mathrm{aOR}=2.92 ; 95 \% \mathrm{CI} 2.98,3.05$ and $\mathrm{aOR}=1.41 ; 95 \%$ CI $1.35,1.48$, respectively). Children whose mothers were married monogamously also had higher likelihood of testing HIV positive $(\mathrm{aOR}=1.69 ; 95 \% \mathrm{CI} 1.62$, 1.77). Children whose mothers were employed had higher odds of testing HIV positive than children whose mothers were unemployed (aOR=1.44; 95\% CI 1.42, 1.46). The likelihood of HIV seropositivity is higher for children and whose mother had high HIV/AIDS awareness compared to those whose mothers had low level of HIV/AIDS awareness (aOR=1.46; 95\% CI 1.44, 1.48). However, children and whose mothers had moderate level awareness of HIV/AIDS had a $15 \%$ reduced odds of testing HIV positive as compared to children whose mother had high HIV/AIDS awareness.

\subsection{Discussion}

The complexity of child HIV seropositivity in sub-Saharan Africa calls for a holistic approach in examining the biological, demographic, psychosocial, and behavioral factors at various levels. The principal finding of the current study is that even after adjusting for maternal HIV status other individual maternal characteristics were significantly associated with testing HIV positive among children. Although the model that included the two community contextual variables did not seem to provide a better overall explanation for the variation in HIV seropositivity there remained a significant unexplained variations in the odds of testing HIV positive among children residing in different communities.

The association between the biological factor of maternal HIV seropositivity and children's seropositivity is consistent with existing literature. Several studies have noted that vertical transmission accounts for the strongest predictor of pediatric HIV infection and accounts for $90 \%$ of childhood HIV infections (Coutsoudis, Kwaan \& Thomson, 2010; Koye \& Zeleke, 
2013). Research has also shown that children who become infected with HIV in utero or intrapartum are likely to develop more serious and fatal disease than those who become infected during breastfeeding (Zijenah et. al., 2004; Newell et. al., 2004). Other studies have demonstrated that the onset and progression of the disease in children is associated with the maternal HIV-RNA viral load, infections, nutrition and coupled with other social determinants of health (Rouet et. al., 2003; Spira et. al., 1999). Breastfeeding practices have been shown to be associated with pediatric HIV infection and are known to influence the rate at which postnatal transmission occurs from the mother to the child (Coutsoudis et. al., 2001; Iliffe et. al., 2005; Coovadia et. al., 2007). A study conducted in South Africa demonstrated that infants are at a greater risk of HIV infection through postnatal transmission if they are not exclusively breastfed during the first six months (Coutsoudis et. al., 2001). Recent studies that have also shown that the risk of pediatric transmission of HIV is lower among infants who are exclusively breastfed compared to infants who receive partial breastfeeding complemented by other sources of nutrition (Coovadia et. al., 2007; Iliffe et. al., 2005). Unfortunately, these variables were not captured in AIS datasets.

The literature on the association between maternal age and risk of MTCT is inconsistent (Coovadia et. al., 2007; Prestes-Carneiro et al., 2012). A possible mechanism for the association between younger maternal age and lower odds of HIV infection in children is the level of advancement or stage of the disease. Compared to younger mothers who are at the early stages of the disease, older mothers with advanced stages of the disease and lower CD4+ lymphocyte count have higher rate of vertical transmission (Coetzee et. al., 2005; Ahmad, 2011). Younger age may also imply less sexual exposure and thus lower risk of HIV seropositivity. Further studies are needed to explore the role of other potential mechanisms such as maternal use and 
adherence to prevention of mother to child antiretroviral (PMTCT ARV) treatments that are known to differ by maternal age (Nassali et al., 2009; Barigye et al., 2010; Igwegbe et al., 2010). The association between having a mother who is widowed or divorced and higher odds of HIV seropositivity in children can be explained by the higher prevalence of HIV among widowed and divorced mothers. However, similar to maternal age, this finding could possibly relate to differences in patterns of adherence to PMTCT by different categories of marital status. Research examining the association between marital status and adherence to antiretroviral therapy (ART) in low and middle income settings have demonstrated mixed results. There is evidence showing a positive association between being single and adherence to ART (ByakikaTusiime et al., 2005) while others have shown a negative association between being single and adherence to ART (Uzochukwu et al., 2009). Further studies are needed to explore additional mechanisms explaining the association between maternal marital status and children's HIV serostatus.

In addition, a possible explanation for negative association between maternal employment status and increased odds HIV seropositivity in children observed in this study could be poor adherence to ART among employed mothers. A recent systematic review and meta-analysis demonstrated higher likelihood of ART adherence among employed women (International Labor Organization, 2013). On the other hand, other multi-country studies conducted in Africa have shown that being employed is negatively associated with adherence to ART (Etienne et al., 2010). Employed women are less likely to have the time to visit health facilities for the ART medication refills and are more likely to face stigma and discrimination that affects their adherence (Etienne et al., 2010). It has to be noted that the current study did not include variables related to ART availability, although the countries in the current study are 
major recipients of funding from international organizations that support HIV prevention, treatment and care. Future studies need to explore this and additional mechanisms explaining the relationship between maternal employment and HIV seropositivity in children.

The increased odds in HIV seropositivity among children whose mothers had high HIV/AIDS awareness support the claim that knowledge may be a necessary but not sufficient condition for improved health outcome. However, children whose mothers had moderate level awareness of HIV/AIDS had a 15\% reduced odds of testing HIV positive as compared to children whose mother had high HIV/AIDS awareness. With respect to adherence to ARV for PMTCT. Research examining the relationship between having sufficient HIV related knowledge and adherence showed mixed results (Gourlay et al., 2013). It has to be noted that, the association observed in the current study association could simply be an artifact of the fact that HIV positive mothers could have gained high level of HIV/AIDS awareness after being infected. However, due to the cross-sectional nature of this study design, temporal associations cannot necessarily be inferred.

One of the main strengths of this study is that it is based on a large population based sample of children. However, the study has several limitations. The cross-sectional study design precludes causation of HIV infection in children. Secondly both DHS and AIS data does not have information on maternal HIV viral load, CD4+ lymphocyte count, duration of disease, patterns of adherence to ART which are factors that need to be taken into account in examining factors contributing to HIV seropositivity in children. Similarly, AIS data does not have information related to breastfeeding practices, which is another major route for postnatal vertical transmission. The risk of transmission through breastfeeding is determined by other factors such as the age of the infant, nature duration and consistency of breastfeeding, health condition of the 
breast, level of viral load and immune status of the mother, maternal susceptibility of HIV infection as well as oral health of infants (Embree et al., 2000; Leroy et al., 2001; Ciaranello et al., 2011). The absence of these potential contributing variables limits generalizability of factors identified in this study. Thirdly, data on maternal behavioral characteristics obtained is subject to recall and social desirability bias as women had to recall events from their experiences. Despite these limitations, this study presented evidence on the importance of an inclusive holistic approach to understand the dynamics and complexity of factors associated with HIV seropositivity among children in sub-Saharan Africa.

In conclusion, this study adds to the literature the importance of importance of biological and socio-demographic characteristics factors associated with HIV seropositivity in children and in sub-Saharan Africa. The relevance of factors identified in the current study should be acknowledged while developing future interventions aimed at reducing HIV infection in children. Further research is needed to explore the magnitude and relative contribution of factors identified in the current study and other community level characteristics while adjusting for established biological and behavioral risk factors for HIV seropositivity in children. 


\section{Chapter 5 \\ Discussion}

\subsection{Summary of key findings}

The current study utilized nationally representative data from the Demographic and Health Survey (DHS) and AIDS Indicator Surveys conducted between 2006 and 2012 from 25 countries in sub-Saharan Africa. The research examined individual, community and countrylevel factors associated with HIV testing and receipt of test results, and HIV seropositivity in women 15-49 years and HIV seropositivity in children 0-14 years. The study on children was limited to data from three countries, namely: Mozambique, Swaziland and Uganda.

In the first study, approximately $40 \%$ of women in sub-Saharan Africa reported having been tested and receiving test results. Women who were married or who had been married were more likely to report HIV testing and receiving test results as compared to never married women. Previous studies examining the relationship between marital status and HIV testing showed mixed results (Demssie et al., 2009; Fabiani et.al, 2003; Westheimer, 2004). Whereas current literature on the association between parity and HIV testing remain inconclusive, in the current study, women had higher likelihood of HIV testing and receiving test results compared to their nulliparous counterparts. Consistent with existing literature, this study found reduced odds of HIV testing and receiving test results with decreasing education and decreasing household wealth status (Gage \& Ali, 2005; Cremin et al. 2009; Mitchell; 2010). Employed women were more likely to report HIV testing and receipt of test results than their unemployed counterparts. However, this result has not previously been described and should be further examined to better

understand the relationship]. The finding that rural residents were less likely to be tested than their urban counterparts could be a reflection of the fact that rural residents have limited knowledge and access to preventive services (Bankole et al., 2007). The likelihood of HIV 
testing is higher for women with moderate and high media exposure, compared to women with low media exposure is an indication that access to information is an important factor. Confirming the findings from previous studies, the odds of HIV testing and receipt of test results was lower among women with high level enacted stigma towards people living with HIV/AIDS (Painter et al., 2011; Turan et al., 2008; Larsson et al., 2009; Stringer et. al, 2008). At the country-level, expenditure on public health (\% of GDP) (\%), was positively associated with the odds of testing and receipt of test results. Future studies need to examine the mechanism of each of these and additional individual, community and country-level variables on HIV testing in sub-Saharan Africa.

Based on the second study, the overall prevalence of HIV seropositivity among women of childbearing age in sub-Saharan Africa was 5.5\%. Consistent with existing literature, the odds of HIV seropositivity was highest among women who were in their thirties compared to those women aged 45-49 years (Humphrey et. al., 2007; Magadi \& Desta 2011; Wand \& Ramjee, 2012). Contrary to existing literature, this study found lower likelihood of HIV seropositivity among women, women who were in monogamous marriage had lower odds of testing HIV positive compared to never married women. However, the higher likelihood of HIV seropositivity among widowed and divorced women has previously been noted (Magadi \& Desta 2011; Hajizadeh et al., 2014). The higher odds of testing HIV positive among primiparous and reduced odds of testing positive among multiparous as compared to nulliparous women need further examination. The higher odds of HIV seropositivity among non-pregnant women compared to their pregnant counterpart may partly be explained by the lack of desire among HIV positive women to have children (Doskoch, 2013; Snow et al.; 2013; Kaida 2011). This study was not able to detect shifting higher prevalence of HIV seropositivity among the least educated 
in sub-Saharan Africa observed previously (Hargreaves et al., 2008), although women with primary level education had higher likelihood of HIV seropositivity compared to women without no education. The lower odds of testing HIV positive in rural areas compared to women residing in urban areas has been documented previously (Magadi \& Desta 2011; Magadi, 2013).

Likewise, confirming the finding of previous studies women with higher level of enacted stigma had higher odds of testing HIV positive compared to women with low enacted stigma (Clum et. al., 2009; Mustanski, 2007; Magadi, 2012). The association between early sexual debut and higher odds of testing HIV positive observed in the current study has widely been noted (Stockl et al., 2012; Slaymaker et al. 2009; Ghebremichael et al., 2009; Pettifor et al., 2004; Pettifor et al., 2008). In this study, women who reported involvement in premarital sex and women who had multiple sex partners had higher odds of testing HIV positive (Zaba et al., 2009; Ghebremichael \& Finkelman, 2013). After adjusting for individual level variables, this study was unable to detect significant associations between community and country-level variables and the odds of testing HIV positive. Future studies are needed to examine the mechanism of each of these and additional individual, community and country-level variables on HIV seropositivity in sub-Saharan Africa.

In the third study, the prevalence of HIV seropositivity among children 0-14 years was 1.2\%. Consistent with existing literature, maternal positive HIV serostatus was strongly associated with child's HIV seropositivity (Coutsoudis, Kwaan \& Thomson, 2010; Koye \& Zeleke, 2013). The study also found that children whose maternal age at birth was greater than 16 years had higher odds of HIV seropositivity compared to those whose age at birth was less than 16 years. A possible explanation could be that older mothers have advanced stage of the disease with high viral load and low CD4+ lypmocyte count, which are established risk factors 
for increased rate of vertical transmission (Coetzee et. al., 2005; Ahmad, 2011). The association between having a mother who is widowed or divorced and higher odds of HIV seropositivity in children 0-14 years can be explained by the higher prevalence of HIV among widowed and divorced mothers. Higher odds of HIV seropositivity in children whose mothers were unemployed could possibly be related to poor adherence to antiretroviral treatment (ART) among employed mothers (Etienne et al., 2010). However, other studies have reported higher likelihood of ART adherence among employed women (International Labor Organization, 2013). Increased odds of HIV seropositivity in children whose mothers had high HIV/AIDS awareness compared to those whose mothers had low level of HIV/AIDS awareness could be attributed to reverse causality. Although this study was unable to detect a significant association between community level characteristics adjusted in the model, the community-level variance in the odds of HIV seropositivity remains large, suggesting noticeable differences in the odds of testing for HIV seropositivity across communities. A holistic approach that incorporated biological, sociodemographic and behavioral factors at various levels is essential for the development of an effective prevention of MTCT of HIV.

\subsection{Significance of the study}

Studies utilizing nationally representative datasets and multilevel approaches to examine socio-demographic and behavioral factors associated with HIV testing and receipt of test results, and HIV seropositivity are currently lacking. In the current study, the utility of these approaches was clearly established. The findings revealed that several socio-demographic and behavioral characteristics at various levels influence HIV testing and receipt of test results, and HIV seropositivity. The findings from the current study can serve a guide to HIV/AIDS program to create targeted prevention programs. It may also help policy makers to identify important 
determinants that need to be addressed at various levels. The study can benefit future researchers as their reference. The design and implementation of interventions for individuals, communities, and overall society need to acknowledge the need for a sufficient understanding of the role of different factors at various levels.

\subsection{Strengths and limitations}

One of the main strengths of the three studies is large sample size that is representative of the general population in sub-Saharan Africa. Studies examining patterns of HIV testing and HIV seropositivity in sub-Saharan Africa have often relied on small high-risk groups or health facility-based populations which may not represent the general population and may be susceptible for selection bias. Having such a large data also allowed adjusting as many individual level variables as possible. This study also has a number of limitations. Primarily, the crosssectional design of the current study precludes making any causal or temporal associations observed in the three studies. However, it has to be noted that cross-sectional studies have widely been used to generate causal hypotheses. Secondly, data related to women's participation in HIV testing and receipt of test results were derived from self-reports which are susceptible underreporting and/or over-reporting. Thirdly, potential determinants that are known to influence patterns of HIV testing, receipt of test results, and HIV seropositivity such as distance and accessibility of HIV testing, treatment and care services, perceived risk for HIV, injection drug use were not measured in standard and DHS and AIS. Fourthly, due to social desirability and recall bias, sensitive topics that include involvement in premarital sex, risky sexual behavior and having multiple sex partners may have been misreported. However, although DHS and AIS data are collected using face-to-face interviews, no identifiable personal information is collected and data sets are confidential. 


\subsection{Future research}

HIV infection continues to be one of the leading preventable causes of morbidity and mortality in sub-Saharan Africa (Jamison, 2006; Mathers et al., 2009). Furthermore, the consequences of MTCT of HIV are widely known and indisputable. Most children under the age of 15 years are infected through MTCT and HIV infected children will eventually die of HIVrelated diseases. With almost 260,000 new MTCT infections each year, there is an unequivocal need for evidence-based interventions for women of childbearing age. Research on the prevention of HIV and MTCT of HIV shows that only a handful of programs demonstrate meaningful results, indicating that the overwhelming majority women are unresponsive to current efforts to reduce HIV infection in the general population and MTCT of HIV (Medley et al. 2009; Bothand Van Roosmalen, 2010).

Findings from this study suggest the need for a deeper understanding of the mechanisms by which factors identified by the three studies influence HIV testing and receipt of test results as well as HIV seropositivity among women and children 0-14 years in sub-Saharan Africa. This information will allow an opportunity to develop an effective policy and strategy to curb the spread of the HIV in sub-region. Efforts should be placed to studying trends and multi-level determinants of HIV testing and HIV seropositivity and perhaps inclusion of other factors which influence outcomes examined in the current study. Additional DHS and AIS assessment efforts are currently underway in many parts of the sub-Saharan Africa. The availability of these datasets will continue to play a major role to our understanding of patterns of HIV testing and HIV seropositivity in this part of the world. In addition to the new datasets that will be available for future analyses, evidence presented from the current study can inform the development of 
appropriate interventions. Utilizing a holistic approach that incorporates behavioral, biomedical and social strategies, significant reductions in risk and rates of HIV infection can be achieved (Ross et al., 2006).

In the current study, selection of study variables in the three studies was inspired by World Health Organizations' Commission for Social Determinants of Health framework. Using the findings from the current study future research should aim at utilizing this conceptual framework in the development of interventions to improve uptake of HIV testing and preventing HIV infection. Additionally, future research should be directed at the application of other alternative theories to identify the mechanisms by which factors identified in the current study are associated with each outcome. A very important line of investigation is the influence of community viral load on HIV seropositivity in women and children. Recent studies have shown that community viral load is an important marker of the transmission of HIV at the population level (Das et al., 2010; Castel et al., 2012). Research should also be directed at examination of the role of country-level HIV/AIDS related policy and its association with HIV testing and HIV seropositivity in sub-Saharan Africa.

More effective interventions targeting women and children are needed. A multidisciplinary effort that incorporates research on the molecular, psychosocial, epidemiological, behavioral perspectives at various levels have the potential to curb the devastating impact of HIV in sub-Saharan Africa. Public health policy makers can benefit from such holistic and inclusive perspectives in appropriating care in communities with limited resources while planning the design and implementation of HIV prevention strategies. 


\section{Chapter 1 References}

Ciaranello, A. L., Perez, F., Maruva, M., Chu, J., Engelsmann, B., Keatinge, et al. (2011). WHO 2010 guidelines for prevention of mother-to-child HIV transmission in Zimbabwe: modeling clinical outcomes in infants and mothers. PloS one, 6(6), e20224.

Cohen, M.S., Y.Q. Chen, M. McCauley, et al. (2011). Prevention of HIV-1 infection with early antiretroviral therapy. New England Journal of Medicine 365 (6), 493-505.

Commission on Social Determinants of Health. (2008). Closing the gap in a generation: health equity through action on the social determinants of health: final report of the commission on social determinants of health. World Health Organization: Geneva.

Csete, J. \& Elliot R. (2006). Scaling up HIV testing: human rights and hidden costs. HIV/AIDS Law Review 11(1), 5-10.

Cremin, I., Cauchemez, S., Garnett, G., \& Gregson, S. (2012). Patterns of uptake of HIV testing in sub-Saharan Africa in the pre-treatment era. Tropical Medicine \& International Health 17(8), e26-e37. doi:10.1111/j.1365-3156.2011.02937.

Daniel, O.J. \& Oladapo O.T. (2006). Acceptability of prenatal HIV screening at the primary care level in Nigeria. Journal of the Institute of Obstetrics and Gynecology 26(3), 191-194.

Denison, J., K. O’Reilly, G. Schmid, C. Kennedy, and M. Sweat. 2008. HIV voluntary counseling and testing and behavioral risk reduction in developing countries: A Meta-analysis, 1990-2005. AIDS and Behavior 12 (3), 363-373.

Embree, J. E., Njenga, S., Datta, P., Nagelkerke, N. J., Ndinya-Achola, J. O., Mohammed, et al. (2000). Risk factors for postnatal mother-child transmission of HIV-1. AIDS, 14(16), 2535-2541.

Feeley, F. G., Collier, A. C., Richards, S. C., Van der Borght, S. F., \& Rinke de Wit, T. F. (2007). A successful workplace program for voluntary counseling, testing, and treatment of HIV/AIDS at Heineken, Rwanda. International Journal of Occupational and Environmental Health 13(1), 99-106.

Fowler, M. G., Lampe, M. A., Jamieson, D. J., Kourtis, A. P., \& Rogers, M. F. (2007). Reducing the risk of mother-to-child human immunodeficiency virus transmission: past successes, current progress and challenges, and future directions. American Journal of Obstetrics and Gynecology, 197(3), S3-S9.

Gage, A.J, Ali, D. (2005) Factors associated with self-reported HIV testing among men in Uganda. AIDS Care 17, 153-165.

Granich, R. M., Gilks, C. F., Dye, C., De Cock, K. M., \& Williams, B. G. (2009). Universal voluntary HIV testing with immediate antiretroviral therapy as a strategy for elimination of HIV transmission: a mathematical model. The Lancet, 373(9657), 48-57. 
Greener, R. (2004). The impact of HIV/AIDS on poverty and inequality. The macroeconomics of HIV/AIDS, 167-81.

Helleringer, S., Kohler, H. P., Frimpong, J. A., \& Mkandawire, J. (2009). Increasing uptake of HIV testing and counseling among the poorest in sub-Saharan countries through home-based service provision. JAIDS Journal of Acquired Immune Deficiency Syndromes, 51(2), 185-193.

Hutchinson, P., Mahlalela, X., and Yukich, J. (2007). Mass media, stigma, and disclosure of HIV test results: multilevel analysis in the Eastern Cape, South Africa. AIDS Education and Prevention, 19(6), 489-510.

Jereni, B. H., \& Muula, A. S. (2008). Availability of supplies and motivations for accessing voluntary HIV counseling and testing services in Blantyre, Malawi. BMC Health Services Research, 8(1), 17.

Karim, Q. A., Sibeko, S., \& Baxter, C. (2010). Preventing HIV infection in women: a global health imperative. Clinical Infectious Diseases, 50(Supplement 3), S122-S129.

Ibor, U. W., Anjorin, O. A., Ita, A. E., Otu, M. A., \& Bassey, T. I. (2011). Utilization of antenatal care in Ibadan north local government area, Oyo state, Nigeria. Trends in Medical Research, 6(4), 273-280.

Leroy, V., Montcho, C., Manigart, O., Van de Perre, P., Dabis, F., Msellati, et al. (2001). Maternal plasma viral load, zidovudine and mother-to-child transmission of HIV-1 in Africa: DITRAME ANRS 049a trial . AIDS, 15(4), 517-522.

Leta, T. H., Sand øy, I. F., \& Fylkesnes, K. (2012). Factors affecting voluntary HIV counselling and testing among men in Ethiopia: a cross-sectional survey. BMC public health, 12(1), 438.

Morin, S. F., Khumalo-Sakutukwa, G., Charlebois, E. D., Routh, J., Fritz, et al. (2006). Removing barriers to knowing HIV status: same-day mobile HIV testing in Zimbabwe. Journal of Acquired Immune Deficiency Syndromes, 41(2), 218-224.

Newell, M. L. (2006). Current issues in the prevention of mother-to-child transmission of HIV-1 infection. Transactions of the Royal Society of Tropical Medicine and Hygiene, 100(1), 1-5.

Ngwende, S., Gombe, N. T., Midzi, S., Tshimanga, M., Shambira, G., \& Chadambuka, A. (2013). Factors associated with HIV infection among children born to mothers on the prevention of mother to child transmission programme at Chitungwiza Hospital, Zimbabwe, 2008. BMC Public Health, 13(1), 1181.

Peters, A. J., Van Driel, F. T., \& Jansen, W. H. (2013). Silencing women's sexuality: global AIDS policies and the case of the female condom. Journal of the International AIDS Society, 16(1).

Measure DHS. (2013). Over 30 years of history. http://www.measuredhs.com/aboutdhs/history.cfm Accessed February March 22, 2014 
Matovu, J. K., \& Makumbi, F. E. (2007). Expanding access to voluntary HIV counselling and testing in sub-Saharan Africa: alternative approaches for improving uptake, 20012007. Tropical Medicine \& International Health, 12(11), 1315-1322.

May, A. (2003). Social and Economic Impacts of HIV, AIDS in Sub-Saharan Africa, with Specific Reference to Aging. Inst. of Behavioral Science, University of Colorado.

Musheke, M., Ntalasha, H., Gari, S., Mckenzie, O., Bond, et al. (2013). A systematic review of qualitative findings on factors enabling and deterring uptake of HIV testing in Sub-Saharan Africa. BMC public health, 13(1), 220.

Rosen, S., Vincent, J. R., MacLeod, W., Fox, M., Thea, et al. (2004). The cost of HIV/AIDS to businesses in southern Africa. Aids, 18(2), 317-324.

Taha, T. E. (2011). Mother-to-child transmission of HIV-1 in sub-Saharan Africa: past, present and future challenges. Life Sciences, 88(21), 917-921.

Ubesie, A. (2012). Pediatric HIV/AIDS in sub-Saharan Africa: emerging issues and way forward. African Health Sciences, 12(3), 297-304.

UNAIDS. (2011). UNAIDS World AIDS Day Report 2011. Retrieved on March 20, 2014 from http://www.unaids.org/en/media/unaids/contentassets/documents/unaidspublication/2011/JC221_ WorldAIDSday_report_2011_en.pdf.

UNAIDS. (2012). Women Out Loud: How women living with HIV will help the world end AIDS. Available at http://www.unaids.org/en/media/unaids/contentassets/documents/unaidspublication/2012/201212 $\underline{11 \text { Wome_Out_Loud_en.pdf }}$

UNAIDS. (2013). Core Slides: Global Summary of the AIDS Epidemic; 2013. Retrieved on March 18, 2014 from http://www.unaids.org/en/media/unaids/contentassets/documents/ epidemiology/2013/gr2013/201309_epi_core_en.pdf

WHO/UNAIDS/UNICEF (2011) 'Global HIV/AIDS Response: Epidemic update and health sector progress towards Universal Access 2011 http://www.who.int/hiv/pub/progress_report2011/en/

WHO. 2012. Service delivery approaches to HIV testing and counselling (HTC): a strategic HTC policy framework. Geneva: WHO. Available at http://apps.who.int/iris/bitstream/10665/75206/1/9789241593877_eng.pdf

Worku, G., \& Enquselassie, F. (2007). Factors determining acceptance of voluntary HIV counseling and testing among pregnant women attending antenatal clinic at army hospitals in Addis Ababa. Ethiopian Medical Journal, 45(1), 1-8. 
Wringe, A., Isingo, R., Urassa, M., Maiseli, G., Manyalla, et al. (2008). Uptake of HIV voluntary counselling and testing services in rural Tanzania: implications for effective HIV prevention and equitable access to treatment. Tropical Medicine \& International Health, 13(3), 319-327.

\section{Chapter 2 References}

Asante, A.D. (2007). Scaling up HIV prevention: why routine or mandatory testing is not feasible for sub-Saharan Africa. Bulletin of the World Health Organization 85 (8) 644-646.

Andrulis, D., \& Brach, C. (2007). Integrating literacy, culture, and language to improve health care quality for diverse populations. American Journal of Health Behavior, 31S122-33.

Bankole, A., Ahmed, F. H., Neema, S., Ouedraogo, C., \& Konyani, S. (2007). Knowledge of correct condom use and consistency of use among adolescents in four countries in Sub-Saharan Africa. African Journal of Reproductive Health, 11(3), 197.

Bayer, R., \& C. Edington. 2009. HIV testing, human rights, and global AIDS policy: Exceptionalism and its discontents. Journal of Health Politics, Policy and Law 34 (3), 301-323.

Bertrand, J. T., \& Anhang, R. (2006). 7. The effectiveness of mass media in changing HIV/AIDS-related behavior among young people in developing countries. Technical Report Series, (938), 205.

Cohen, M.S., Y.Q. Chen, M. McCauley, et al. (2011). Prevention of HIV-1 infection with early antiretroviral therapy. New England Journal of Medicine 365 (6), 493-505.

Commission on Social Determinants of Health. (2008). Closing the gap in a generation: health equity through action on the social determinants of health: final report of the commission on social determinants of health. World Health Organization: Geneva.

Cremin, I., Cauchemez, S., Garnett, G., \& Gregson, S. (2012). Patterns of uptake of HIV testing in sub-Saharan Africa in the pre-treatment era. Tropical Medicine \& International Health 17(8), e26-e37. doi:10.1111/j.1365-3156.2011.02937.

Collier AC, Van der Borght SF, Rinke de Wit T, Richards SC, and FG Feeley (2007). A successful workplace program for voluntary counseling and testing and treatment of HIV/AIDS at Heineken, Rwanda. International Journal of Occupational Health 13(1), 99-106.

Csete, J. \& R. Elliot (2006). Scaling up HIV testing: human rights and hidden costs. HIV/AIDS Law Review 11(1), 5-10.

Daniel, O.J. \& O.T. Oladapo (2006). Acceptability of prenatal HIV screening at the primary care level in Nigeria. Journal of the Institute of Obstetrics and Gynecology 26(3), 191-194. 
De Cock, K.M., R. Bunnell, and J. Mermin. (2006). Unfinished business expanding HIV testing in developing countries. New England Journal of Medicine 354 (5), 440-442.

Denison, J., K. O’Reilly, G. Schmid, C. Kennedy, and M. Sweat. (2008). HIV voluntary counseling and testing and behavioral risk reduction in developing countries: A Meta-analysis, 1990-2005. AIDS and Behavior 12 (3), 363-373.

Demissie, A. A., Deribew, A. A., \& Abera, M. M. (2009). Determinants of Acceptance of Voluntary HIV Testing among Antenatal Clinic Attendees at Dil Chora Hospital, Dire Dawa, East Ethiopia. The Ethiopian Journal of Health Development, 23(2), 141-147.

Gage, A.J, Ali, D. (2005) Factors associated with self-reported HIV testing among men in Uganda. AIDS Care 17, 153-165.

Elisabeth D., R., Timothy R., S., Bryan, S., Tsetsele, F., \& Joseph, M. (2007). HIV in the Workplace in Botswana Incidence, Prevalence, and Disease Severity. AIDS Research \& Human Retroviruses, 23(12), 1453.

Fabiani, M., Cawthorne, A., Nattabi, B., Ayella, E. O., Ogwang, M., \& Declich, S. (2007). Investigating factors associated with uptake of HIV voluntary counselling and testing among pregnant women living in North Uganda. AIDS care, 19(6), 733-739.

Fox, K., Ferguson, J., Ajose, W., Singh, J., Marum, E., Baggaley, R. (2013). ANNEX 15: Adolescent consent to testing: a review of current policies and issues in sub-Saharan Africa. In HIV and adolescents: guidance for HIV testing and counselling and care for adolescents living with HIV. WHO/HIV/2013.141.

Granich R, Gilks C, Dye C, De Cock K, Williams B. (2009). Universal voluntary HIV testing with immediate antiretroviral therapy as a strategy for elimination of HIV transmission: a mathematical model. The Lancet, (9657):48-57.

Merson, M. H. (2006). The HIV-AIDS pandemic at 25 - The global response. The New England Journal of Medicine, (23), 2414.

Houdmont, J., Munir, F., \& Grey, M. (2013). Acceptance of repeat worksite HIV voluntary counselling and testing in a rural South African factory. AIDS Care, 25(9), 1199-1202.

Helleringer, S., Kohler, H. P., Frimpong, J. A., \& Mkandawire, J. (2009). Increasing uptake of HIV testing and counseling among the poorest in sub-Saharan countries through home-based service provision. Journal of Acquired Immune Deficiency Syndromes (1999), 51(2), 185.

Hendriksen, E. S., Hlubinka, D., Chariyalertsak, S., Chingono, A., Gray, et al. (2009). Keep talking about it: HIV/AIDS-related communication and prior HIV testing in Tanzania, Zimbabwe, South Africa, and Thailand. AIDS and Behavior, 13(6), 1213-1221. 
Hutchinson, P., Mahlalela, X., \& Yukich, J. (2007). Mass media, stigma, and disclosure of HIV test results: multilevel analysis in the Eastern Cape, South Africa. AIDS Education and Prevention, 19(6), 489-510.

Ibor, U. W., Anjorin, O. A., Ita, A. E., Otu, M. A., \& Bassey, T. I. (2011). Utilization of antenatal care in Ibadan north local government area, Oyo state, Nigeria. Trends in Medical Research, 6(4), 273-280.

Kigozi, I. M., Dobkin, L. M., Martin, J. N., Geng, E. H., Muyindike, et al. (2009). Late-disease stage at presentation to an HIV clinic in the era of free antiretroviral therapy in sub-Saharan Africa. JAIDS Journal of Acquired Immune Deficiency Syndromes, 52(2), 280-289.

Kilewo, C., Massawe, A., Lyamuya, E., Semali, I., Kalokola, et al. (2001). HIV counseling and testing of pregnant women in sub-Saharan Africa: experiences from a study on prevention of mother-to-child HIV-1 transmission in Dar es Salaam, Tanzania. JAIDS Journal of Acquired Immune Deficiency Syndromes, 28(5), 458-462.

Klimas, N., Koneru, A., \& Fletcher, M. (2008). Overview of HIV . Psychosomatic Medicine, 70(5), 523-530

Larsson, E., Waiswa, P., Thorson, A., Tomson, G., Peterson, S., Pariyo, G., \& Ekström, A. (2009). Low uptake of HIV testing during antenatal care: a population-based study from eastern Uganda. AIDS (London, England), 23(14), 1924-1926.

Larose, A., Moore, S., Harper, S., \& Lynch, J. (2011). Global income-related inequalities in HIV testing. Journal of Public Health, 33(3), 345-352.

Lifson, A. R., \& Rybicki, S. L. (2007). Routine opt-out HIV testing. The Lancet, (9561), 539.

Wringe, A., Isingo, R., Urassa, M., Maiseli, G., Manyalla, R., Changalucha, J., \& ... Zaba, B. (2008). Uptake of HIV voluntary counselling and testing services in rural Tanzania: implications for effective HIV prevention and equitable access to treatment. Tropical Medicine \& International Health, 13(3), 319-327.

Matovu, J., Gray, R., Makumbi, F., Wawer, M., Serwadda, D., Kigozi, G., \& .Nalugoda, F. (2005). Voluntary HIV counseling and testing acceptance, sexual risk behavior and HIV incidence in Rakai, Uganda. AIDS, 19(5), 503-511.

Matovu, J. B., \& Makumbi, F. E. (2007). Expanding access to voluntary HIV counselling and testing in sub-Saharan Africa: alternative approaches for improving uptake, 2001-2007. Tropical Medicine \& International Health, 12(11), 1315-1322.

MEASURE DHS (2013).Methodology. http://www.dhsprogram.com/What-WeDo/Methodology.cfm 
Mitchell, Steven, et al. "Equity in HIV testing: evidence from a cross-sectional study in ten Southern African countries." BMC international health and human rights 10.1 (2010): 23.

Mishra V, Vaessen M, Sangha J, et al. (2006). HIV testing in national population-based surveys: experience from the Demographic and Health Surveys. World Health Organization. Bulletin 84(7):537-545.

Mishra V., Barrere B, Hong R, and S Khan. (2008). Evaluation of bias in HIV seroprevalence estimates from national household surveys. Sexually Transmitted Infections 84 (supplement I):63 -70 .

Morin, S. F., Khumalo-Sakutukwa, G., Charlebois, E. D., Routh, J., Fritz, K., Lane, T., \& Coates, T. J. (2006). Removing barriers to knowing HIV status: Same-day mobile HIV testing in Zimbabwe. Journal of Acquired Immune Deficiency Syndromes (1999), (2), 218.

Mugore, L. L., Engelsmann, B. B., Ndoro, T. T., Dabis, F. F., \& Perez, F. F. (2008). An assessment of the understanding of the offer of routine HIV testing among pregnant women in rural Zimbabwe. AIDS Care, 20(6), 660-666.

Nwogu, E. C. (2009). Utilization of maternity care in Nigeria. Global Journal of Pure and Applied Sciences, 15(3), 439-447. 39.

Painter, T., Diaby, K., Matia, D., Lin, L., Sibailly, T., Kouassims, M., \& ... Wiktor, S. (2005). Sociodemographic factors associated with participation by HIV-1-positive pregnant women in an intervention to prevent mother-to-child transmission of HIV in Cote d'Ivoire. International Journal of STD \& AIDS, 16(3), 237-242.

Richter, K., Phillips, S. C., McInnis, A. M., \& Rice, D. A. (2012). Effectiveness of a multicountry workplace intervention in sub-Saharan Africa. AIDS Care, 24(2), 180-185.

Staveteig, S., Wang, S., Head, S., Bradley, S., \& Nybro, E. Demographic Patterns of HIV Testing Uptake in Sub-Saharan Africa. DHS Comparative Reports No. 30. April 2013. ICF International Calverton, Maryland, USA http://dhsprogram.com/pubs/pdf/CR30/CR30.pdf

Singhal, \& Rogers, E.M. (2003). Combatting AIDS: Communication Strategies in action.

Singleton, K., \& Krause, E. (2009). Understanding cultural and linguistic barriers to health literacy. Online Journal of Issues in Nursing, 14(3), 2.

Snijders, T. and R. Bosker. 1999. Multilevel Analysis - An Introduction to Basic and Advanced Multilevel Modelling, Thousand Oaks, California, SAGE publications.

Stringer, J., Stringer, E., Chi, B., Chintu, N., Creek, T., Ekouevi, D., \& ... Stringer, J. (2008). Monitoring effectiveness of programmes to prevent mother-to-child HIV transmission in lowerincome countries. World Health Organization. Bulletin, 86(1), 57-62 
Ramjee, G., \& Daniels, B. (2013). Women and HIV in Sub-Saharan Africa. AIDS Research and Therapy, 10:30.

Rutstein, Shea O. and Kiersten Johnson. (2004). The DHS Wealth Index. DHS Comparative Reports No. 6. Calverton, Maryland: ORC Macro.

Sohail, A. (2012). Factors associated with HIV testing and condom use in Mozambique: implications for programs. Reproductive Health, 9(1), 20-28.

Tedrow, V.A., J. Denison, C.E. Kennedy, K. O'Reilly, and M. Sweat. (2011). Voluntary counseling and testing (VCT) for changing HIV-related risk behavior in developing countries. The Cochrane Library.

Turan, J., Miller, S., Bukusi, E., Sande, J., \& Cohen, C. (2008). HIV/AIDS and maternity care in Kenya: how fears of stigma and discrimination affect uptake and provision of labor and delivery services. AIDS Care, 20(8), 938-945.

Turan, J., Bukusi, E., Onono, M., Holzemer, W., Miller, S., \& Cohen, C. (2011). HIV/AIDS stigma and refusal of HIV testing among pregnant women in rural Kenya: results from the MAMAS Study. AIDS and Behavior, 15(6), 1111-1120.

Venkatesh, K. K., Madiba, P., De Bruyn, G., Lurie, M. N., Coates, T. J., \& Gray, G. E. (2011). Who gets tested for HIV in a South African urban township? Implications for test and treat and gender-based prevention interventions. JAIDS Journal of Acquired Immune Deficiency Syndromes, 58(2), 151-165.

UNFPA, IPPF, \& Global Coalition on Women and AIDS. 2008b. Rwanda: Report card on HIV prevention for girls and young women. Available at http://rwanda.unfpa.org/drive/rwanda_reportcard.pdf.

United Nations, Department of Economic and Social Affairs, Population Division, Population Estimates and Projections Section. (2013). United Nations World Population Prospects: The 2012 Revision (http://esa.un.org/wpp/)

Warwick, Z. (2006). The influence of antiretroviral therapy on the uptake of HIV testing in Tutume, Botswana. International Journal of STD \& AIDS, 17(7), 479-481.

Westheimer, E. F., Aboud, S., Msamanga, G., Fawzi, W. W., Wei, R., Baylin, A., \& Urassa, W. (2004). Acceptance of HIV testing among pregnant women in Dar-es-Salaam, Tanzania. Journal of Acquired Immune Deficiency Syndromes (1999), (1), 1197.

WHO/UNAIDS/UNICEF (2011) 'Global HIV/AIDS Response: Epidemic update and health sector progress towards Universal Access 2011 http://www.who.int/hiv/pub/progress_report2011/en/ 
WHO/UNAIDS/UNICEF. 2011. Global HIV/AIDS response: Epidemic update and health sector Progress towards universal access. Progress Report 2011. Available at http://www.who.int/hiv/pub/progress_report2011/en/index.html.

WHO. 2012. Service delivery approaches to HIV testing and counselling (HTC): a strategic HTC policy framework. Geneva: WHO. Available at http://apps.who.int/iris/bitstream/10665/75206/1/9789241593877_eng.pdf

Worku, G., and F, Enquselassie. (2007). Factors determining acceptance of voluntary HIV counseling and testing among pregnant women attending antenatal clinic at army hospitals in Addis Ababa. Ethiopian Medical Journal 45(1), 1-8.

WHO (2013). Data on the HIV/AIDS response: HIV testing and counselling Data by country. Available at http://apps.who.int/gho/data/node.main.625?lang=en

World Bank (2012a). "World Development Indicators 2012." Washington, D.C.: World Bank. http://data.worldbank.org. http://data.worldbank.org/data-catalog/world-development-indicators Accessed August 22, 2013.

\section{Chapter 3 References}

Awusabo-Asare, K., \& Annim, M. S. K. (2008). Wealth status and risky sexual behaviour in Ghana and Kenya. Applied Health Economics and Health Policy,6(1), 27-39.

Bakilana, A. (2005). Age at sexual debut in South Africa. African journal of AIDS research, $4(1), 1-5$.

Bärnighausen, T., Hosegood, V., Timaeus, I. M., \& Newell, M. L. (2007). The socioeconomic determinants of HIV incidence: evidence from a longitudinal, population-based study in rural South Africa. AIDS (London, England), 21(Suppl 7), S29.

Commission on Social Determinants of Health. (2008). Closing the gap in a generation: health equity through action on the social determinants of health: final report of the commission on social determinants of health. World Health Organization: Geneva.

Clum, G., Chung, S. E., Ellen, J. M., \& Adolescent Medicine Trials Network for HIV/AIDS Interventions. (2009). Mediators of HIV-related stigma and risk behavior in HIV infected young women. AIDS care, 21(11), 1455-1462.

CIDRZ Foundation (2007). Women with AIDS face cervical cancer threat. Science Daily. Retrieved April 23, 2014, from http://www.sciencedaily.com/releases/2007/11/071130115652.htm

Decosas, J., \& Adrien, A. (1996). Migration and HIV. AIDS (London, England), 11, S77-84. 
Doskoch, P. P. (2013). Having HIV linked to reduced fertility desires in Uganda. International Perspectives on Sexual and Reproductive Health, (1), 49.

Fox, A. M. (2010). The social determinants of HIV serostatus in sub-Saharan Africa: an inverse relationship between poverty and HIV? Public Health Reports, 125(Suppl 4), 16.

Ghebremichael, M., Larsen, U., \& Paintsil, E. (2009). Association of age at first sex with HIV-1, HSV-2 and other sexual transmitted infections among women in northern Tanzania. Sexually Transmitted Diseases, 36(9), 570.

Ghebremichael, M. S., \& Finkelman, M. D. (2013). The Effect of Premarital Sex on Sexually Transmitted Infections (STIs) and High Risk Behaviors in Women. Journal of AIDS and HIV Research (Online), 5(2), 59.

Hajizadeh, M., Sia, D., Heymann, S. J., \& Nandi, A. (2014). Socioeconomic inequalities in HIV/AIDS prevalence in sub-Saharan African countries: evidence from the Demographic Health Surveys. International journal for equity in health, 13(1), 18.

Hallett, T. B., Lewis, J. J., Lopman, B. A., Nyamukapa, C. A., Mushati, P., Wambe, M., ... \& Gregson, S. (2007). Age at first sex and HIV infection in rural Zimbabwe. Studies in Family Planning, 38(1), 1-10.

Hargreaves, J. R., Bonell, C. P., Boler, T., Boccia, D., Birdthistle, I., Fletcher, et.al. (2008). Systematic review exploring time trends in the association between educational attainment and risk of HIV infection in sub-Saharan Africa. AIDS, 22(3), 403-414.

Hargreaves, J. R., \& Glynn, J. R. (2002). Educational attainment and HIV-1 infection in developing countries: a systematic review. Tropical Medicine \& International Health, 7(6), 489498.

Harrison K. (2010). Addressing social determinants of HIV/AIDS, Viral Hepatitis, STD and TB. Powerpoint presentation for Centers for Disease Control and Prevention. Retrieved April 24, 2014 from http://aids.gov/federal-resources/pacha/meetings/2010/mcdavidharrison-sdh-forpacha-30sept2010.pdf

Hladik, F., \& McElrath, M. J. (2008). Setting the stage: host invasion by HIV. Nature Reviews Immunology, 8(6), 447-457.

Humphrey, J. H., Nathoo, K. J., Hargrove, J. W., Iliff, P. J., Mutasa, K. E., Moulton, L. H., ... \& Ward, B. J. (2007). HIV-1 and HIV-2 prevalence and associated risk factors among postnatal women in Harare, Zimbabwe. Epidemiology and Infection, 135(06), 933-942.

Hunt, C. W. (1989). Migrant labor and sexually transmitted disease: AIDS in Africa. Journal of Health and Social Behavior, 30(4), 353-373.

Jewkes, R., \& Abrahams, N. (2002). The epidemiology of rape and sexual coercion in South Africa: an overview. Social Science \& Medicine, 55(7), 1231-1244. 
Johnson, L and Budlender, D. (2002). HIV risk factors: a review of the demographic, socioeconomic, biomedical and behavioral determinants of HIV prevalence in South Africa. CARE Monograph No.8. University of Cape Town Center for Actuarial Research. Rondebosch: SA.

Kaida, A., Laher, F., Strathdee, S. A., Janssen, P. A., Money, D., Hogg, R. S., \& Gray, G. (2011). Childbearing intentions of HIV-positive women of reproductive age in Soweto, South Africa: the influence of expanding access to HAART in an HIV hyperendemic setting. American journal of Public Health, 101(2).

Karim, Q. A., Sibeko, S., \& Baxter, C. (2010). Preventing HIV infection in women: a global health imperative. Clinical Infectious Diseases, 50(Supplement 3), S122-S129.

Marmot, M., Friel, S., Bell, R., Houweling, T. A., \& Taylor, S. (2008). Closing the gap in a generation: health equity through action on the social determinants of health. The Lancet, 372(9650), 1661-1669.

Marmot, M., \& Wilkinson, R. (Eds.). (2005). Social Determinants of Health. Oxford University Press.

Mishra, V., Bignami-Van Assche, S., Greener, R., Vaessen, M., Hong, R., Ghys, P. D. \& Rutstein, S. (2007). HIV infection does not disproportionately affect the poorer in sub-Saharan Africa. AIDS, 21, S17-S28.

Magadi, M., \& Desta, M. (2011). A multilevel analysis of the determinants and cross-national variations of HIV seropositivity in sub-Saharan Africa: evidence from the DHS. Health \& Place, 17(5), 1067-1083.

Magadi, M. A. (2013). The disproportionate high risk of HIV infection among the urban poor in sub-Saharan Africa. AIDS and Behavior, 17(5), 1645-1654.

Mazumder, B. (2008). Does education improve health? A reexamination of the evidence from compulsory schooling laws. Economic Perspectives, 33(2), 1-15.

MEASURE DHS, 2014. HIV prevalence and HIV testing. Retrieved on March 03, 2014 from http://dhsprogram.com/topics/HIV-Corner/HIV-Prevalence-and-HIV-Testing.cfm

Mustanski, B. (2007). The influence of state and trait affect on HIV risk behaviors: A daily diary study of MSM. Health Psychology, 26(5), 618

Ncube, N. M. (2009). Gender Inequality and HIV Risk in South Africa: Education and Socioeconomic Empowerment of Women as Protective Factors against HIV Infection. International Journal of Learning, 16(5): 489-497.

Nwoye, A. (2007). The practice of interventive polygamy in two regions of Africa: Background, theory and techniques. Dialectical Anthropology, 31(4), 383-421. 
Padian, N. S., Shiboski, S. C., Glass, S. O., \& Vittinghoff, E. (1997). Heterosexual transmission of human immunodeficiency virus (HIV) in northern California: results from a ten-year study. American Journal of Epidemiology,146(4), 350-357.

Pettifor, A. E., Levandowski, B. A., MacPhail, C., Padian, N. S., Cohen, M. S., \& Rees, H. V. (2008). Keep them in school: the importance of education as a protective factor against HIV infection among young South African women. International Journal of Epidemiology, 37(6), 1266-1273.

Pettifor, A. E., van der Straten, A., Dunbar, M. S., Shiboski, S. C., \& Padian, N. S. (2004). Early age of first sex: a risk factor for HIV infection among women in Zimbabwe. AIDS, 18(10), 14351442.

Türmen, T. (2003). Gender and HIV/AIDS. International Journal of Gynecology \& Obstetrics, 82(3), 411-418.

UNICEF. (n.d.). Preventing HIV infection among adolescents and young people. Retrieved on April 24, 2014 from http://www.unicef.org/esaro/5482 HIV prevention.html

Ramjee, G., \& Daniels, B. (2013). Women and HIV in Sub-Saharan Africa. AIDS Research and Therapy, $10(1), 30$.

Ramogale, M. R., Moodley, J. \& Sebitloane, M. H. (2007). HIV-associated maternal mortalityprimary causes at King Edward V11 hospital, Durban. South African Medical Journal, 97, 363366.

Rogo, K. O., Oucho, J. \& Mwalali, P. (2006). Maternal mortality. In D. T. Jamison, R. G., Feachman, F. K., Baingana, K. J., Hoffman \& K. O. Rogo (eds.), Disease and Mortality in subSaharan Africa, 2nd edition (Chapter 16). Washington, DC: World Bank.

Rombo, D. O. (2009). Marital risk factors and HIV infection among women: A comparison between Ghana and Kenya (Doctoral dissertation, University of Minnesota).

Rutstein, Shea O. and Kiersten Johnson. 2004. The DHS Wealth Index. DHS Comparative Reports No. 6. Calverton, Maryland: ORC Macro.

Ruzagira, E., Wandiembe, S., Abaasa, A., Bwanika, A. N., Bahemuka, U., Amornkul, et al. (2011). HIV incidence and risk factors for acquisition in HIV discordant couples in Masaka, Uganda: an HIV vaccine preparedness study. PloS one, 6(8), e24037.

Snijders, T. and R. Bosker. (1999). Multilevel Analysis - An Introduction to Basic and Advanced Multilevel Modelling, Thousand Oaks, California, SAGE publications.

Shelton, J. D., Halperin, D. T., Nantulya, V., Potts, M., Gayle, H. D., \& Holmes, K. K. (2004). Partner reduction is crucial for balanced "ABC" approach to HIV prevention. BMJ, 328(7444), 891-893. 
Snow, R. C., Mutumba, M., Resnicow, K., \& Mugyenyi, G. (2013). The social legacy of AIDS: Fertility aspirations among HIV-affected women in Uganda. American Journal of Public Health, 103(2), 278-285.

Slaymaker, E., Bwanika, J. B., Kasamba, I., Lutalo, T., Maher, D., \& Todd, J. (2009). Trends in age at first sex in Uganda: evidence from Demographic and Health Survey data and longitudinal cohorts in Masaka and Rakai. Sexually Transmitted Infections, 85(Suppl 1), i12-i19.

Stöckl, H., Kalra, N., Jacobi, J., \& Watts, C. (2013). Is Early Sexual Debut a Risk Factor for HIV Infection Among Women in Sub-Saharan Africa? A Systematic Review. American Journal of Reproductive Immunology, 69(s1), 27-40.

MEASURE DHS (2014). HIV prevalence and testing. Available at: http://dhsprogram.com/topics/HIV-Corner/HIV-Prevalence-and-HIV-Testing.cfm

The Henry J. Kaiser Foundation. (2013). The Global HIV/AIDS Epidemic. Retrieved from http://kff.org/global-health-policy/fact-sheet/the-global-hivaids-epidemic

UNAIDS. (2011). UNAIDS World AIDS Day Report 2011. Retrieved on March 20, 2014 from http://www.unaids.org/en/media/unaids/contentassets/documents/unaidspublication/2011/JC221_ WorldAIDSday_report_2011_en.pdf.

UNAIDS. (2012). Women Out Loud: How women living with HIV will help the world end AIDS. Available at http://www.unaids.org/en/media/unaids/contentassets/documents/unaidspublication/2012/2 0121211 Wome Out Loud en.pdf

UNAIDS. (2013). Core Slides: Global Summary of the AIDS Epidemic; 2013. Retrieved on March 18, 2014 from http://www.unaids.org/en/media/unaids/contentassets/documents/ epidemiology/2013/gr2013/201309_epi_core_en.pdf

Wand, H., \& Ramjee, G. (2012). The relationship between age of coital debut and HIV seroprevalence among women in Durban, South Africa: a cohort study. BMJ open, 2(1).

World Health Organization. (2011). Global HIV/AIDS response. Progress report 2011. Retrieved on March 30, 2014 from http://www.who.int/hiv/pub/progress report2011/en/.

Population Reference Bureau. 2012 World Population Data Sheet; 2012. Retrieved on March 30, 2014 from http://www.prb.org/Publications/Datasheets/2012/world-population-data-sheet.aspx

Żaba, B., Isingo, R., Wringe, A., Marston, M., Slaymaker, E., \& Urassa, M. (2009). Influence of timing of sexual debut and first marriage on sexual behaviour in later life: findings from four survey rounds in the Kisesa cohort in northern Tanzania. Sexually Transmitted Infections, 85(Suppl 1), i20-i26.

World Bank (2012a). World Development Indicators 2012. Washington, D.C.: World Bank. http://data.worldbank.org. http://data.worldbank.org/data-catalog/world-development-indicators Accessed August 22, 2013. 


\section{Chapter 4 References}

Ahmad, N. (2011). Molecular mechanisms of HIV-1 mother-to-child transmission and infection in neonatal target cells. Life sciences, 88(21), 980-986.

Anderson V. M. (1997). The placental barrier to maternal HIV infection. Obstetrics and Gynecology Clinics of North America, 24(4):797-820.

Barigye, H., Levin, J., Maher, D., Tindiwegi, G., Atuhumuza, E., Nakibinge, S., \& Grosskurth, H. (2010). Operational evaluation of a service for prevention of mother-to-child transmission of HIV in rural Uganda: barriers to uptake of single-dose nevirapine and the role of birth reporting. Tropical Medicine \& International Health, 15(10), 1163-1171.

Boily-Larouche, G., Iscache, A. L., Zijenah, L. S., Humphrey, J. H., Mouland, A. J., Ward, B. J., \& Roger, M. (2009). Functional genetic variants in DC-SIGNR are associated with mother-tochild transmission of HIV-1. PLoS One, 4(10), e7211.

Byakika-Tusiime, J., Oyugi, J. H., Tumwikirize, W. A., Katabira, E. T., Mugyenyi, P. N., \& Bangsberg, D. R. (2005). Adherence to HIV antiretroviral therapy in HIV+ Ugandan patients purchasing therapy. International Journal of STD \& AIDS, 16(1), 38-41.

Ciaranello, A. L., Perez, F., Maruva, M., Chu, J., Engelsmann, B., Keatinge, et al. (2011). WHO 2010 guidelines for prevention of mother-to-child HIV transmission in Zimbabwe: modeling clinical outcomes in infants and mothers. PloS one, 6(6), e20224.

Chi, B. H., Mudenda, V., Levy, J., Sinkala, M., Goldenberg, R. L., \& Stringer, J. S. (2006). Acute and chronic chorioamnionitis and the risk of perinatal human immunodeficiency virus-1 transmission. American Journal of Obstetrics and Gynecology, 194(1), 174-181.

Coetzee, D., Hilderbrand, K., Boulle, A., Draper, B., Abdullah, F., \& Goemaere, E. (2005). Effectiveness of the first district-wide programme for the prevention of mother-to-child transmission of HIV in South Africa. Bulletin of the World Health Organization, 83(7), 489-494.

Commission on Social Determinants of Health. (2008). Closing the gap in a generation: health equity through action on the social determinants of health: final report of the commission on social determinants of health. World Health Organization: Geneva.

Coovadia, H. M., Rollins, N. C., Bland, R. M., Little, K., Coutsoudis, A., Bennish, M. L., \& Newell, M. L. (2007). Mother-to-child transmission of HIV-1 infection during exclusive breastfeeding in the first 6 months of life: an intervention cohort study. The Lancet, 369(9567), 1107-1116.

Coutsoudis, A., Pillay, K., Kuhn, L., Spooner, E., Tsai, W. Y., Coovadia, H. M., \& South African Vitamin A Study Group. (2001). Method of feeding and transmission of HIV-1 from mothers to children by 15 months of age: prospective cohort study from Durban, South Africa. AIDS, 15(3), 379-387.

Coutsoudis, A., Kwaan, L., \& Thomson, M. (2010). Prevention of vertical transmission of HIV-1 in resource-limited settings. Expert Review of Anti-Infective Therapy, 8(10), 1163-1175. 
de F Bonolo, P., César, C. C., Acúrcio, F. A., Maria das Graças, B. C., de Pádua, C. A. M., Álvares, J., ... \& Guimarães, M. D. (2005). Non-adherence among patients initiating antiretroviral therapy: a challenge for health professionals in Brazil. AIDS, 19, S5-S13.

De Cock, K. M., Fowler, M. G., Mercier, E., de Vincenzi, I., Saba, J., Hoff, et al. (2000). Prevention of mother-to-child HIV transmission in resource-poor countries: translating research into policy and practice. Journal of American Medical Association, 283(9), 1175-1182.

Etienne, M., Hossain, M., Redfield, R., Stafford, K., \& Amoroso, A. (2010). Indicators of adherence to antiretroviral therapy treatment among HIV/AIDS patients in 5 African countries. Journal of the International Association of Physicians in AIDS Care, 9(2), 98-103.

Embree, J. E., Njenga, S., Datta, P., Nagelkerke, N. J., Ndinya-Achola, J. O., Mohammed, et al. (2000). Risk factors for postnatal mother-child transmission of HIV-1. Aids, 14(16), 2535-2541.

Fowler, M. G., Lampe, M. A., Jamieson, D. J., Kourtis, A. P., \& Rogers, M. F. (2007). Reducing the risk of mother-to-child human immunodeficiency virus transmission: past successes, current progress and challenges, and future directions. American Journal of Obstetrics and Gynecology, 197(3), S3-S9.

Gourlay, A., Birdthistle, I., Mburu, G., Iorpenda, K., \& Wringe, A. (2013). Barriers and facilitating factors to the uptake of antiretroviral drugs for prevention of mother-to-child transmission of HIV in sub-Saharan Africa: a systematic review. Journal of the International AIDS Society, 16(1).

Harvard Medical School. (2011). Cases in Global Health Delivery. Botswana's Program for Preventing Mother-to-Child Transmission of HIV. Available at http://sana.mit.edu/uploads/hsts14/Botswana.GHD007-PDF-ENG.pdf.

International Labor Organization. (2013). The impact of employment on HIV treatment adherence. International Labor Office, Geneva.

Igwegbe, A. O., Ugboaja, J. O., \& Nwajiaku, L. A. (2010). Prevalence and determinants of nonadherence to antiretroviral therapy among HIV-positive pregnant women in Nnewi, Nigeria. International Journal of Medicine and Medical Sciences, 2(8), 238-245.

Iliff, P. J., Piwoz, E. G., Tavengwa, N. V., Zunguza, C. D., Marinda, E. T., Nathoo, K. J., ... \& ZVITAMBO Study Group. (2005). Early exclusive breastfeeding reduces the risk of postnatal HIV-1 transmission and increases HIV-free survival. AIDS, 19(7), 699-708.

Koye, D. N., \& Zeleke, B. M. (2013). Mother-to-child transmission of HIV and its predictors among HIV-exposed infants at a PMTCT clinic in northwest Ethiopia. BMC Public Health, 13(1), 398.

Leroy, V., Montcho, C., Manigart, O., Van de Perre, P., Dabis, F., Msellati, et al. (2001). Maternal plasma viral load, zidovudine and mother-to-child transmission of HIV-1 in Africa: DITRAME ANRS 049a trial. AIDS, 15(4), 517-522.

MEASURE DHS (2014). HIV prevalence and testing. Available at: http://dhsprogram.com/topics/HIV-Corner/HIV-Prevalence-and-HIV-Testing.cfm 
Nassali, M., Nakanjako, D., Kyabayinze, D., Beyeza, J., Okoth, A., \& Mutyaba, T. (2009). Access to HIV/AIDS care for mothers and children in sub-Saharan Africa: adherence to the postnatal PMTCT program. AIDS Care, 21(9), 1124-1131.

Mofenson, L. M., Lambert, J. S., Stiehm, E. R., Bethel, J., Meyer, W. A., Whitehouse, J., ... \& Nemo, G. J. (1999). Risk factors for perinatal transmission of human immunodeficiency virus type 1 in women treated with zidovudine. New England Journal of Medicine, 341(6), 385-393.

Newell, M. L. (1998). Mechanisms and timing of mother-to-child transmission of HIV1. AIDS, 12(8), 831-837.

Newell, M. L., Coovadia, H., Cortina-Borja, M., Rollins, N., Gaillard, P., \& Dabis, F. (2004). Mortality of infected and uninfected infants born to HIV-infected mothers in Africa: a pooled analysis. The Lancet, 364(9441), 1236-1243.

Newell, M. L. (2006). Current issues in the prevention of mother-to-child transmission of HIV-1 infection. Transactions of the Royal Society of Tropical Medicine and Hygiene, 100(1), 1-5.

Ngwende, S., Gombe, N. T., Midzi, S., Tshimanga, M., Shambira, G., \& Chadambuka, A. (2013). Factors associated with HIV infection among children born to mothers on the prevention of mother to child transmission programme at Chitungwiza Hospital, Zimbabwe, 2008. BMC Public Health, 13(1), 1181.

Peltzer, K., Mosala, T., Dana, P., \& Fomundam, H. (2008). Follow-up survey of women who have undergone a prevention of mother-to-child transmission program in a resource-poor setting in South Africa. The Journal of the Association of Nurses in AIDS Care, 19(6), 450-460.

Prestes-Carneiro, L. E., Spir, P. R. N., Ribeiro, A. A., \& Gonçalves, V. L. M. A. (2012). HIV-1mother-to-child transmission and associated characteristics in a public maternity unit in Presidente Prudente, Brazil. Revista do Instituto de Medicina Tropical de São Paulo, 54(1), 2529.

Rouet, F., Sakarovitch, C., Msellati, P., Elenga, N., Montcho, C., et al. (2003). Pediatric viral human immunodeficiency virus type 1 RNA levels, timing of infection, and disease progression in African HIV-1-infected children. Pediatrics, 112(4), e289-e289.

Spira, R., Lepage, P., Msellati, P., Van de Perre, P., Leroy, V., Simonon, et al. (1999). Natural history of human immunodefiency virus type 1 infection in children: a five-year prospective study in Rwanda. Pediatrics, 104(5), e56-e56.

Snijders, T. \& R. Bosker. (1999). Multilevel Analysis - An Introduction to Basic and Advanced Multilevel Modelling, Thousand Oaks, California, SAGE publications.

Rutstein, Shea O. \& Kiersten Johnson. 2004. The DHS Wealth Index. DHS Comparative Reports No. 6. Calverton, Maryland: ORC Macro.

Taha, T. E. (2011). Mother-to-child transmission of HIV-1 in sub-Saharan Africa: past, present and future challenges. Life Sciences, 88(21), 917-921. 
Ubesie, A. (2012). Pediatric HIV/AIDS in sub-Saharan Africa: emerging issues and way forward. African Health Sciences, 12(3), 297-304.

UNAIDS. (2014, May). Children and HIV: Fact sheet. Geneva, Switzerland. Retrieved from http://www.unaids.org/en/media/unaids/contentassets/documents/unaidspublication/2014/FactSh eet_Children_en.pdf

UNAIDS. (2013, June 25). New HIV infections have been reduced by $50 \%$ or more in seven countries in sub-Saharan Africa. Press Release. Geneva Switzerland. Retrieved from http://www.unaids.org/en/resources/presscentre/pressreleaseandstatementarchive/2013/june/2013 0625prglobalplan/

UNAIDS: Paediatric HIV infection and AIDS: UNAIDS point of view. UNAIDS best practice collection. Geneva; 2002. http://data.unaids.org/publications/IRCpub02/jc750-paediatricpov_en.pdf accessed 12/12/13.

US Global Health Policy. Fact Sheet: The Global HIV/AIDS Epidemic. December 2010. Retrieved from: http://www.kff.org/hivaids/upload/3030-15.pdf

Uzochukwu, B. S. C., Onwujekwe, O. E., Onoka, A. C., Okoli, C., Uguru, N. P., \& Chukwuogo, O. I. (2009). Determinants of non-adherence to subsidized anti-retroviral treatment in southeast Nigeria. Health policy and planning, 24(3), 189-196.

WHO. (2012). Treatment of children living with HIV. Retrieved from: http://www.who.int/hiv/topics/paediatric/en/index.html

WHO. (2013). Mother to child transmission of HIV. Retrieved from http://www.who.int/hiv/topics/mtct/en/

WHO, UNAIDS, UNICEF. (2012). WHO: Global HIV/AIDS Response: Epidemic update and health sector response towards universal access. Progress report 2011. Retrieved from http://www.who.int/hiv/pub/progress_report2011/en/index.html

Zijenah, L. S., Moulton, L. H., Iliff, P., Nathoo, K., Munjoma, M. W., Mutasa, et al. (2004). Timing of mother-to-child transmission of HIV-1 and infant mortality in the first 6 months of life in Harare, Zimbabwe. AIDS, 18(2), 273-280. 


\section{Chapter 5 References}

Ahmad, N. (2011). Molecular mechanisms of HIV-1 mother-to-child transmission and infection in neonatal target cells. Life Sciences, 88(21), 980-986.

Anderson V. M. (1997). The placental barrier to maternal HIV infection. Obstetrics and Gynecology Clinics of North America, 24(4):797-820.

Barigye, H., Levin, J., Maher, D., Tindiwegi, G., Atuhumuza, E., Nakibinge, S., \& Grosskurth, H. (2010). Operational evaluation of a service for prevention of mother-to-child transmission of HIV in rural Uganda: barriers to uptake of single-dose nevirapine and the role of birth reporting. Tropical Medicine \& International Health, 15(10), 1163-1171.

Boily-Larouche, G., Iscache, A. L., Zijenah, L. S., Humphrey, J. H., Mouland, A. J., Ward, B. J., \& Roger, M. (2009). Functional genetic variants in DC-SIGNR are associated with mother-tochild transmission of HIV-1. PLoS One, 4(10), e7211.

Byakika-Tusiime, J., Oyugi, J. H., Tumwikirize, W. A., Katabira, E. T., Mugyenyi, P. N., \& Bangsberg, D. R. (2005). Adherence to HIV antiretroviral therapy in HIV+ Ugandan patients purchasing therapy. International Journal of STD \& AIDS, 16(1), 38-41.

Castel, A. D., Befus, M., Willis, S., Griffin, A., West, T., Hader, S., \& Greenberg, A. E. (2012). Use of the community viral load as a population-based biomarker of HIV burden. AIDS, 26(3), 345-353.

Ciaranello, A. L., Perez, F., Maruva, M., Chu, J., Engelsmann, B., Keatinge, et al. (2011). WHO 2010 guidelines for prevention of mother-to-child HIV transmission in Zimbabwe: modeling clinical outcomes in infants and mothers. PloS one, 6(6), e20224.

Chi, B. H., Mudenda, V., Levy, J., Sinkala, M., Goldenberg, R. L., \& Stringer, J. S. (2006). Acute and chronic chorioamnionitis and the risk of perinatal human immunodeficiency virus-1 transmission. American Journal of Obstetrics and Gynecology, 194(1), 174-181.

Coetzee, D., Hilderbrand, K., Boulle, A., Draper, B., Abdullah, F., \& Goemaere, E. (2005). Effectiveness of the first district-wide programme for the prevention of mother-to-child transmission of HIV in South Africa. Bulletin of the World Health Organization, 83(7), 489-494.

Commission on Social Determinants of Health. (2008). Closing the gap in a generation: health equity through action on the social determinants of health: final report of the commission on social determinants of health. World Health Organization: Geneva.

Coovadia, H. M., Rollins, N. C., Bland, R. M., Little, K., Coutsoudis, A., Bennish, M. L., \& Newell, M. L. (2007). Mother-to-child transmission of HIV-1 infection during exclusive breastfeeding in the first 6 months of life: an intervention cohort study. The Lancet, 369(9567), 1107-1116.

Coutsoudis, A., Pillay, K., Kuhn, L., Spooner, E., Tsai, W. Y., Coovadia, H. M., \& South African Vitamin A Study Group. (2001). Method of feeding and transmission of HIV-1 from mothers to children by 15 months of age: prospective cohort study from Durban, South Africa. AIDS, 15(3), 379-387. 
Coutsoudis, A., Kwaan, L., \& Thomson, M. (2010). Prevention of vertical transmission of HIV-1 in resource-limited settings. Expert Review of Anti-Infective Therapy, 8(10), 1163-1175.

Das, M., Chu, P. L., Santos, G. M., Scheer, S., Vittinghoff, E., McFarland, W., \& Colfax, G. N. (2010). Decreases in community viral load are accompanied by reductions in new HIV infections in San Francisco. PloS One, 5(6), e11068.

de F Bonolo, P., César, C. C., Acúrcio, F. A., Maria das Graças, B. C., de Pádua, C. A. M., Álvares, J., ... \& Guimarães, M. D. (2005). Non-adherence among patients initiating antiretroviral therapy: a challenge for health professionals in Brazil. AIDS, 19, S5-S13.

De Cock, K. M., Fowler, M. G., Mercier, E., de Vincenzi, I., Saba, J., Hoff, et al. (2000). Prevention of mother-to-child HIV transmission in resource-poor countries: translating research into policy and practice. Journal of American Medical Association, 283(9), 1175-1182.

Etienne, M., Hossain, M., Redfield, R., Stafford, K., \& Amoroso, A. (2010). Indicators of adherence to antiretroviral therapy treatment among HIV/AIDS patients in 5 African countries. Journal of the International Association of Physicians in AIDS Care, 9(2), 98-103.

Embree, J. E., Njenga, S., Datta, P., Nagelkerke, N. J., Ndinya-Achola, J. O., Mohammed, et al. (2000). Risk factors for postnatal mother-child transmission of HIV-1. AIDS, 14(16), 2535-2541.

Fowler, M. G., Lampe, M. A., Jamieson, D. J., Kourtis, A. P., \& Rogers, M. F. (2007). Reducing the risk of mother-to-child human immunodeficiency virus transmission: past successes, current progress and challenges, and future directions. American Journal of Obstetrics and Gynecology, 197(3), S3-S9.

Gourlay, A., Birdthistle, I., Mburu, G., Iorpenda, K., \& Wringe, A. (2013). Barriers and facilitating factors to the uptake of antiretroviral drugs for prevention of mother-to-child transmission of HIV in sub-Saharan Africa: a systematic review. Journal of the International AIDS Society, 16(1).

Harvard Medical School. (2011). Cases in Global Health Delivery. Botswana's Program for Preventing Mother-to-Child Transmission of HIV. Available at http://sana.mit.edu/uploads/hsts14/Botswana.GHD007-PDF-ENG.pdf.

International Labor Organization. (2013). The impact of employment on HIV treatment adherence. International Labor office, Geneva.

Igwegbe, A. O., Ugboaja, J. O., \& Nwajiaku, L. A. (2010). Prevalence and determinants of nonadherence to antiretroviral therapy among HIV-positive pregnant women in Nnewi, Nigeria. International Journal of Medicine and Medical Sciences, 2(8), 238-245.

Iliff, P. J., Piwoz, E. G., Tavengwa, N. V., Zunguza, C. D., Marinda, E. T., Nathoo, K. J., ... \& ZVITAMBO Study Group. (2005). Early exclusive breastfeeding reduces the risk of postnatal HIV-1 transmission and increases HIV-free survival. AIDS, 19(7), 699-708.

Koye, D. N., \& Zeleke, B. M. (2013). Mother-to-child transmission of HIV and its predictors among HIV-exposed infants at a PMTCT clinic in northwest Ethiopia. BMC Public Health, 13(1), 398. 
Leroy, V., Montcho, C., Manigart, O., Van de Perre, P., Dabis, F., Msellati, et al. (2001). Maternal plasma viral load, zidovudine and mother-to-child transmission of HIV-1 in Africa: DITRAME ANRS 049a trial. AIDS, 15(4), 517-522.

MEASURE DHS (2014). HIV prevalence and testing. Available at: http://dhsprogram.com/topics/HIV-Corner/HIV-Prevalence-and-HIV-Testing.cfm

Nassali, M., Nakanjako, D., Kyabayinze, D., Beyeza, J., Okoth, A., \& Mutyaba, T. (2009). Access to HIV/AIDS care for mothers and children in sub-Saharan Africa: adherence to the postnatal PMTCT program. AIDS care, 21(9), 1124-1131.

Mofenson, L. M., Lambert, J. S., Stiehm, E. R., Bethel, J., Meyer, W. A., Whitehouse, J., ... \& Nemo, G. J. (1999). Risk factors for perinatal transmission of human immunodeficiency virus type 1 in women treated with zidovudine. New England Journal of Medicine, 341(6), 385-393.

Newell, M. L. (1998). Mechanisms and timing of mother-to-child transmission of HIV1. AIDS, 12(8), 831-837.

Newell, M. L., Coovadia, H., Cortina-Borja, M., Rollins, N., Gaillard, P., \& Dabis, F. (2004). Mortality of infected and uninfected infants born to HIV-infected mothers in Africa: a pooled analysis. The Lancet, 364(9441), 1236-1243.

Newell, M. L. (2006). Current issues in the prevention of mother-to-child transmission of HIV-1 infection. Transactions of the Royal Society of Tropical Medicine and Hygiene, 100(1), 1-5.

Ngwende, S., Gombe, N. T., Midzi, S., Tshimanga, M., Shambira, G., \& Chadambuka, A. (2013). Factors associated with HIV infection among children born to mothers on the prevention of mother to child transmission programme at Chitungwiza Hospital, Zimbabwe, 2008. BMC Public Health, 13(1), 1181.

Peltzer, K., Mosala, T., Dana, P., \& Fomundam, H. (2008). Follow-up survey of women who have undergone a prevention of mother-to-child transmission program in a resource-poor setting in South Africa. The Journal of the Association of Nurses in AIDS Care, 19(6), 450-460.

Rouet, F., Sakarovitch, C., Msellati, P., Elenga, N., Montcho, C., et al. (2003). Pediatric viral human immunodeficiency virus type 1 RNA levels, timing of infection, and disease progression in African HIV-1-infected children. Pediatrics, 112(4), e289-e289.

Spira, R., Lepage, P., Msellati, P., Van de Perre, P., Leroy, V., Simonon, et al. (1999). Natural history of human immunodefiency virus type 1 infection in children: a five-year prospective study in Rwanda. Pediatrics, 104(5), e56-e56.

Snijders, T. \& R. Bosker. (1999). Multilevel Analysis - An Introduction to Basic and Advanced Multilevel Modelling, Thousand Oaks, California, SAGE publications.

Rutstein, Shea O. \& Kiersten Johnson. 2004. The DHS Wealth Index. DHS Comparative Reports No. 6. Calverton, Maryland: ORC Macro.

Taha, T. E. (2011). Mother-to-child transmission of HIV-1 in sub-Saharan Africa: past, present and future challenges. Life Sciences, 88(21), 917-921. 
Ubesie, A. (2012). Pediatric HIV/AIDS in sub-Saharan Africa: emerging issues and way forward. African Health Sciences, 12(3), 297-304.

UNAIDS. (2014, May). Children and HIV: Fact sheet. Geneva, Switzerland. Retrieved from http://www.unaids.org/en/media/unaids/contentassets/documents/unaidspublication/2014/FactSh eet_Children_en.pdf

UNAIDS. (2013, June 25). New HIV infections have been reduced by $50 \%$ or more in seven countries in sub-Saharan Africa. Press Release. Geneva Switzerland. Retrieved from http://www.unaids.org/en/resources/presscentre/pressreleaseandstatementarchive/2013/june/2013 0625prglobalplan/

UNAIDS: Paediatric HIV infection and AIDS: UNAIDS point of view. UNAIDS best practice collection. Geneva; 2002. http://data.unaids.org/publications/IRCpub02/jc750-paediatricpov_en.pdf accessed 12/12/13.

US Global Health Policy. Fact Sheet: The Global HIV/AIDS Epidemic. December 2010. Retrieved from: http://www.kff.org/hivaids/upload/3030-15.pdf

Uzochukwu, B. S. C., Onwujekwe, O. E., Onoka, A. C., Okoli, C., Uguru, N. P., \& Chukwuogo, O. I. (2009). Determinants of non-adherence to subsidized anti-retroviral treatment in southeast Nigeria. Health Policy and Planning, 24(3), 189-196.

WHO. (2012). Treatment of children living with HIV. Retrieved from: http://www.who.int/hiv/topics/paediatric/en/index.html

WHO. (2013). Mother to child transmission of HIV. Retrieved from http://www.who.int/hiv/topics/mtct/en/

WHO, UNAIDS, UNICEF. (2012). WHO: Global HIV/AIDS Response: Epidemic update and health sector response towards universal access. Progress report 2011. Retrieved from http://www.who.int/hiv/pub/progress_report2011/en/index.html

Zijenah, L. S., Moulton, L. H., Iliff, P., Nathoo, K., Munjoma, M. W., Mutasa, et al. (2004). Timing of mother-to-child transmission of HIV-1 and infant mortality in the first 6 months of life in Harare, Zimbabwe. AIDS, 18(2), 273-280. 


\section{Figures}

Figure 1. World Health Organization's Social Determinants of Health Conceptual Framework (CSDH, 2008)

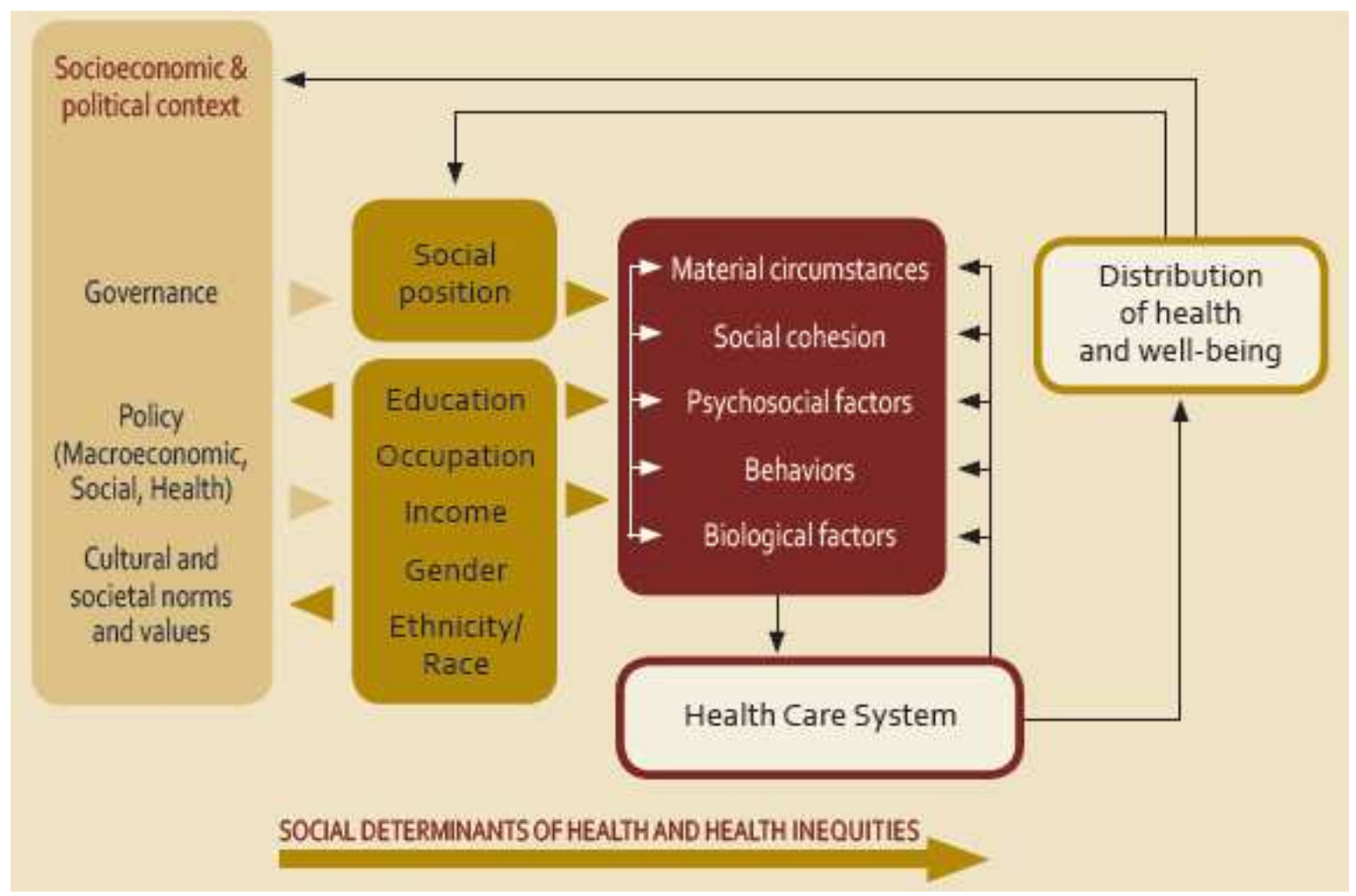


Figure 2. Study sample proportions of female participants in the Demographic and Health Survey and AIDS Indicator Survey in sub-Saharan Africa (2006-2012)

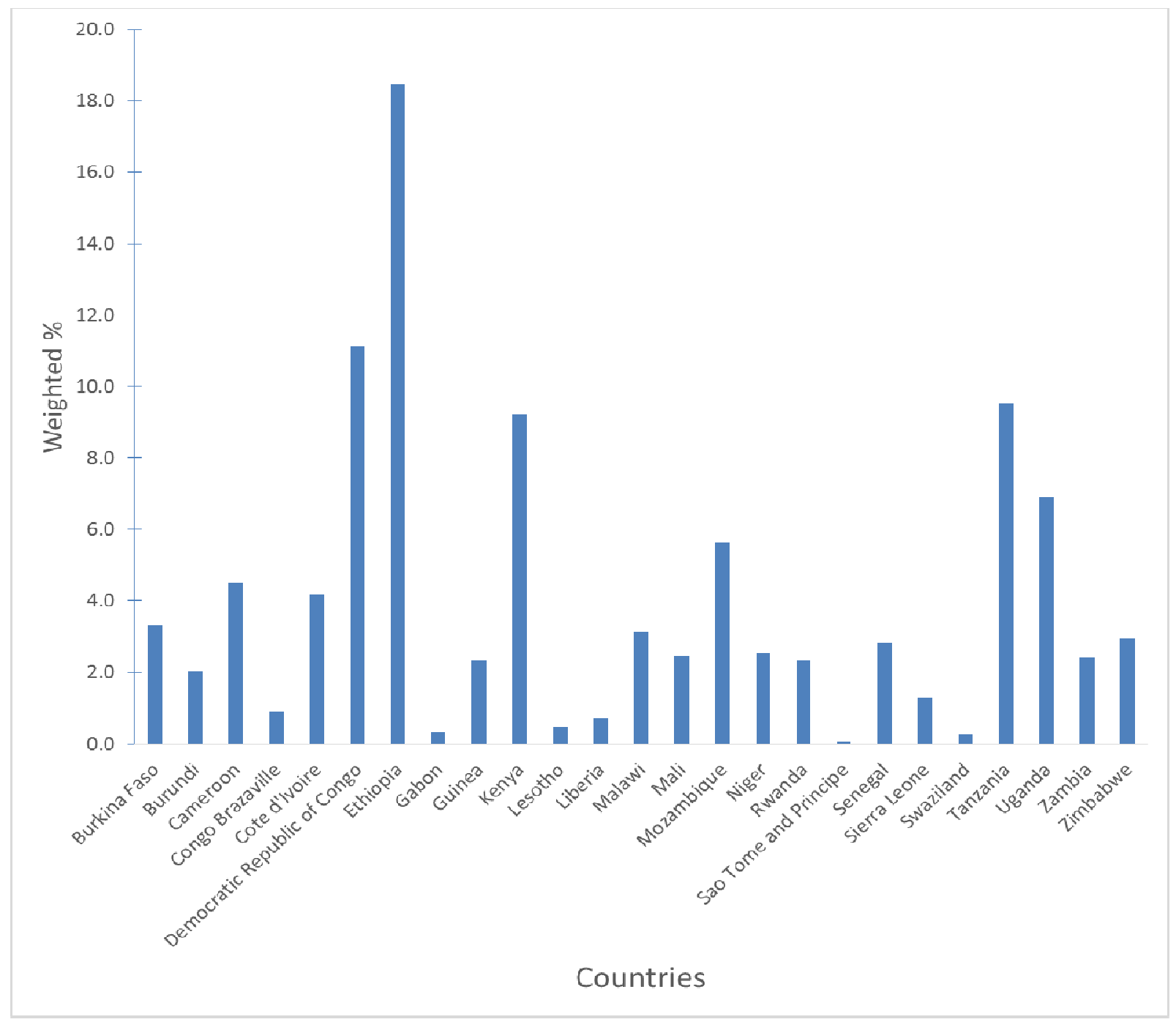




\section{Chapter 2 Tables}

Table 2.1 Study sample proportions of female participants in the Demographic and Health Survey and AIDS Indicator Survey in sub-Saharan Africa $(n=260,986)$

\begin{tabular}{|c|c|c|c|c|}
\hline Country & Survey Year & $\mathrm{n}$ & wt. $\%$ & SE \\
\hline Burkina Faso & 2010 & 17087 & 3.30 & 0.0807 \\
\hline Burundi & 2010 & 9389 & 2.03 & 0.0397 \\
\hline Cameroon & 2011 & 15426 & 4.51 & 0.101 \\
\hline Congo Brazaville & 2009 & 6550 & 0.91 & 0.0409 \\
\hline Cote d'Ivoire & $2011-12$ & 10060 & 4.19 & 0.1412 \\
\hline Democratic Republic of Congo & 2007 & 9995 & 11.13 & 0.6383 \\
\hline Ethiopia & 2011 & 16515 & 18.47 & 0.3453 \\
\hline Gabon & 2012 & 8422 & 0.35 & 0.0161 \\
\hline Guinea & 2005 & 9142 & 2.34 & 0.0732 \\
\hline Kenya & 2008-09 & 8444 & 9.22 & 0.4485 \\
\hline Lesotho & 2009 & 7624 & 0.47 & 0.0132 \\
\hline Liberia & 2007 & 7092 & 0.71 & 0.0217 \\
\hline Malawi & 2010 & 23020 & 3.12 & 0.0653 \\
\hline Mali & 2006 & 14583 & 2.47 & 0.1051 \\
\hline Mozambique & 2009 & 5647 & 5.66 & 0.2261 \\
\hline Niger & 2006 & 9223 & 2.55 & 0.0582 \\
\hline Rwanda & 2010 & 13671 & 2.36 & 0.0354 \\
\hline Sao Tome and Principe & 2008-09 & 2615 & 0.04 & 0.0017 \\
\hline Senegal & $2010-11$ & 15688 & 2.84 & 0.0837 \\
\hline Sierra Leone & 2008 & 7374 & 1.29 & 0.0429 \\
\hline Swaziland & $2006-07$ & 4987 & 0.25 & 0.0067 \\
\hline Tanzania & 2011-12 & 10967 & 9.53 & 0.2766 \\
\hline Uganda & 2011 & 11148 & 6.90 & 0.1766 \\
\hline Zambia & 2007 & 7146 & 2.41 & 0.0591 \\
\hline Zimbabwe & $2010-11$ & 9171 & 2.95 & 0.0698 \\
\hline
\end{tabular}

Wt \%: weighted percent; $\mathrm{N}$ : number of participants. Weighted percentages were obtained to control for complex sample design, therefore division of individual cell sizes by the total sample will not reflect weighted percentages. Pooled sample weights were derived from individual country sample weights and population sizes during the survey year for each country. 
Table 2.2 Description and characteristics of female participants in the DHS and AIS 2006-2012 $(\mathrm{n}=255,048)$

Individual level $(\mathrm{n}=\mathbf{2 5 5}, 048)$

Age

15-19

$20-24$

25-29

$30-34$

35-39

40-44

45-49

Marital status

Never married

Married-monogamous

Married-polygamous

Widowed

Divorced/separated

Parity

None

1

2 or more

Pregnant

No

Yes

Education

None

Primary

Secondary or more

Wealth index

Poorest

Poorer

Middle

Richer

Richest

Employment

No

Yes

Residence

Urban

Rural

Media exposure*

Low

Moderate

High n

wt.\%

$55425 \quad 21.7$

$48908 \quad 19.3$

$44906 \quad 17.8$

$34615 \quad 13.6$

$29569 \quad 11.5$

$22358 \quad 8.6$

$19267 \quad 7.5$

$65161 \quad 25.2$

$128000 \quad 53.2$

$38302 \quad 11.8$

$8182 \quad 3.2$

$\begin{array}{ll}15242 & 6.7\end{array}$

$68031 \quad 27.4$

$68223 \quad 25.8$

$119000 \quad 46.9$

$231000 \quad 90.7$

$23780 \quad 9.3$

$89832 \quad 33.2$

$96140 \quad 42.0$

$69062 \quad 24.8$

$49767 \quad 17.6$

$47241 \quad 18.5$

$47470 \quad 19.0$

$50504 \quad 20.3$

$60066 \quad 24.6$

$109000 \quad 42.2$

$146000 \quad 57.8$

$87881 \quad 32.0$

$167000 \quad 68.0$

$79547 \quad 35.3$

$76246 \quad 31.6$

$86271 \quad 33.1$ 
HIV/AIDS awareness

Low

Moderate

High

HIV/AIDS stigma

Low

High

Age at first marriage

Never married

$<16$

16-17

18-19

$\geq 20$

Age at first sex

Never had sex

$<16$

16-17

18-19

$\geq 20$

Premarital sex

No

Yes

Multiple sex partners

No

Yes

Risky sexual behavior

No

Yes

Survey year

2006-2009

2010-2012

Community level $(n=10,029)$

Less than high school education (\%)

Poorer/est household wealth index $(\%)$

Low media exposure (\%)*

Country level $(n=25)$

GDP per capita (2005 PPP) USD

Expenditure on public health (\% of GDP) (\%)
77119

74030

33.1

81444

32.3

34.6

$148000 \quad 64.8$

$71813 \quad 35.2$

$65161 \quad 25.2$

$53291 \quad 22.2$

$45595 \quad 17.6$

$37979 \quad 14.8$

$53022 \quad 20.3$

$38922 \quad 16.0$

$78876 \quad 31.4$

$60131 \quad 22.7$

$42124 \quad 16.6$

$34531 \quad 13.3$

$196000 \quad 77.1$

$59225 \quad 22.9$

$248000 \quad 97.7$

$6728 \quad 2.3$

$236000 \quad 92.7$

$19518 \quad 7.3$

$89209 \quad 37.0$

$166000 \quad 63.0$

Median IQR

$85.23 \quad 36.07$

$32.33 \quad 63.42$

$30.43 \quad 38.84$

$977.49 \quad 542.93$

$2.40 \quad 1.25$

DHS: demographic and health survey; AIS: AIDS indicator survey;

Wt \%: weighted percent; N: number of participants; IQR: interquartile range; USD: United States dollar; PPP: purchasing power parity; GDP: gross domestic product Weighted percentages were obtained to control for complex sample design, therefore division of individual cell sizes by the total sample will not reflect weighted percentages. Pooled sample weights were derived from individual country sample weights and population sizes during the survey year for each country. *Data not available for Congo Brazzaville and Mozambique. 
Table 2.3 Description and characteristics of female participants in the DHS and AIS 2006-2012 by status of HIV test and receipt of test result $(n=255,048)$

\begin{tabular}{|c|c|c|c|c|c|}
\hline \multirow[b]{3}{*}{ Individual level (N= 260, 986) } & \multicolumn{4}{|c|}{ Tested for HIV and received result } & \multirow[b]{2}{*}{ P-value } \\
\hline & \multicolumn{2}{|c|}{ No } & \multicolumn{2}{|c|}{ Yes } & \\
\hline & $\mathrm{n}$ & wt. $\%$ & $\mathrm{n}$ & wt.\% & \\
\hline Age & & & & & $<0.001$ \\
\hline 15-19 & 42500 & 27.1 & 12925 & 13.4 & \\
\hline $20-24$ & 25892 & 17.1 & 23016 & 22.7 & \\
\hline $25-29$ & 22629 & 15.1 & 22277 & 22.1 & \\
\hline $30-34$ & 18210 & 12.0 & 16405 & 16.1 & \\
\hline $35-39$ & 16873 & 11.0 & 12696 & 12.5 & \\
\hline $40-44$ & 14085 & 9.1 & 8273 & 7.9 & \\
\hline $45-49$ & 13271 & 8.8 & 5996 & 5.4 & \\
\hline Marital status & & & & & $<0.001$ \\
\hline Never married & 46015 & 29.2 & 19146 & 18.9 & \\
\hline Married-monogamous & 67438 & 47.3 & 60722 & 62.2 & \\
\hline Married-polygamous & 28803 & 15.1 & 9499 & 6.7 & \\
\hline Widowed & 4227 & 2.9 & 3955 & 3.6 & \\
\hline Divorced/separated & 6976 & 5.5 & 8266 & 8.5 & \\
\hline Parity & & & & & $<0.001$ \\
\hline None & 50553 & 33.0 & 17478 & 18.6 & \\
\hline 1 & 32746 & 20.5 & 35477 & 33.9 & \\
\hline 2 or more & 70161 & 46.5 & 48633 & 47.5 & \\
\hline Pregnant & & & & & $<0.001$ \\
\hline No & 140000 & 91.3 & 91226 & 90.0 & \\
\hline Yes & 13445 & 8.7 & 10335 & 10.0 & \\
\hline Education & & & & & $<0.001$ \\
\hline None & 70858 & 42.3 & 18974 & 19.2 & \\
\hline Primary & 48461 & 37.1 & 47679 & 49.6 & \\
\hline Secondary or more & 34129 & 20.7 & 34933 & 31.2 & \\
\hline Wealth index & & & & & $<0.001$ \\
\hline Poorest & 34392 & 21.0 & 15375 & 12.4 & \\
\hline Poorer & 30461 & 20.7 & 16780 & 15.0 & \\
\hline Middle & 29598 & 20.3 & 17872 & 16.9 & \\
\hline Richer & 29396 & 19.5 & 21108 & 21.6 & \\
\hline Richest & 29613 & 18.5 & 30453 & 34.1 & \\
\hline Employment & & & & & $<0.001$ \\
\hline No & 68998 & 45.4 & 39981 & 37.2 & \\
\hline Yes & 84462 & 54.6 & 61607 & 62.8 & \\
\hline \multicolumn{6}{|l|}{ Residence } \\
\hline Urban & 49114 & 28.1 & 38767 & 38.0 & \\
\hline Rural & 104000 & 71.9 & 62821 & 62.0 & \\
\hline Media exposure* & & & & & $<0.001$ \\
\hline Low & 55487 & 42.8 & 24060 & 24.0 & \\
\hline Moderate & 44069 & 29.6 & 32177 & 34.7 & \\
\hline High & 44738 & 27.6 & 41533 & 41.3 & \\
\hline
\end{tabular}




\begin{tabular}{|c|c|c|c|c|c|}
\hline HIV/AIDS awareness & & & & & $<0.001$ \\
\hline Low & 47046 & 36.0 & 30073 & 29.1 & \\
\hline Moderate & 43230 & 33.4 & 30800 & 30.8 & \\
\hline High & 41629 & 30.6 & 39815 & 40.1 & \\
\hline HIV/AIDS stigma & & & & & $<0.001$ \\
\hline Low & 74357 & 58.0 & 73772 & 75.0 & \\
\hline High & 52104 & 42.0 & 19709 & 25.0 & \\
\hline Age at first marriage & & & & & $<0.001$ \\
\hline Never married & 46015 & 29.2 & 19146 & 18.9 & \\
\hline$<16$ & 37337 & 25.2 & 15954 & 17.5 & \\
\hline $16-17$ & 25978 & 17.0 & 19617 & 18.6 & \\
\hline $18-19$ & 19468 & 12.8 & 18511 & 17.8 & \\
\hline$\geq 20$ & 24662 & 15.8 & 28360 & 27.1 & \\
\hline Age at first sex & & & & & $<0.001$ \\
\hline Never had sex & 31411 & 20.8 & 7511 & 8.5 & \\
\hline$<16$ & 52881 & 34.7 & 25995 & 26.5 & \\
\hline $16-17$ & 33474 & 21.0 & 26657 & 25.2 & \\
\hline $18-19$ & 20296 & 13.6 & 21828 & 21.4 & \\
\hline$\geq 20$ & 15072 & 9.9 & 19459 & 18.5 & \\
\hline Premarital sex & & & & & $<0.001$ \\
\hline No & 124000 & 81.1 & 71850 & 70.9 & \\
\hline Yes & 29545 & 18.9 & 29680 & 29.1 & \\
\hline Multiple sex partners & & & & & 0.009 \\
\hline No & 150000 & 97.8 & 98793 & 97.5 & \\
\hline Yes & 3933 & 2.2 & 2795 & 2.5 & \\
\hline Risky sexual behavior & & & & & 0.090 \\
\hline No & 142000 & 92.9 & 93802 & 92.4 & \\
\hline Yes & 11732 & 7.1 & 7786 & 7.6 & \\
\hline Survey year & & & & & $<0.001$ \\
\hline 2006-2009 & 66784 & 44.5 & 22425 & 25.5 & \\
\hline $2010-2012$ & 86676 & 55.5 & 79163 & 74.5 & \\
\hline \multicolumn{6}{|l|}{ Community level $(n=10,029)$} \\
\hline & Median & IQR & Median & IQR & \\
\hline Less than high school education (\%) & 89.81 & 33.75 & 77.70 & 37.47 & \\
\hline Poorer/est household wealth index $(\%)$ & 41.99 & 64.76 & 18.62 & 52.38 & \\
\hline Low media exposure $(\%)^{*}$ & 39.10 & 40.81 & 21.38 & 29.12 & \\
\hline \multicolumn{6}{|l|}{ Country level $(n=25)$} \\
\hline GDP per capita (2005 PPP) USD & 945.11 & 693.26 & 1154.98 & 408.74 & \\
\hline Expenditure on public health (\% of GDP) (\%) & 2.37 & 1.08 & 2.25 & 1.92 & \\
\hline
\end{tabular}

DHS: demographic and health survey; AIS: AIDS indicator survey;

Wt \%: weighted percent; N: number of participants; IQR: interquartile range; USD: United States dollar; PPP: purchasing power parity; GDP: gross domestic product. Weighted percentages were obtained to control for complex sample design, therefore division of individual cell sizes by the total sample will not reflect weighted percentages. Pooled sample weights were derived from individual country sample weights and population sizes during the survey year for each country.

* Data not available for Congo Brazzaville and Mozambique.

p-values calculated using Rao-Scott adjusted chi-squares 
Table 2.4 Association of individual, community and country-level factors and testing for HIV and receipt of test results among female participants in the DHS and AIS 2006-2012 in sub-Sharan Africa $(n=242,851)$

\begin{tabular}{|c|c|c|c|c|}
\hline & Model 1 & Model 2 & Model 3 & Model 4 \\
\hline \multicolumn{5}{|l|}{ Fixed Effects } \\
\hline Constant & $0.48(0.28,0.84)$ & $0.01(0.00,0.02)$ & $0.01(0.00,0.03)$ & $0.00(0.00,0.01)$ \\
\hline \multicolumn{5}{|l|}{ Age } \\
\hline 45-49 (Ref) & & 1 & 1 & 1 \\
\hline $15-19$ & & $2.10(1.67,2.64)$ & $2.16(1.73,2.70)$ & $2.13(1.69,2.68)$ \\
\hline $20-24$ & & $3.33(2.65,4.19)$ & $3.45(2.76,4.31)$ & $3.36(2.64,4.26)$ \\
\hline $25-29$ & & $3.00(2.65,4.19)$ & $2.53(2.13,3.00)$ & $3.02(2.45,3.72)$ \\
\hline $30-34$ & & $2.47(2.07,2.94)$ & $2.07(1.76,2.43)$ & $2.47(2.08,2.95)$ \\
\hline $35-39$ & & $2.03(1.73,2.39)$ & $1.48(1.33,1.64)$ & $2.03(1.71,2.41)$ \\
\hline $40-44$ & & $1.46(1.31,1.63)$ & $1.46(1.31,1.64)$ & $1.46(1.30,1.64)$ \\
\hline \multicolumn{5}{|l|}{ Marital status } \\
\hline Never married (Ref) & & 1 & 1 & 1 \\
\hline Married-monogamous & & $1.21(1.09,1.34)$ & $1.23(1.11,1.36)$ & $1.23(1.11,1.36)$ \\
\hline Married-polygamous & & $1.08(0.98,1.19)$ & $1.11(1.00,1.23)$ & $1.10(1.00,1.22)$ \\
\hline Widowed & & $1.19(1.07,1.32)$ & $1.20(1.09,1.33)$ & $1.20(1.08,1.33)$ \\
\hline Divorced/separated & & $1.19(1.08,1.31)$ & $1.20(1.10,1.32)$ & $1.20(1.09,1.31)$ \\
\hline \multicolumn{5}{|l|}{ Parity } \\
\hline None (Ref) & & 1 & 1 & 1 \\
\hline 1 & & $2.82(2.19,3.64)$ & $2.86(2.22,3.68)$ & $2.77(2.19,3.51)$ \\
\hline 2 or more & & $2.87(2.12,3.90)$ & $2.92(2.16,3.96)$ & $2.83(2.11,3.81)$ \\
\hline \multicolumn{5}{|l|}{ Pregnant } \\
\hline No (Ref) & & 1 & 1 & 1 \\
\hline Yes & & $1.22(1.14,1.30)$ & $1.22(1.14,1.30)$ & $1.22(1.15,1.30)$ \\
\hline \multicolumn{5}{|l|}{ Education } \\
\hline None (Ref) & & 1 & 1 & 1 \\
\hline Primary & & $1.66(1.43,1.92)$ & $1.64(1.42,1.90)$ & $1.64(1.41,1.89)$ \\
\hline Secondary or more & & $2.71(2.36,3.12)$ & $2.64(2.30,3.02)$ & $2.57(2.26,2.92)$ \\
\hline \multicolumn{5}{|l|}{ Wealth index } \\
\hline Poorest (Ref) & & 1 & 1 & 1 \\
\hline Poorer & & $1.17(1.08,1.26)$ & $1.12(1.05,1.20)$ & $1.12(1.04,1.20)$ \\
\hline Middle & & $1.23(1.11,1.36)$ & $1.13(1.03,1.23)$ & $1.13(1.03,1.23)$ \\
\hline Richer & & $1.34(1.17,1.52)$ & $1.19(1.07,1.33)$ & $1.19(1.07,1.33)$ \\
\hline Richest & & $1.59(1.33,1.91)$ & $1.38(1.17,1.61)$ & $1.38(1.17,1.62)$ \\
\hline \multicolumn{5}{|l|}{ Employment } \\
\hline No (Ref) & & 1 & 1 & 1 \\
\hline Yes & & $1.11(1.04,1.18)$ & $1.11(1.04,1.18)$ & $1.10(1.03,1.18)$ \\
\hline \multicolumn{5}{|l|}{ Residence } \\
\hline Urban (Ref) & & 1 & 1 & 1 \\
\hline Rural & & $1.71(1.50,1.94)$ & $1.27(1.11,1.44)$ & $1.27(1.11,1.45)$ \\
\hline \multicolumn{5}{|l|}{ Media exposure* } \\
\hline Low (Ref) & & 1 & 1 & 1 \\
\hline Moderate & & $1.20(1.15,1.26)$ & $1.17(1.12,1.21)$ & $1.16(1.12,1.21)$ \\
\hline High & & $1.23(1.16,1.29)$ & $1.19(1.14,1.25)$ & $1.19(1.14,1.24)$ \\
\hline
\end{tabular}




\begin{tabular}{|c|c|c|c|c|}
\hline \multicolumn{5}{|l|}{ HIV/AIDS awareness } \\
\hline \multicolumn{2}{|l|}{ Low (Ref) } & 1 & 1 & 1 \\
\hline \multicolumn{2}{|l|}{ Moderate } & $1.03(0.99,1.07)$ & $1.03(0.99,1.07)$ & $1.02(0.99,1.06)$ \\
\hline \multicolumn{2}{|l|}{ High } & $1.10(1.04,1.16)$ & $1.10(1.04,1.16)$ & $1.10(1.04,1.16)$ \\
\hline \multicolumn{5}{|l|}{ HIV/AIDS stigma } \\
\hline \multicolumn{2}{|l|}{ Low (Ref) } & 1 & 1 & 1 \\
\hline \multicolumn{2}{|l|}{ High } & $0.76(0.72,0.81)$ & $0.76(0.72,0.81)$ & $0.77(0.72,0.81)$ \\
\hline \multicolumn{5}{|l|}{ Age at first sex } \\
\hline \multicolumn{2}{|l|}{ Never had sex (Ref) } & 1 & 1 & 1 \\
\hline \multicolumn{2}{|l|}{$<16$} & $2.42(1.92,3.04)$ & $2.42(1.93,3.04)$ & $2.37(1.92,2.93)$ \\
\hline \multicolumn{2}{|l|}{$16-17$} & $2.80(2.21,3.53)$ & $2.80(2.23,3.51)$ & $2.72(2.20,3.37)$ \\
\hline \multicolumn{2}{|l|}{$18-19$} & $2.97(2.35,3.74)$ & $2.97(2.37,3.73)$ & $2.89(2.34,3.57)$ \\
\hline \multicolumn{2}{|l|}{$\geq 20$} & $3.13(2.41,4.07)$ & $3.13(2.43,4.04)$ & $3.03(2.40,3.82)$ \\
\hline \multicolumn{5}{|l|}{ Premarital sex } \\
\hline \multicolumn{2}{|l|}{ No (Ref) } & 1 & 1 & 1 \\
\hline \multicolumn{2}{|l|}{ Yes } & $1.24(1.16,1.33)$ & $1.23(1.16,1.32)$ & $1.23(1.15,1.31)$ \\
\hline \multicolumn{5}{|l|}{ Multiple sexpartners } \\
\hline \multicolumn{2}{|l|}{ No (Ref) } & 1 & 1 & 1 \\
\hline \multicolumn{2}{|l|}{ Yes } & $1.00(0.92,1.09)$ & $1.00(0.91,1.09)$ & $1.00(0.91,1.09)$ \\
\hline \multicolumn{5}{|l|}{ Risky sexual behavior } \\
\hline \multicolumn{2}{|l|}{ No (Ref) } & 1 & 1 & 1 \\
\hline \multicolumn{2}{|l|}{ Yes } & $1.06(0.99,1.13)$ & $1.06(0.99,1.13)$ & $1.05(0.99,1.12)$ \\
\hline \multicolumn{5}{|l|}{ Survey year } \\
\hline \multicolumn{2}{|l|}{ 2006-2009 (Ref) } & 1 & 1 & 1 \\
\hline \multicolumn{2}{|l|}{ 2010-2012 } & $4.45(1.47,13.51)$ & $4.79(1.63,14.07)$ & $5.33(2.09,13.61)$ \\
\hline \multicolumn{5}{|l|}{ Community level } \\
\hline \multicolumn{2}{|c|}{ Less than high school education (\%) } & & $1.00(0.99,1.00)$ & $1.00(0.99,1.00)$ \\
\hline \multicolumn{2}{|c|}{ Poorer/est household wealth index $(\%)$} & & $1.00(0.99,1.00)$ & $1.00(0.99,1.00)$ \\
\hline Low media exposure $(\%)^{*}$ & & & $1.00(0.99,1.00)$ & $1.00(0.99,1.00)$ \\
\hline Country level & & & & \\
\hline GDP per capita (2005 PPP) USD & & & & $1.00(1.00,1.00)$ \\
\hline Expenditure on public health $(9$ & GDP) $(\%)$ & & & $1.48(1.19,1.83)$ \\
\hline Random effects & & & & \\
\hline Community level variance (SE) & $0.494(0.069)$ & $0.427(0.073)$ & $0.427(0.065)$ & $0.413(0.068)$ \\
\hline Country level variance (SE) & $1.966(0.468)$ & $1.522(0.388)$ & $1.424(0.373)$ & $1.033(0.280)$ \\
\hline ICC-Community & 42.8 & 37.2 & 36.0 & 30.5 \\
\hline ICC-Country & 34.2 & 29.1 & 27.7 & 21.8 \\
\hline
\end{tabular}

DHS: demographic and health survey; AIS: AIDS indicator survey; $\mathrm{Wt} \%$ : weighted percent; N: number of participants; IQR: interquartile range; USD: United States dollar; PPP: purchasing power parity; GDP: gros s domestic product; SE: standard error; ICC: intra-cluster correlation coefficient

Pooled sample weights were derived from individual country sample weights and population sizes during the survey year for each country.

*Data not available for Congo Brazzaville and Mozambique. 


\section{Chapter 3 Tables}

Table 3.1 Description and characteristics of female participants in the DHS and AIS HIV testing 2006-2012 ( $\mathrm{n}=155,356)$

\begin{tabular}{|c|c|c|}
\hline \multicolumn{3}{|l|}{ Individual level $(n=155,356)$} \\
\hline Age & $\mathrm{n}$ & wt.\% \\
\hline 15-19 & 33847 & 21.6 \\
\hline $20-24$ & 29777 & 19.3 \\
\hline $25-29$ & 27257 & 17.9 \\
\hline $30-34$ & 20884 & 13.5 \\
\hline $35-39$ & 18184 & 11.6 \\
\hline $40-44$ & 13607 & 8.6 \\
\hline 45-49 & 11800 & 7.6 \\
\hline \multicolumn{3}{|l|}{ Marital status } \\
\hline Never married & 40390 & 24.9 \\
\hline Married-monogamous & 80090 & 53.5 \\
\hline Married-polygamous & 19435 & 11.7 \\
\hline Widowed & 5239 & 3.2 \\
\hline Divorced/separated & 10201 & 6.7 \\
\hline \multicolumn{3}{|l|}{ Parity } \\
\hline None & 40803 & 26.8 \\
\hline 1 & 42088 & 25.6 \\
\hline 2 or more & 72465 & 47.5 \\
\hline \multicolumn{3}{|l|}{ Pregnant } \\
\hline No & 141000 & 90.6 \\
\hline Yes & 14637 & 9.4 \\
\hline \multicolumn{3}{|l|}{ Education } \\
\hline None & 49113 & 33.4 \\
\hline Primary & 61802 & 42.3 \\
\hline Secondary or more & 44431 & 24.2 \\
\hline \multicolumn{3}{|l|}{ Wealth index } \\
\hline Poorest & 31080 & 17.8 \\
\hline Poorer & 28986 & 18.5 \\
\hline Middle & 28474 & 19.0 \\
\hline Richer & 30721 & 20.5 \\
\hline Richest & 36095 & 24.2 \\
\hline \multicolumn{3}{|l|}{ Employment } \\
\hline No & 67280 & 42.2 \\
\hline Yes & 88076 & 57.8 \\
\hline \multicolumn{3}{|l|}{ Residence } \\
\hline Urban & 52852 & 31.4 \\
\hline Rural & 103000 & 68.6 \\
\hline \multicolumn{3}{|l|}{ Media exposure* } \\
\hline Low & 47281 & 35.2 \\
\hline Moderate & 44784 & 31.8 \\
\hline High & 51036 & 33.1 \\
\hline
\end{tabular}


HIV/AIDS awareness

Low

Moderate

High

HIV/AIDS stigma

Low

High

Age at first marriage

Never married

$<16$

16-17

18-19

$\geq 20$

Age at first sex

Never had sex

$<16$

16-17

18-19

$\geq 20$

Premarital sex

No

Yes

Multiple sex partners

No

Yes

Risky sexual behavior

No

Yes

Survey year

2006-2009

2010-2012

Community level $(n=10,029)$

Less than high school education (\%)

Poorer/poorest household wealth index $(\%)$

Low media exposure (\%)*

Country level $(n=25)$

GDP per capita (2005 PPP) USD

Expenditure on public health (\% of GDP) (\%)
50152

46196

51184

33.5

32.3

34.2

$90164 \quad 64.8$

$43979 \quad 35.2$

$40390 \quad 24.9$

$31337 \quad 22.4$

$27443 \quad 17.7$

$23332 \quad 14.9$

$32854 \quad 20.2$

$23036 \quad 15.6$

$48250 \quad 31.6$

$37450 \quad 22.8$

$25883 \quad 16.7$

$20428 \quad 13.2$

$117000 \quad 77.0$

$38656 \quad 23.0$

$151000 \quad 97.7$

$4462 \quad 2.3$

$142000 \quad 92.6$

$13241 \quad 7.4$

$55835 \quad 36.8$

$99521 \quad 63.2$

Median IQR

$86.99 \quad 34.03$

$33.11 \quad 63.51$

$29.95 \quad 37.27$

$972.34 \quad 475.54$

$2.44 \quad 1.78$

DHS: demographic and health survey; AIS: AIDS indicator survey;

Wt \%: weighted percent; N: number of participants; IQR: interquartile range; USD: United States dollar; PPP: purchasing power parity; GDP: gross domestic product Weighted percentages were obtained to control for complex sample design, therefore division of individual cell sizes by the total sample will not reflect weighted percentages. Pooled sample weights were derived from individual country sample weights and population sizes during the survey year for each country. *Data not available for Congo Brazzaville and Mozambique. 
Table 3.2 Description and characteristics of female participants in the DHS and AIS HIV testing 20062012 by HIV status $(\mathrm{n}=155,356)$

\begin{tabular}{|c|c|c|c|c|c|}
\hline \multirow[b]{3}{*}{ Individual level ( $N=155,356)$} & \multicolumn{4}{|c|}{ HIV Status } & \multirow{3}{*}{ P-value } \\
\hline & \multicolumn{2}{|c|}{ Negative } & \multicolumn{2}{|c|}{ Positive } & \\
\hline & $\mathrm{n}$ & & $\mathrm{n}$ & wt.\% & \\
\hline Age & & & & & $<0.001$ \\
\hline 15-19 & 33110 & 22.5 & 737 & 6.7 & \\
\hline $20-24$ & 28054 & 19.6 & 1723 & 14.5 & \\
\hline $25-29$ & 24914 & 17.6 & 2343 & 22.3 & \\
\hline $30-34$ & 18728 & 13.2 & 2156 & 19.9 & \\
\hline $35-39$ & 16382 & 11.3 & 1802 & 16.3 & \\
\hline $40-44$ & 12396 & 8.4 & 1211 & 12.1 & \\
\hline $45-49$ & 10846 & 7.5 & 954 & 8.3 & \\
\hline Marital status & & & & & $<0.001$ \\
\hline Never married & 38527 & 25.6 & 1863 & 12.3 & \\
\hline Married-monogamous & 75063 & 53.8 & 5027 & 48.6 & \\
\hline Married-polygamous & 18469 & 11.9 & 966 & 7.8 & \\
\hline Widowed & 3721 & 2.5 & 1518 & 15.5 & \\
\hline Divorced/separated & 8649 & 6.1 & 1552 & 15.8 & \\
\hline Parity & & & & & $<0.001$ \\
\hline None & 39430 & 27.7 & 1373 & 11.8 & \\
\hline 1 & 38046 & 25.0 & 4042 & 35.7 & \\
\hline 2 or more & 66954 & 47.2 & 5511 & 52.5 & \\
\hline Pregnant & & & & & $<0.001$ \\
\hline No & 130000 & 90.5 & 10190 & 93.5 & \\
\hline Yes & 13917 & 9.5 & 720 & 6.5 & \\
\hline Education & & & & & $<0.001$ \\
\hline None & 47551 & 34.4 & 1562 & 17.0 & \\
\hline Primary & 56525 & 41.7 & 5277 & 53.7 & \\
\hline Secondary or more & 40344 & 23.9 & 4087 & 29.4 & \\
\hline Wealth index & & & & & $<0.001$ \\
\hline Poorest & 29488 & 18.1 & 1592 & 12.1 & \\
\hline Poorer & 27190 & 18.7 & 1796 & 14.9 & \\
\hline Middle & 26592 & 19.2 & 1882 & 15.9 & \\
\hline Richer & 28200 & 20.3 & 2521 & 23.4 & \\
\hline Richest & 32960 & 23.7 & 3135 & 33.7 & \\
\hline Employment & & & & & $<0.001$ \\
\hline No & 62842 & 42.7 & 4438 & 33.2 & \\
\hline Yes & 81588 & 57.3 & 6488 & 66.8 & \\
\hline \multicolumn{6}{|l|}{ Residence } \\
\hline Urban & 48194 & 30.7 & 4658 & 43.4 & \\
\hline Rural & 96236 & 69.3 & 6268 & 56.6 & \\
\hline Media exposure* & & & & & $<0.001$ \\
\hline Low & 44585 & 35.6 & 2696 & 27.2 & \\
\hline Moderate & 41915 & 31.8 & 2869 & 31.0 & \\
\hline High & 46751 & 32.6 & 4285 & 41.8 & \\
\hline
\end{tabular}




\begin{tabular}{|c|c|c|c|c|c|}
\hline HIV/AIDS awareness & & & & & $<0.001$ \\
\hline Low & 46903 & 33.8 & 3249 & 29.1 & \\
\hline Moderate & 43136 & 32.4 & 3060 & 29.7 & \\
\hline High & 46793 & 33.8 & 4391 & 41.3 & \\
\hline HIV/AIDS stigma & & & & & $<0.001$ \\
\hline Low & 82338 & 63.9 & 7826 & 80.4 & \\
\hline High & 42111 & 36.1 & 1868 & 19.6 & \\
\hline Age at first marriage & & & & & $<0.001$ \\
\hline Never married & 38527 & 25.6 & 1863 & 12.3 & \\
\hline$<16$ & 29482 & 22.4 & 1855 & 21.8 & \\
\hline $16-17$ & 25499 & 17.6 & 1944 & 18.6 & \\
\hline $18-19$ & 21466 & 14.8 & 1866 & 17.2 & \\
\hline$\geq 20$ & 29456 & 19.6 & 3398 & 30.1 & \\
\hline Age at first sex & & & & & $<0.001$ \\
\hline Never had sex & 22743 & 16.4 & 293 & 2.7 & \\
\hline$<16$ & 44829 & 31.4 & 3421 & 34.8 & \\
\hline $16-17$ & 34362 & 22.6 & 3088 & 26.6 & \\
\hline $18-19$ & 23494 & 16.5 & 2389 & 20.5 & \\
\hline$\geq 20$ & 18725 & 13.1 & 1703 & 15.4 & \\
\hline Premarital sex & & & & & $<0.001$ \\
\hline No & 110000 & 78.0 & 6430 & 60.5 & \\
\hline Yes & 34179 & 22.0 & 4477 & 39.5 & \\
\hline Multiple sex partners & & & & & $<0.001$ \\
\hline No & 140000 & 97.8 & 10396 & 95.5 & \\
\hline Yes & 3932 & 2.2 & 530 & 4.5 & \\
\hline Risky sexual behavior & & & & & $<0.001$ \\
\hline No & 133000 & 92.8 & 9523 & 89.0 & \\
\hline Yes & 11838 & 7.2 & 1403 & 11.0 & \\
\hline Survey year & & & & & $<0.001$ \\
\hline 2006-2009 & 50656 & 36.5 & 5179 & 42.7 & \\
\hline 2010-2012 & 93774 & 63.5 & 5747 & 57.3 & \\
\hline \multicolumn{6}{|l|}{ Community level $(n=10,029)$} \\
\hline & Median & IQR & Median & IQR & \\
\hline Less than high school education (\%) & 87.49 & 33.23 & 70.45 & 43.21 & \\
\hline Poorer/poorest household wealth index $(\%)$ & 34.72 & 64.15 & 11.79 & 49.35 & \\
\hline Low media exposure $(\%)^{*}$ & 30.68 & 37.50 & 21.21 & 28.17 & \\
\hline \multicolumn{6}{|l|}{ Country level $(n=25)$} \\
\hline GDP per capita (2005 PPP) USD & 970.99 & 438.65 & 1153.51 & 531.55 & \\
\hline Expenditure on public health (\% of GDP) (\%) & 2.44 & 1.35 & 2.51 & 1.99 & \\
\hline
\end{tabular}

DHS: demographic and health survey; AIS: AIDS indicator survey;

Wt \%: weighted percent; N: number of participants; IQR: interquartile range; USD: United States dollar; PPP: purchasing power parity; GDP: gross domestic product

Weighted percentages were obtained to control for complex sample design, therefore division of individual cell sizes by the total sample will not reflect weighted percentages.

Pooled sample weights were derived from individual country sample weights and population sizes during the survey year for each country.

* Data not available for Congo Brazzaville and Mozambique.

p-values calculated using Rao-Scott adjusted chi-squares 
Table 3.3 Association of individual, community and country level factors and HIV seropositivity among female participants in the DHS and AIS HIV testing 2006-2012 in sub-Sharan Africa $(n=143,159)$

\begin{tabular}{|c|c|c|c|c|}
\hline & Model 1 & Model 2 & Model 3 & Model 4 \\
\hline \multicolumn{5}{|l|}{ Fixed Effects } \\
\hline Constant & $0.08(0.05,0.13)$ & $0.04(0.02,0.10)$ & $0.05(0.02,0.10)$ & $0.02(0.00,0.08)$ \\
\hline \multicolumn{5}{|l|}{ Age } \\
\hline 45-49 (Ref) & & 1 & 1 & 1 \\
\hline $15-19$ & & $0.43(0.31,0.58)$ & $0.42(0.31,0.58)$ & $0.42(0.29,0.60)$ \\
\hline $20-24$ & & $0.72(0.57,0.90)$ & $0.72(0.57,0.90)$ & $0.71(0.55,0.91)$ \\
\hline $25-29$ & & $1.37(1.12,1.68)$ & $1.37(1.12,1.68)$ & $1.37(1.10,1.70)$ \\
\hline $30-34$ & & $1.831 .52,2.20)$ & $1.831 .52,2.21)$ & $1.831 .49,2.24)$ \\
\hline $35-39$ & & $1.74(1.49,2.02)$ & $1.75(1.50,2.04)$ & $1.75(1.48,2.06)$ \\
\hline $40-44$ & & $1.55(1.24,1.93)$ & $1.55(1.24,1.94)$ & $1.55(1.21,1.99)$ \\
\hline \multicolumn{5}{|l|}{ Marital status } \\
\hline Never married (Ref) & & 1 & 1 & 1 \\
\hline Married-monogamous & & $0.75(0.61,0.92)$ & $0.75(0.61,0.92)$ & $0.75(0.60,0.93)$ \\
\hline Married-polygamous & & $0.93(0.80,1.09)$ & $0.93(0.80,1.09)$ & $0.94(0.79,1.11)$ \\
\hline Widowed & & $3.79(3.03,4.75)$ & $3.84(3.07,4.81)$ & $3.81(2.95,4.92)$ \\
\hline Divorced/separated & & $1.60(1.37,1.85)$ & $1.60(1.38,1.86)$ & $1.61(1.37,1.90)$ \\
\hline \multicolumn{5}{|l|}{ Parity } \\
\hline None (Ref) & & 1 & 1 & 1 \\
\hline 1 & & $1.21(1.04,1.41)$ & $1.21(1.03,1.41)$ & $1.21(1.02,1.45)$ \\
\hline 2 or more & & $0.78(0.70,0.88)$ & $0.78(0.70,0.88)$ & $0.78(0.69,0.89)$ \\
\hline \multicolumn{5}{|l|}{ Pregnant } \\
\hline No (Ref) & & 1 & 1 & 1 \\
\hline Yes & & $0.83(0.74,0.93)$ & $0.82(0.73,0.93)$ & $0.82(0.72,0.94)$ \\
\hline \multicolumn{5}{|l|}{ Education } \\
\hline None (Ref) & & 1 & 1 & 1 \\
\hline Primary & & $1.19(1.04,1.36)$ & $1.19(1.04,1.37)$ & $1.19(1.02,1.39)$ \\
\hline Secondary or more & & $0.97(0.85,1.11)$ & $0.97(0.85,1.11)$ & $0.97(0.83,1.13)$ \\
\hline \multicolumn{5}{|l|}{ Wealth index } \\
\hline Poorest (Ref) & & 1 & 1 & 1 \\
\hline Poorer & & $1.04(0.97,1.12)$ & $1.04(0.96,1.12)$ & $1.04(0.95,1.13)$ \\
\hline Middle & & $1.060 .97,1.15)$ & $1.060 .96,1.16)$ & $1.050 .95,1.17)$ \\
\hline Richer & & $1.07(0.92,1.25)$ & $1.07(0.92,1.25)$ & $1.07(0.91,1.26)$ \\
\hline Richest & & $1.10(0.84,1.44)$ & $1.10(0.84,1.44)$ & $1.10(0.82,1.46)$ \\
\hline \multicolumn{5}{|l|}{ Employment } \\
\hline No (Ref) & & 1 & 1 & 1 \\
\hline Yes & & $1.09(0.98,1.22)$ & $1.09(0.98,1.22)$ & $1.09(0.97,1.24)$ \\
\hline \multicolumn{5}{|l|}{ Residence } \\
\hline Urban (Ref) & & 1 & 1 & 1 \\
\hline Rural & & $0.61(0.52,071)$ & $0.72(0.64,0.81)$ & $0.72(0.64,0.81)$ \\
\hline \multicolumn{5}{|l|}{ Media exposure* } \\
\hline Low (Ref) & & 1 & 1 & 1 \\
\hline Moderate & & $0.97(0.90,1.04)$ & $0.97(0.90,1.04)$ & $0.96(0.89,1.04)$ \\
\hline High & & $0.97(0.89,1.06)$ & $0.97(0.89,1.06)$ & $0.97(0.88,1.07)$ \\
\hline
\end{tabular}




\begin{tabular}{|c|c|c|c|c|}
\hline \multicolumn{5}{|l|}{ HIV/AIDS awareness } \\
\hline \multicolumn{2}{|l|}{ Low (Ref) } & 1 & 1 & 1 \\
\hline \multicolumn{2}{|l|}{ Moderate } & $0.95(0.89,1.02)$ & $0.95(0.89,1.02)$ & $0.96(0.88,1.03)$ \\
\hline \multicolumn{2}{|l|}{ High } & $1.01(0.95,1.08)$ & $1.02(0.95,1.09)$ & $1.02(0.95,1.10)$ \\
\hline \multicolumn{5}{|l|}{ HIV/AIDS stigma } \\
\hline \multicolumn{2}{|l|}{ Low (Ref) } & 1 & 1 & 1 \\
\hline \multicolumn{2}{|l|}{ High } & $1.19(1.11,1.28)$ & $1.20(1.11,1.30)$ & $1.20(1.11,1.30)$ \\
\hline \multicolumn{5}{|l|}{ Age at first sex } \\
\hline \multicolumn{2}{|l|}{ Never had sex (Ref) } & 1 & 1 & 1 \\
\hline \multicolumn{2}{|l|}{$<16$} & $3.46(2.82,4.24)$ & $3.46(2.82,4.24)$ & $3.45(2.77,4.30)$ \\
\hline \multicolumn{2}{|l|}{$16-17$} & $2.90(2.47,3.40)$ & $2.89(2.47,3.39)$ & $2.87(2.42,3.41)$ \\
\hline \multicolumn{2}{|l|}{$18-19$} & $2.87(2.37,3.47)$ & $2.87(2.37,3.46)$ & $2.85(2.32,3.49)$ \\
\hline \multicolumn{2}{|l|}{$\geq 20$} & $2.38(1.99,2.83)$ & $2.37(1.99,2.82)$ & $2.35(1.94,2.85)$ \\
\hline \multicolumn{5}{|l|}{ Premarital sex } \\
\hline \multicolumn{2}{|l|}{ No (Ref) } & 1 & 1 & 1 \\
\hline \multicolumn{2}{|l|}{ Yes } & $1.16(1.06,1.28)$ & $1.17(1.07,1.28)$ & $1.17(1.06,1.29)$ \\
\hline \multicolumn{5}{|l|}{ Multiple sex partners } \\
\hline \multicolumn{2}{|l|}{ No (Ref) } & 1 & 1 & 1 \\
\hline \multicolumn{2}{|l|}{ Yes } & $1.38(1.06,1.81)$ & $1.39(1.06,1.82)$ & $1.39(1.02,1.88)$ \\
\hline \multicolumn{5}{|l|}{ Risky sexual behavior } \\
\hline \multicolumn{2}{|l|}{ No (Ref) } & 1 & 1 & 1 \\
\hline \multicolumn{2}{|l|}{ Yes } & $0.88(0.69,1.13)$ & $0.88(0.68,1.14)$ & $0.89(0.67,1.17)$ \\
\hline \multicolumn{5}{|l|}{ Survey year } \\
\hline \multicolumn{2}{|l|}{ 2006-2009 (Ref) } & 1 & 1 & 1 \\
\hline \multicolumn{2}{|l|}{ 2010-2012 } & $0.58(0.22,1.53)$ & $0.51(0.24,1.59)$ & $0.85(0.35,2.05)$ \\
\hline \multicolumn{5}{|l|}{ Community level } \\
\hline \multicolumn{3}{|c|}{ Less than high school education (\%) } & $1.00(1.00,1.00)$ & $1.00(1.00,1.00)$ \\
\hline \multicolumn{3}{|c|}{ Poorer/poorest household wealth index $(\%)$} & $1.00(1.00,1.00)$ & $1.00(1.00,1.00)$ \\
\hline Low media exposure $(\%)^{*}$ & & & $1.00(1.00,1.00)$ & $1.00(0.99,1.00)$ \\
\hline Country level & & & & \\
\hline GDP per capita (2005 PPP) USD & & & & $1.00(1.00,1.00)$ \\
\hline Expenditure on public health $(\%$ & GDP) $(\%)$ & & & $1.16(0.79,1.71)$ \\
\hline Random effects & & & & \\
\hline Community level variance (SE) & $1.649(0.548)$ & $2.202(0.482)$ & $2.166(0.427)$ & $2.128(0.406)$ \\
\hline Country level variance (SE) & $1.384(0.548)$ & $1.218(0.414)$ & $1.178(0.397)$ & $1.250(0.560)$ \\
\hline ICC-Community & 48.0 & 51.0 & 50.4 & 50.7 \\
\hline ICC-Country & 21.9 & 18.2 & 17.8 & 18.7 \\
\hline
\end{tabular}

United States dollar; PPP: purchasing power parity; GDP: gross domestic product; SE: standard error; ICC: intra-cluster correlation coefficient.

Pooled sample weights were derived from individual country sample weights and population sizes during the survey year for each country.

* Data not available for Congo Brazzaville and Mozambique. 


\section{Chapter 4 Tables}

Table 4.1 Description and characteristics of children who participated in the DHS and AIS HIV testing 2006-2011 ( $\mathrm{n}=15,034)$

\section{Individual level $(n=15,034)$}

Child's age

$0-1$

2-4

5-9

$10-14$

Child's sex

Male

Female

Maternal HIV status

Negative

Positive

Maternal age at birth

$<16$

16-19

20-24

$>24$

Maternal marital status

Never married

Married-monogamous

Married-polygamous

Widowed

Divorced/separated

Maternal parity

1

2 or more

Maternal education

None

Primary

Secondary or more

Household wealth index

Poorest/poorer

Middle

Richer/richest

Maternal employment status

Unemployed

Employed

Residence

Urban

Rural

Maternal HIV/AIDS awareness

Low

Moderate

High

Maternal HIV/AIDS stigma

Low

High

\begin{tabular}{cc}
$\mathrm{n}$ & wt.\% \\
\hline 3827 & 23.7 \\
6216 & 35.8 \\
2033 & 15.0 \\
2913 & 25.5 \\
& \\
7580 & 51.0
\end{tabular}

$7454 \quad 49.0$

$13365 \quad 91.0$

$1669 \quad 9.0$

$203 \quad 1.6$

$2173 \quad 15.2$

$4257 \quad 28.2$

$8401 \quad 55.0$

$655 \quad 2.3$

$12132 \quad 85.8$

$477 \quad 0.4$

$672 \quad 3.7$

$1098 \quad 7.8$

$3113 \quad 17.6$

$11921 \quad 82.4$

$3337 \quad 27.2$

$8971 \quad 61.0$

$2726 \quad 11.8$

$6378 \quad 44.2$

$3009 \quad 20.4$

$5647 \quad 35.4$

$4848 \quad 30.7$

$10194 \quad 69.3$

$3482 \quad 20.4$

$11552 \quad 79.6$

$5034 \quad 31.8$

$4569 \quad 31.3$

$5431 \quad 36.9$

$11489 \quad 74.9$

$3545 \quad 25.1$ 
Maternal age at first marriage

Never married

655

$<16$

4176

33.1

16-17

3376

22.6

18-19

3069

19.5

$\geq 20$

3758

22.5

Maternal age at first sex

$<16$

5587

41.3

16-17

4403

27.3

18-19

3190

19.2

$\geq 20$

1854

12.2

Mother had premarital sex

No

9169

67.1

Yes

5865

32.9

Mother had multiple sex partners

No

$14750 \quad 97.6$

Yes

Maternal involvement in risky sexual behavior

No

14056

93.8

Yes

978

Mother tested for HIV and received results during ANC visit

No

$7265 \quad 55.2$

Yes

Maternal exposure to HIV related information during ANC vis it

Poor

$6090 \quad 46.4$

Optimal

$8944 \quad 53.6$

Survey year

2006-2007

$1742 \quad 1.5$

2009-2011

$13292 \quad 98.5$

Community level $(n=25)$

Less than high school education $(\%)$

Median IQR

$91.48 \quad 12.34$

Poorer/poorest household wealth index $(\%)$

$46.94 \quad 31.94$

DHS: demographic and health survey; AIS: AIDS indicator survey; Wt \%: weighted percent; N: number of participants; IQR: interquartile range; ANC:antenatal care. Weighted percentages were obtained to control for complex sample design, therefore division of individual cell sizes by the total sample will not reflect weighted percentages.

Pooled sample weights were derived from individual country sample weights and population sizes during the survey year for each country. 
Table 4.2 Description and characteristics of children who participated in the DHS and AIS HIV testing 2006-2011 by HIV status $(\mathrm{n}=15,034)$

Individual level $(\mathbf{n}=\mathbf{1 5 , 0 3 4})$

Child's age

0-1

2-4

5-9

10-14

Child's sex

Male

Female

Mother's HIV status

Negative

Positive

Mother's age at birth

$<16$

16-19

20-24

$>24$

Mother's marital status

Never married

Married-monogamous

Married-polygamous

Widowed

Divorced/separated

Mother's parity

1

2 or more

Mother's education

None

Primary

Secondary or more

Household wealth index

Poorest/poorer

Middle

Richer/richest

Mother's employment status

Unemployed

Employed

Residence

Urban

Rural

Mother's HIV/AIDS awareness

Low

Moderate

High

Mother's HIV/AIDS stigma

Low

High

Child's HIV status

\begin{tabular}{|c|c|c|c|c|}
\hline \multicolumn{2}{|c|}{ Negative } & \multicolumn{2}{|c|}{ Positive } & \multirow[t]{2}{*}{ P-value } \\
\hline $\mathrm{n}$ & wt. $\%$ & $\mathrm{n}$ & wt.\% & \\
\hline & & & & 0.036 \\
\hline 3832 & 23.7 & 40 & 26.3 & \\
\hline 6155 & 36.0 & 61 & 22.8 & \\
\hline 2001 & 15.1 & 32 & 11.0 & \\
\hline 2861 & 25.3 & 52 & 39.9 & \\
\hline & & & & 0.497 \\
\hline 7485 & 51.0 & 95 & 55.9 & \\
\hline 7364 & 49.0 & 90 & 44.1 & \\
\hline & & & & $<0.001$ \\
\hline 13302 & 91.7 & 63 & 35.0 & \\
\hline 1547 & 8.3 & 122 & 65.0 & \\
\hline & & & & 0.008 \\
\hline 201 & 1.6 & 2 & 1.0 & \\
\hline 2138 & 15.1 & 35 & 23.8 & \\
\hline 4198 & 28.1 & 59 & 40.6 & \\
\hline 8312 & 55.3 & 89 & 34.6 & \\
\hline & & & & $<0.001$ \\
\hline 642 & 2.3 & 13 & 1.8 & \\
\hline 12018 & 86.0 & 114 & 69.7 & \\
\hline 468 & 0.4 & 9 & 0.7 & \\
\hline 646 & 3.6 & 26 & 9.1 & \\
\hline 1075 & 7.7 & 23 & 18.7 & \\
\hline & & & & 0.252 \\
\hline 3069 & 17.5 & 44 & 22.4 & \\
\hline 11780 & 82.5 & 141 & 77.6 & \\
\hline & & & & 0.674 \\
\hline 3299 & 27.2 & 38 & 27.3 & \\
\hline 8860 & 60.9 & 111 & 65.6 & \\
\hline 2690 & 11.9 & 36 & 7.1 & \\
\hline & & & & 0.939 \\
\hline 6301 & 44.2 & 77 & 41.3 & \\
\hline 2981 & 20.3 & 28 & 23.0 & \\
\hline 5567 & 35.4 & 80 & 35.7 & \\
\hline & & & & 0.026 \\
\hline 4798 & 30.8 & 42 & 18.7 & \\
\hline 10051 & 69.2 & 143 & 81.3 & \\
\hline & & & & 0.966 \\
\hline 3433 & 20.4 & 49 & 20.7 & \\
\hline 11416 & 79.6 & 136 & 79.3 & \\
\hline & & & & 0.009 \\
\hline 4983 & 32.0 & 51 & 19.9 & \\
\hline 4525 & 31.4 & 44 & 24.2 & \\
\hline 5341 & 36.7 & 90 & 55.8 & \\
\hline & & & & 0.450 \\
\hline 11346 & 74.8 & 143 & 79.7 & \\
\hline 3503 & 25.2 & 42 & 20.3 & \\
\hline
\end{tabular}


Mother's age at first marriage

Never married

$<16$

$16-17$

18-19

$\geq 20$

Mother's age at first sex

$<16$

16-17

18-19

$\geq 20$

Mother had premarital sex

No

Yes

Mother had multiple sexpartners

No

Yes

Mother's involvement in risky sexual behavior

No

Yes

Mother tested for HIV and received results during ANC visit

No

Yes

Mother's exposure to HIV related information during ANC visit Insufficient

Sufficient

Survey year

2006-2007

2009-2011

\section{Community level $(n=25)$}

Less than high school education (\%)

Poorer/poorest household wealth index $(\%)$

\begin{tabular}{|c|c|c|c|c|}
\hline & & & & \\
\hline 642 & 2.3 & 13 & 1.8 & \\
\hline 4139 & 33.2 & 37 & 30.7 & \\
\hline 3329 & 22.5 & 47 & 30.0 & \\
\hline 3026 & 19.5 & 43 & 25.9 & \\
\hline 3713 & 22.6 & 45 & 11.6 & \\
\hline & & & & 0.661 \\
\hline 5523 & 41.3 & 64 & 40.9 & \\
\hline 4341 & 27.2 & 62 & 34.2 & \\
\hline 3149 & 19.2 & 41 & 17.8 & \\
\hline 1836 & 12.3 & 18 & 7.1 & \\
\hline & & & & 0.729 \\
\hline 9068 & 67.0 & 101 & 69.6 & \\
\hline 5781 & 33.0 & 84 & 30.4 & \\
\hline & & & & 0.640 \\
\hline 14573 & 97.9 & 177 & 97.0 & \\
\hline 276 & 2.1 & 8 & 3.0 & \\
\hline & & & & 0.733 \\
\hline 13893 & 93.8 & 163 & 92.7 & \\
\hline 956 & 6.2 & 22 & 7.3 & \\
\hline & & & & 0.637 \\
\hline 7157 & 55.2 & 108 & 50.5 & \\
\hline 7692 & 44.8 & 77 & 49.5 & \\
\hline & & & & 0.354 \\
\hline 6005 & 46.5 & 85 & 38.1 & \\
\hline 8844 & 53.5 & 100 & 61.9 & \\
\hline & & & & $<0.001$ \\
\hline 1693 & 1.5 & 49 & 3.6 & \\
\hline 13156 & 98.5 & 136 & 96.4 & \\
\hline Median & IQR & Median & IQR & \\
\hline 91.43 & 12.34 & 95.59 & 11.79 & \\
\hline 46.97 & 31.83 & 43.22 & 50.54 & \\
\hline
\end{tabular}

DHS: demographic and health survey; AIS: AIDS indicator survey; Wt \%: weighted percent; N: number of participants; IQR: interquartile range; ANC:antenatal care. Weighted percentages were obtained to control for complex sample design, therefore division of individual cell sizes by the total sample will not reflect weighted percentages. Pooled sample weights were derived from individual country sample weights and population sizes during the survey year for each country.

p-values calculated using Rao-Scott adjusted chi-squares 
Table 4.3 Association of individual and community and country level factors and HIV seropositivity among children who participated in the DHS and AIS HIV testing 2006-2011 ( $\mathrm{n}=15,034)$

\begin{tabular}{|c|c|c|c|}
\hline & Model 1 & Model 2 & Model 3 \\
\hline \multicolumn{4}{|l|}{ Fixed Effects } \\
\hline Constant & $0.01(0.00,0.02)$ & $0.00(0.00,0.01)$ & $0.00(0.00,0.08)$ \\
\hline \multicolumn{4}{|l|}{ Mother's HIV status } \\
\hline Negative (Ref) & & 1 & 1 \\
\hline Positive & & $16.61(16.40,16.82)$ & $16.61(16.40,16.82)$ \\
\hline \multicolumn{4}{|l|}{ Mother's age at birth } \\
\hline$<16(\operatorname{Ref})$ & & 1 & 1 \\
\hline $16-19$ & & $2.80(2.66,2.96)$ & $2.80(2.66,2.96)$ \\
\hline $20-24$ & & $2.27(2.15,2.39)$ & $2.27(2.15,2.39)$ \\
\hline$>24$ & & $1.32(1.25,1.39)$ & $1.32(1.25,1.39)$ \\
\hline \multicolumn{4}{|l|}{ Mother's marital status } \\
\hline Never married (Ref) & & 1 & 1 \\
\hline Married-monogamous & & $1.69(1.62,1.77)$ & $1.69(1.62,1.77)$ \\
\hline Married-polygamous & & $1.04(0.96,1.13)$ & $1.04(0.96,1.13)$ \\
\hline Widowed & & $1.41(1.35,1.48)$ & $1.41(1.35,1.48)$ \\
\hline Divorced/separated & & $2.92(2.98,3.05)$ & $2.92(2.98,3.05)$ \\
\hline \multicolumn{4}{|l|}{ Mother's employment status } \\
\hline Unemployed (Ref) & & 1 & 1 \\
\hline Employed & & $1.44(1.42,1.46)$ & $1.44(1.42,1.46)$ \\
\hline \multicolumn{4}{|l|}{ Mother's HIV/AIDS awareness } \\
\hline Low (Ref) & & 1 & 1 \\
\hline Moderate & & $0.85(0.83,0.86)$ & $0.85(0.83,0.86)$ \\
\hline High & & $1.46(1.44,1.48)$ & $1.46(1.44,1.48)$ \\
\hline \multicolumn{4}{|l|}{ Survey year } \\
\hline 2006-2007 (Ref) & & 1 & 1 \\
\hline $2009-2011$ & & $0.41(0.06,2.84)$ & $0.35(0.02,6.81)$ \\
\hline \multicolumn{4}{|l|}{ Community level } \\
\hline \multicolumn{3}{|c|}{ Less than high school education $(\%)$} & $1.00(0.94,1.07)$ \\
\hline \multicolumn{3}{|c|}{ Poorer/poorest household wealth index $(\%)$} & $0.99(0.96,1.03)$ \\
\hline \multicolumn{4}{|c|}{ Random effects } \\
\hline Community level variance (SE) & $3.91(1.23)$ & $2.96(0.95)$ & $2.90(0.93)$ \\
\hline ICC-Community & 54.3 & 47.3 & 46.9 \\
\hline \multicolumn{4}{|l|}{ Model fit statistics } \\
\hline $\mathrm{AIC}$ & 1517282.0 & 1234613.0 & 1234616.0 \\
\hline $\mathrm{BIC}$ & 1517285.0 & 1234630.0 & 1234636.0 \\
\hline
\end{tabular}

DHS: demographic and health survey; AIS: AIDS indicator survey; SE: standard error; ICC: intra-cluster correlation coefficient; AIC: Akaike information criterion, BIC: Bayesian information criterion. Pooled sample weights were derived from individual country sample weights and population sizes during the survey year for each country. 